\title{
WestVirginiaUniversity
}

THE RESEARCH REPOSITORY @ WVU

Graduate Theses, Dissertations, and Problem Reports

2013

\section{Access, Retention, and Progression of Marginalized Students in Kisii Schools, Kenya}

\author{
Harrison Ntabo Oonge \\ West Virginia University
}

Follow this and additional works at: https://researchrepository.wvu.edu/etd

\section{Recommended Citation}

Oonge, Harrison Ntabo, "Access, Retention, and Progression of Marginalized Students in Kisii Schools, Kenya" (2013). Graduate Theses, Dissertations, and Problem Reports. 3633.

https://researchrepository.wvu.edu/etd/3633

This Dissertation is protected by copyright and/or related rights. It has been brought to you by the The Research Repository @ WVU with permission from the rights-holder(s). You are free to use this Dissertation in any way that is permitted by the copyright and related rights legislation that applies to your use. For other uses you must obtain permission from the rights-holder(s) directly, unless additional rights are indicated by a Creative Commons license in the record and/ or on the work itself. This Dissertation has been accepted for inclusion in WVU Graduate Theses, Dissertations, and Problem Reports collection by an authorized administrator of The Research Repository @ WVU.

For more information, please contact researchrepository@mail.wvu.edu. 
Access, Retention, and Progression of Marginalized Students in Kisii Schools, Kenya

Harrison Ntabo Oonge

\author{
Dissertation submitted to the \\ College of Education and Human Services at West Virginia University \\ in partial fulfillment of the requirements for the degree of \\ Doctor of Education \\ In \\ Curriculum and Instruction
}

Elizabeth A. Dooley, Ed.D., Chair

Patricia Obenauf, Ph.D.

Sam Stack, Ph.D.

Robert Maxon, Ph.D.

Joy F. Saab, Ed.D.

Sharon B. Hayes, Ph.D.

Department of Curriculum and Instruction, Literacy Studies

Morgantown, West Virginia

2013

Keywords: Marginalized Students, Access, Teacher Practices, Universal Basic Education 


\title{
Abstract \\ Access, Retention, and Progression of Marginalized Students in Kisii Schools, Kenya
}

\author{
Harrison Ntabo Oonge
}

This study examined how teachers perceive Free Primary Education had influenced access, retention and progression of marginalized students in primary schools in Kisii County, Kenya. A critical pedagogy framework was used to unpack and shed light on teacher and school practices that affected access to basic education of at risk students. Data was collected through 217 surveys given to teachers from 28 purposefully selected primary schools in Kisii County, 3 administrator interviews, and 4 focus group interviews comprised of a total of 30 classroom teachers from 14 schools in a sequential mixed methods design. Four research questions that guided this research were: a) How do teachers perceive Free Primary Education in Kenya has influenced access to primary education for marginalized students? b) What do teachers perceive to be at risk categories for marginalized students? c) How do teacher practices influence the retention of marginalized students in education in Kenya? Finally, d) to what extent do teacher beliefs influence their desire to differentiate instruction for marginalized students? Findings from this study indicated that Free Primary Education had led to increased access to basic education through reduction of fees paid by parents to schools, provision of instructional materials, open admission policy, and construction and/or renovation of existing educational facilities. The study also revealed roadblocks that hinder access to basic education for marginalized students such as extra fees levied by schools to parents, poverty, high teacher pupil ratio, lack of skills to equitably educate at risk students in classrooms, and poor health. The participants identified orphans, students with low incidence disabilities, children from extremely poor families, children from single parent households, children engaged in child labor, and children from negligent parents as categories of students who were at risk for marginalization. Moreover, the study revealed some of the teacher and schooling practices with regard to handing marginalized students which included teacher care, professional development, accommodations, remedial teaching, and guidance and counseling. There was a significant correlation between teacher philosophies and teacher willingness to differentiate instruction $\left(r_{s}=0.43\right.$, $p<0.05$ ), and also a significant correlation between teachers' philosophies and their willingness to give various accommodations to marginalized students in their classrooms $\left(r_{s}=0.34, p<0.05\right)$. Further analysis of data revealed that, a $)$ access to basic education as a class issue, $b$ ) access to basic education as a gender issue, c) national tests and measurements as instruments for marginalization, and d) access to education as a teacher critical consciousness issue. 


\section{Dedication}

I dedicate this dissertation to my dear wife Naomi Mon'gare Okemwa, my two kids Jessica Kerubo Ntabo and Edward Basweti Ntabo. You are the pillars in my life. To Jessica and Edward, this dissertation is a testament to the idea that all things are possible. I also dedicate this dissertation to my parents, my dear mother Rose Nyakerario Oonge and my kind father, Joseph Oonge Mobe. Your unfettered love, counsel, and prayers have always guided me through the toughest of times. 


\section{Acknowledgements}

This is dissertation has been made possible because of the wise counsel, inspiration, and mentoring of my committee members, Dr. Elizabeth A. Dooley, Dr. Patricia Obenauf, Dr. Robert Maxon, Dr. Sam Stack, Dr. Joy Saab, and Dr. Sharon Hayes. Specifically, I want to thank Dr. Elizabeth Dooley, for guiding me throughout the dissertation process. I thank Dr. Robert Maxon, Dr. Joy Saab, and Dr. Sam Stack for introducing me to new perspectives. In a special way, I acknowledge all the help I received from Dr. Sharon Hayes and Dr. Patricia Obenauf, who provided feedback and insights to my research. I acknowledge Caleb N. Basweti and Winnie Onyansi for their assistance in data collection related to this dissertation. I acknowledge Dr. Elizabeth Abenga for acting as my supervisor while I engaged in data collection activities in Kenya. I thank Dr. Diane Yendol Hoppey for her encouragement and inspiration. I also acknowledge the Benedum Collaborative for providing me space and financial resources that enabled me complete my graduate studies at West Virginia University. I also thank God for giving me good health and peace of mind throughout the dissertation process. 


\section{Table of Contents}

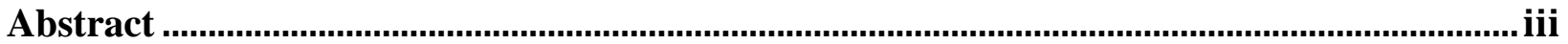

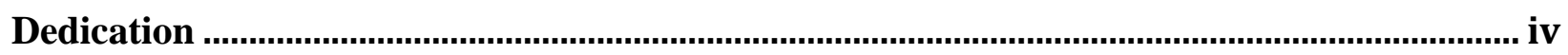

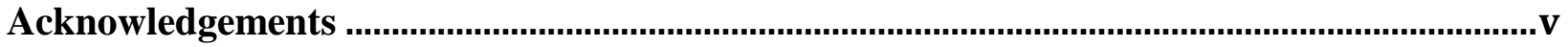

Table of Contents .................................................................................................................... vi

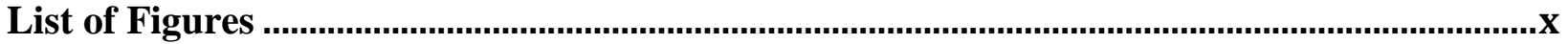

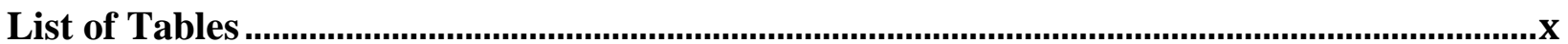

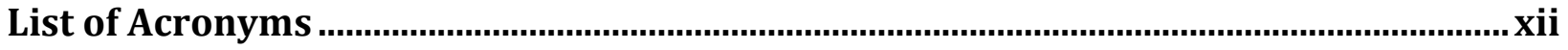

Definitions ......................................................................................................................................xiii

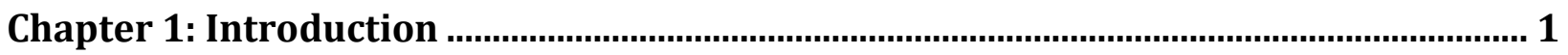

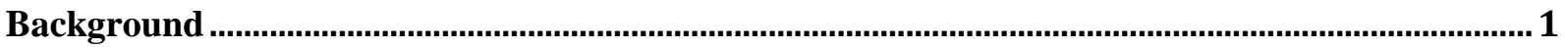

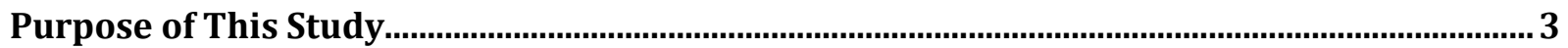

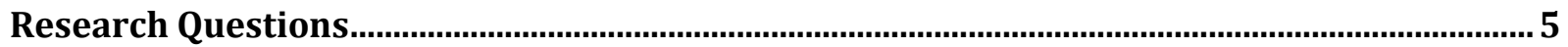

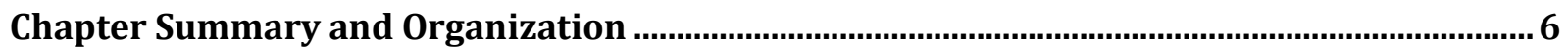

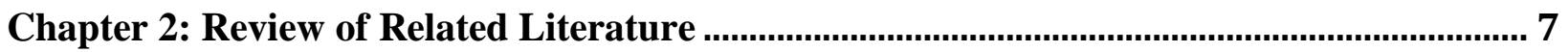

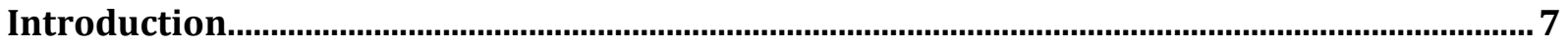

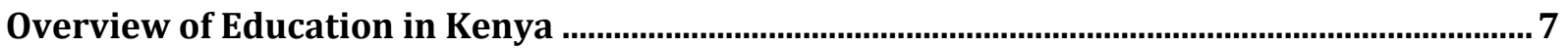

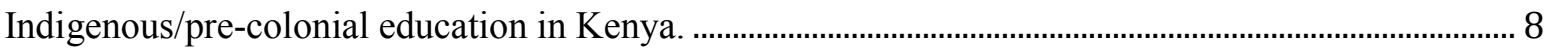

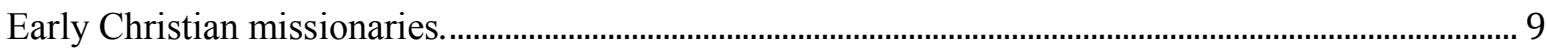

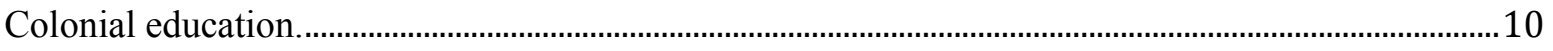

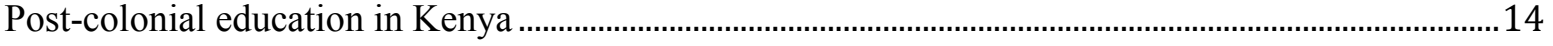




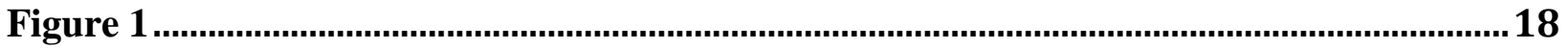

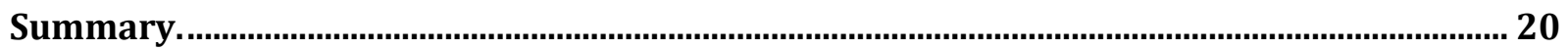

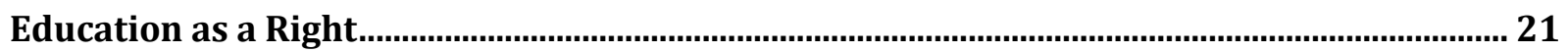

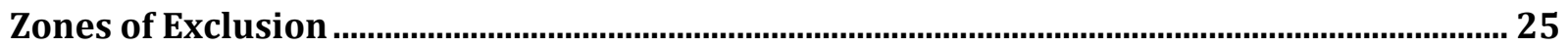

Children Still Excluded From Full Benefits of FPE .................................................................... 27

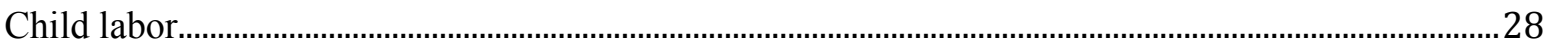

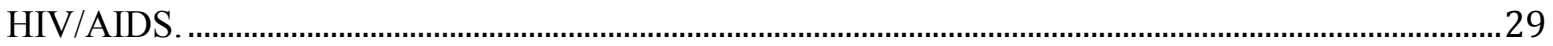

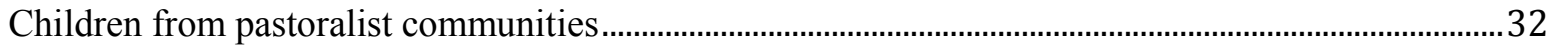

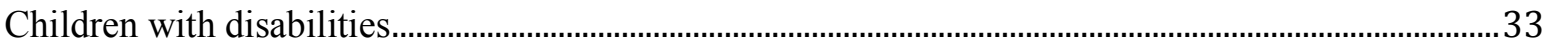

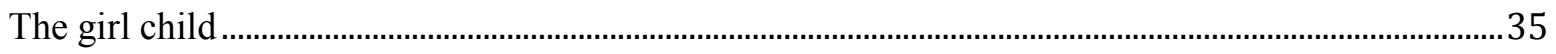

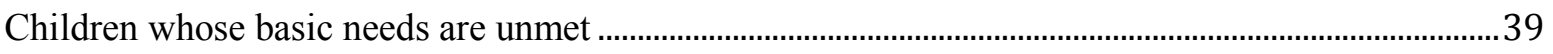

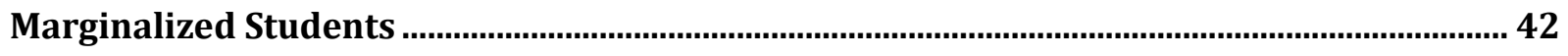

Access

Equity

Inclusion of Learners with Disabilities in Regular Classrooms .............................................. 49

Differentiated Instruction ...................................................................................................... 52

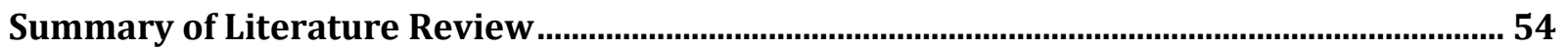

Chapter 3: Methodology

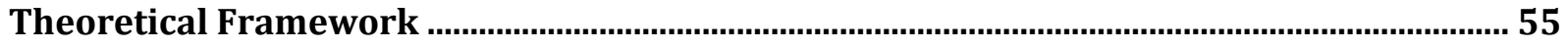

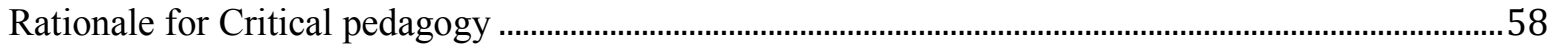

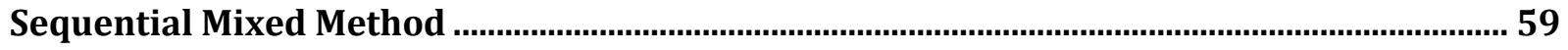

Research Context .......................................................................................................... 61

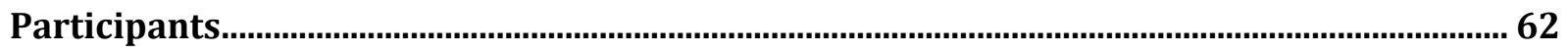

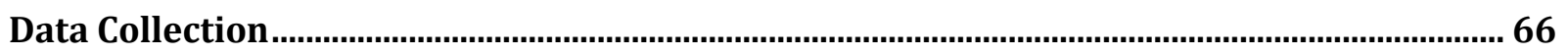

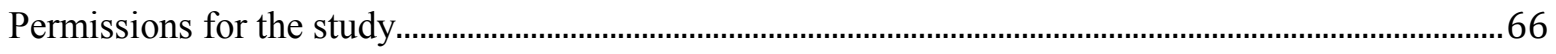




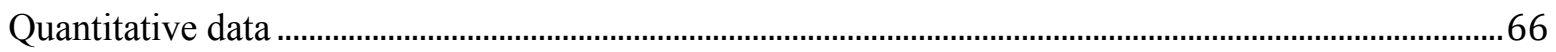

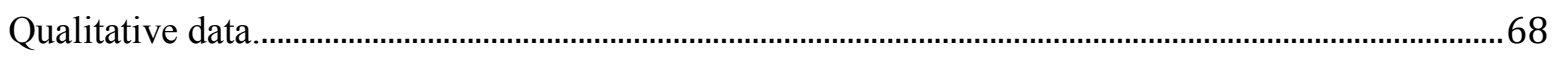

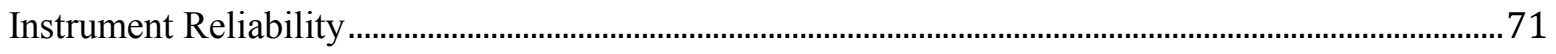

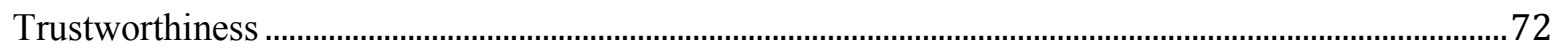

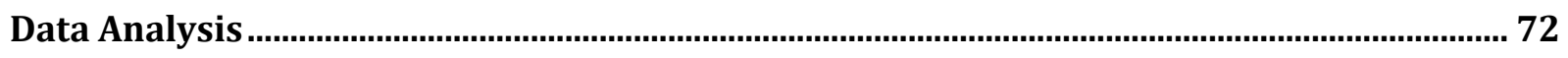

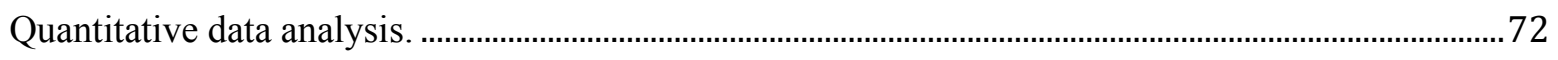

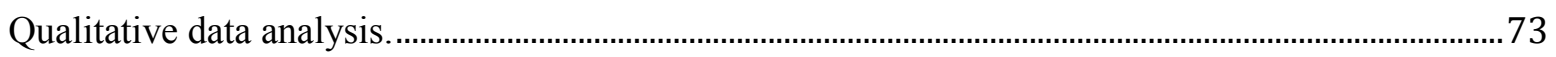

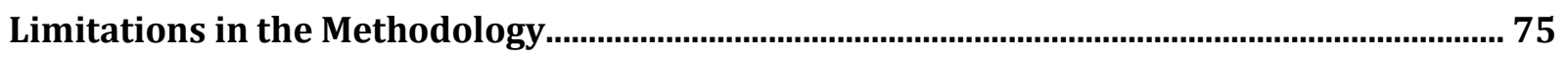

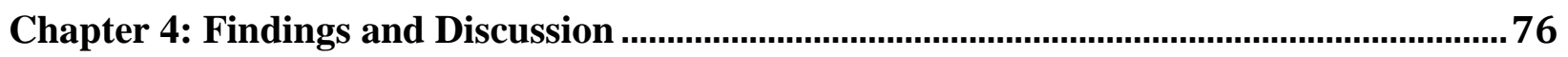

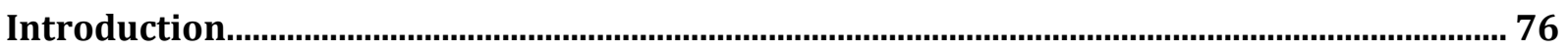

Research Question \# 1: How Teachers Perceive FPE has Influenced Access to Primary

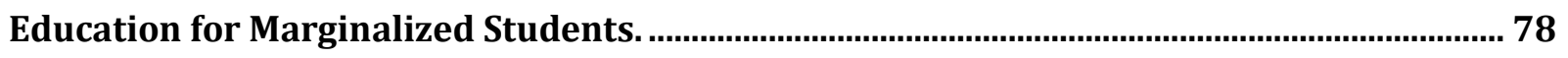

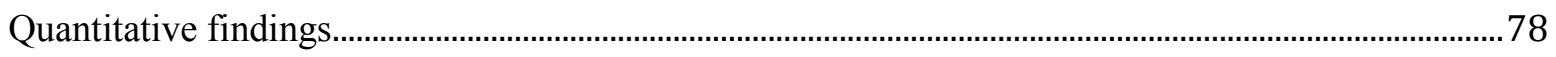

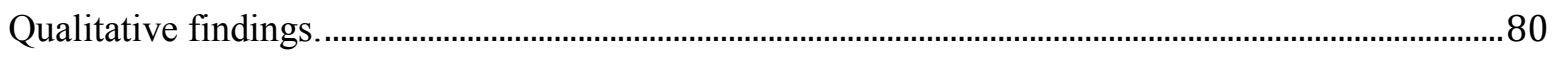

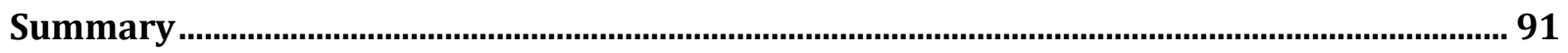

Research Question \# 2: What do Teachers Perceive to be At Risk Categories for

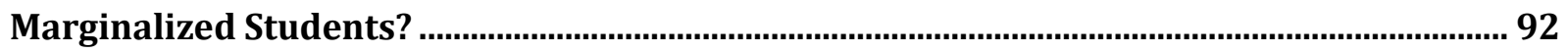

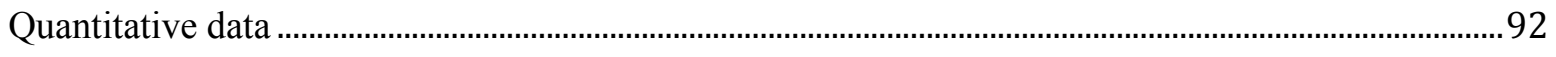

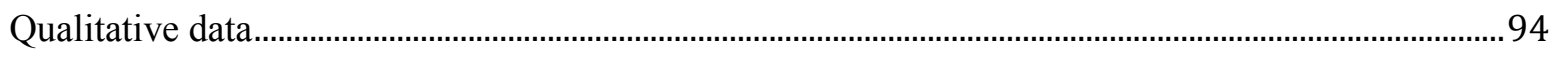

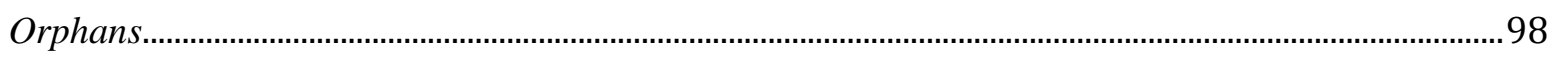

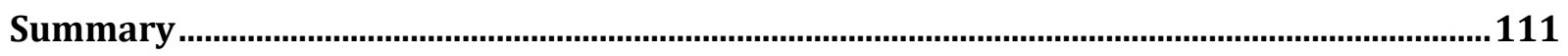

Research Question \# 3: How Do Teacher Practices Influence Retention of Marginalized

Students?

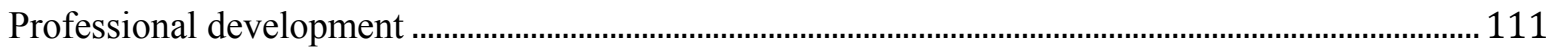

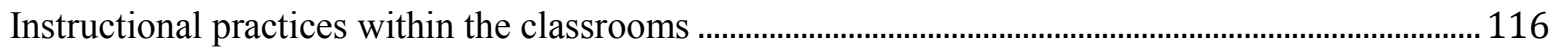


Summary

\section{Research Question \# 4: To What Extent Do Teacher Beliefs Influence their Desire to}

Differentiate Instruction for Marginalized Students …...................................................122

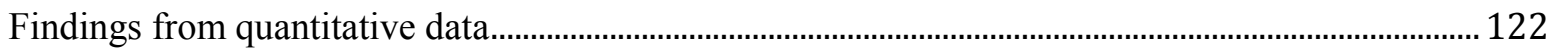

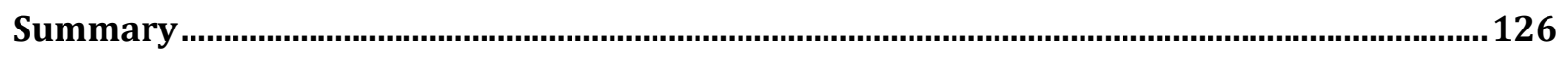

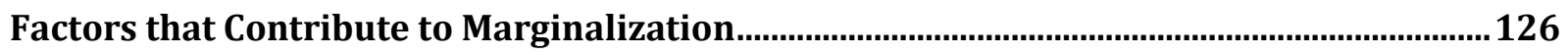

Individual factors

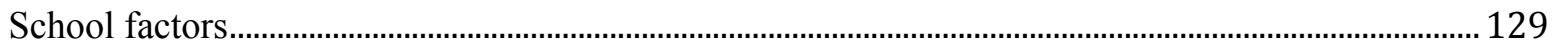

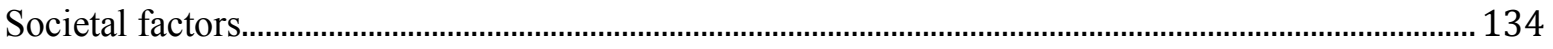

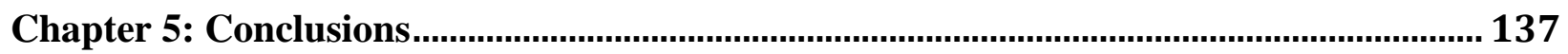

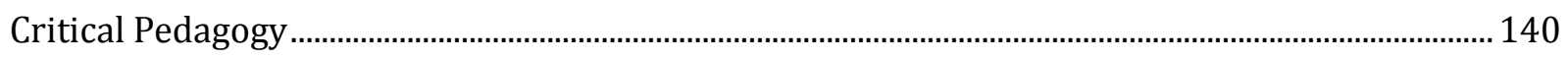

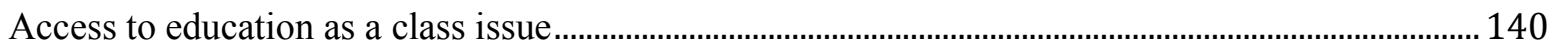

Tests and assessments as an instrument for marginalization ........................................................... 141

Access and retention in education as a critical consciousness issue ............................................... 142

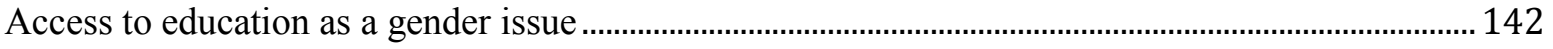

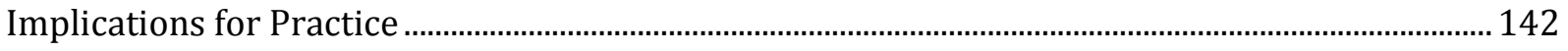

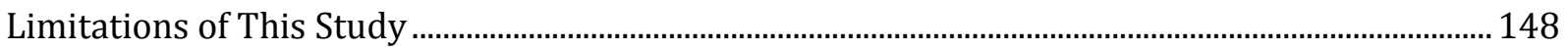

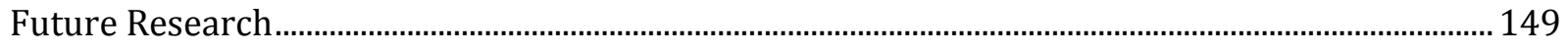

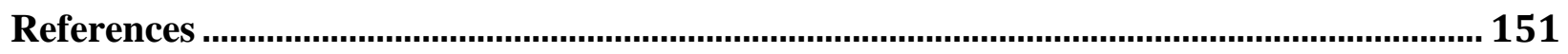

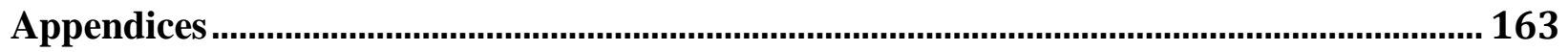

Appendix A: Map of Kenya Showing the County and Constituency Boundaries in Kenya.............. 163

Appendix B: Kenya's Population Distribution for Ages 6 Years to 14 Years by Age and Sex ........ 164

Appendix C: Kisii County Political Units (Constituencies as of 2011) ................................................. 165

Appendix E: Focus Group Screening Protocol................................................................................. 173 
Appendix F: Institutional Review Board of West Virginia University

Appendix H: Permits from District Education Officers andAdminstration......................................... 177

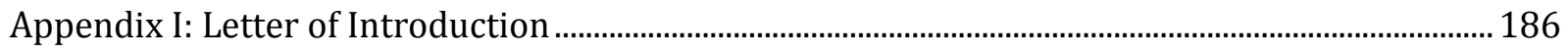

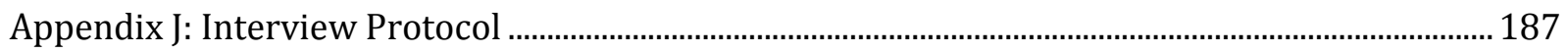

Appendix K: Letter of Invitation to Participate in Focus Group Interview ....................................... 188

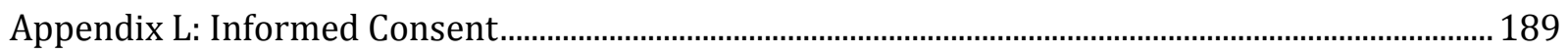

Appendix M: Emergent Codes and Themes from Focus Groups and Administrator Interviews on

who the Consider as Marginalized in their Classrooms ........................................................................ 190

\section{List of Figures}

FIGURE 1:STRUCTURE OF THE 8-4-4 EDUCATION SYSTEM IN KENYA ........................................ 18

FIGURE 2:CREATE ZONES OF EXCLUSION IN PRIMARY SCHOOLS ............................................. 26

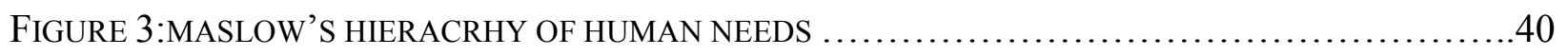

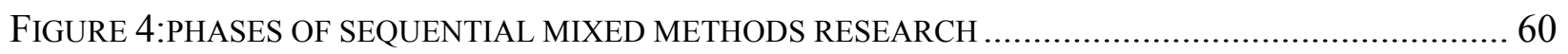

\section{List of Tables}

TABLE 1: EARLIEST Mission CENTERS SET UP IN KENYA BY 1915........................................ 10

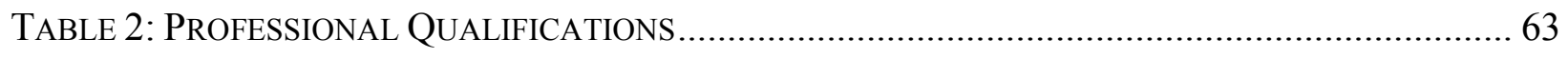

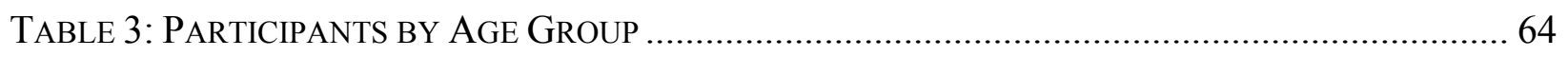

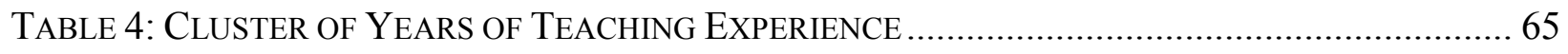

TABle 5: Survey Items used in the SCREEning of Focus Group Participants ................... 66

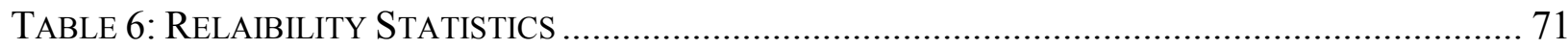


Table 7: Teacher Perceptions on the Extent to Which FPE OBjectives have Been Met 79

TABLE 8: THEMES FROM FOCUS GROUPS AND ADMINISTRATORS' INTERVIEWS ON FPE INFLUENCE

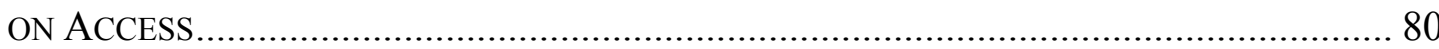

TABLE 9: CATEGORIES OF STUDENTS IDENTIFIED AS 'At RISK' FOR MARGINALIZATION IN THE

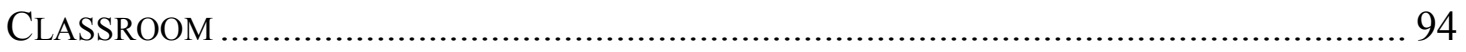

TABle 10: Excerpt on Lack SPecialized Teachers in SPECial EduCATION ....................... 108

TABle 11: Choice of Professional Development Activities ............................................. 112

TABle 12: Categories of Various Professional DeVelopment Activities that Teachers

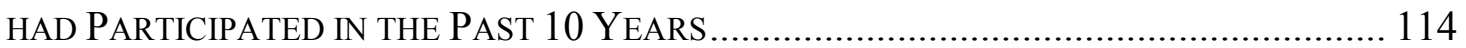

TABLE 13: FREQUENCY With Which TEACHERS PROVIDED VARIOUS ACCOMMODATIONS IN THEIR

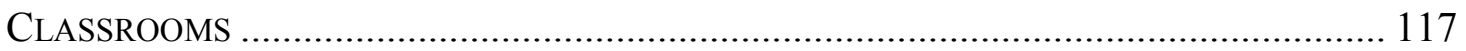

TABle 14 Home Visits as an Example of Teacher CARE ................................................ 119

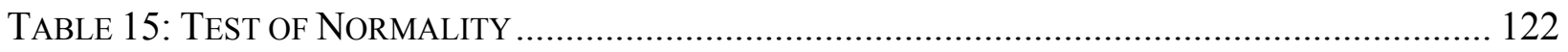

TABle 16: Descriptive Statistics for Teaching Philosophy, Differentiated Instruction,

TEACHING MATERIALS, AND ACCOMMODATIONS SUBSCALES ................................. 123

Table 17: Correlation Coefficient Between Teaching Philosophy, Differentiated

INSTRUCTION, TEACHING MATERIALS, AND ACCOMMODATIONS .............................. 124

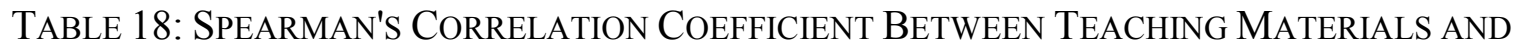

TEACHER WiLlingness to Provide ACCOMmodations to Marginalized Students

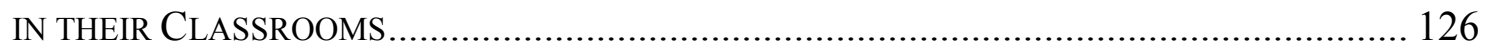




\section{List of Acronyms}

CRC Convention of the rights of the Child

CREATE Consortium for Research on Educational Access Transition and Equity

EFA Education for All

FPE Free Primary Education

KCPE Kenya Certificate of Primary Examination

KCSE Kenya Certificate of Secondary Examination

LNC Local Native Councils

MDG Millennium Development Goals

MVC Most Vulnerable Children

NARC National Alliance Rainbow Coalition

PTA Parents Teachers Association

SAP Structural Adjustment Program

UDHR Universal Declaration of Human Rights

UFPE Universal Free Primary Education

UN United Nations

UNESCO United Nations Education, Scientific, and Cultural Organization

UNDP United Nations Development Program 


\section{Definitions}

Access: Refers to the opportunity to enroll, progress through grades and meaningfully gain from the learning process

Basic education: Refers to education intended to meet basic learning needs; it includes instruction at the first or foundation level on which subsequent learning can be based; it encompasses early childhood and primary (or elementary) education for children as well as education in literacy, general knowledge, and life skills for youth and adults; it may extend into secondary education in some countries.

Disability: means a physical, sensory, mental or other impairments including any visual, hearing, learning or physical incapability, which impacts adversely in economic, social or environmental participation (education)

Education for All: Refers to the provision of basic education for all children, youth and adults. Equity: Involves allocation of resources, instructional time, pedagogy, and treatment, of all students in a fair, just and humane manner, thereby increasing equal participation for all students in a democracy

Marginalized students: Refers to students who come from marginal groups within society (which include: students from families that are extremely poor, children who are homeless, children who are orphans, children engaged in child labor, and children who have disabilities), and who exhibit or are at risk of exhibiting one of the following characteristics: poor attendance, low achievement, repetition of grades, or dropping out of school.

Most Vulnerable Children Fund (MVC): This is a government program that provides additional funds to primary schools in Kenya to assist these schools to purchase school uniforms 
Primary education: Refers to the provision of the first level of instruction to children, usually the 6-13 age group

Public school: Refers to a school maintained or assisted out of public funds

Pupil: Refers to a person enrolled as a pupil or a student in a school

Qualified teacher: means a teacher who has a diploma or certification to teach in Kenya

Syllabus: Refers to a concise statement of contents of a course of instruction in a subject or subjects

Untrained teacher with degree: Refers to a classroom teacher who has earned a degree from a four years college in a content area, but has no certification in teaching

Untrained teacher with diploma: Refers to a classroom teacher who has earned a diploma from a three year college in a content area, but has no certification in teaching

Untrained teacher without degree or diploma: Refers to a classroom teacher who has neither a degree nor a diploma in a content area and has no certification to teach. This individual's only qualification is a high school diploma

Professional teacher with certificate: Refers to a classroom teacher who has gone through a two-year teacher training college and is certified to teach in $1^{\text {st }}$ grade through $8^{\text {th }}$ grade Professional teacher with diploma: Refers to a classroom teacher who has gone through a three-year teacher training college and is certified to teach in a specific content area in $1^{\text {st }}$ grade through $12^{\text {th }}$ grade

Professional teacher with degree: Refers to a classroom teacher who has gone through a fouryear teacher training college and is certified to teach in a specific content area 
Professional teacher with a master's degree: Refers to a classroom teacher who in addition to having a teaching certification from a four-year teacher training college, he/she has a postgraduate diploma. 


\section{Chapter 1: Introduction}

\section{Background}

Despite the initiation of Free Primary Education (FPE) policy in Kenya in 2003, there were about 1.9 million children in 2009 that were not enrolled in formal education (Republic of Kenya, 2010). This number ferments the argument that Kenya is yet to achieve universal access to education for all children. If no measures are taken to address this situation, then, Kenya will fail to achieve the Millennium Development Goals and the Education for All (EFA) goals of 2000 that require all countries, including Kenya, to achieve universal access to basic education for their children by 2015. Specifically, the number of children excluded from accessing basic education, as demonstrated by the census report suggest continued existence of barriers to access to basic education that have not been overcome even with the Free Primary Education initiative.

The Kenyan Free Primary Education (FPE) initiative is rooted in the belief that education is a human right, which is expressed in Article $26^{1}$ of the Universal Declaration of Human Rights (UDHR) of 1948 (United Nations, 1948) and Article $28^{2}$ of the Convention of the Rights of the Child (CRC) of 1989 (United Nations, 1989). In Kenya, the Children's Act of 2001 is the most formidable document that delineates the right of the child to education. Moreover, section 43 and 53 of the recently promulgated constitution of Kenya ${ }^{3}$ require that education be free and compulsory for all children. These proclamations and laws provide a legal basis for universal basic education.

\footnotetext{
${ }^{1}$ Article 26 of Universal Declaration of Human Rights of 1948 states that: Everyone has a right to education. Education shall be free, at least in the elementary and fundamental stages. Elementary education shall be compulsory.

${ }^{2}$ Article 28 of the Convention of the Rights of the Child of 1989 states that: States must recognize the right of the child to education, and with a view of achieving this right progressively and on a basis of equal opportunity, they shall in particular, make primary education compulsory and available free for all.

${ }^{3}$ Section 43 (1) of the Kenyan Constitution states that every person has a right to education. While section 53 (1) states that every child has a right to free and compulsory basic education.
} 
A review of the history of education in post-colonial Kenya reveals several failed attempts to increase access to education for all its children (Republic of Kenya, 1964, 1966, $1970,1976,1981,1991)$. For instance, the gains in enrollments in the late 1970 s due to the abolition of levies (fees) charged in primary schools and the early 1980 s were eroded by the introduction of a cost-sharing policy in the late 1980s. The cost-sharing policy required that parents and the government share the cost of education on a fifty-fifty basis. Children from poor families were major casualties of this policy since their parents could not afford to pay the fees.

Thus the passage of Free Primary Education in Kenya in 2003 provided new hope to children from impoverished families and marginalized groups to have access to primary education. Indeed, the first year of FPE implementation saw increased primary school new student enrolments by 1.3 million children previously excluded due to fee requirements. Almost a decade later, the attainment of universal access was still elusive since about 1.9 million, children who represented about $23 \%$ of primary school age cohort, were still not enrolled in formal schools as indicated by the Kenyan census conducted in 2009 and reported in 2010.

The Kenya population census conducted in 2009 confirmed findings from various studies which indicated that not all children are accessing primary education in Kenya. These studies have identified categories of children who are left out in accessing primary education and include: (a) orphans (UNESCO, 2010; Birger \& Craissati, 2009); (b) children engaged in labor, (Githitho-Muriithi, 2010; Munene \& Ruto, 2010); (c) children from pastoralists (nomadic) communities (Sifuna, 2005); (d) children with disabilities (Birger \& Craissati, 2009;Oriedo, 2003; Mukuria \& Korir, 2006; Bore, Mukuria, \& Adera, 2007) and e) the girl child (Glick, 2008; Kane, 2004; Lloyd, Mensch, \& Clark, 2000; Southern and Eastern Africa Consortium for Monitoring Educational Quality-SACMEQ, 2011; Shabaya \& Konadu-Agyemang, 2004). While 
some of these children may initially enroll in primary schools, a study by Ackers, Migoli, \& Nzomo (2001) reports that many children drop out of schools between grades 1 and 2, and grades 6 and 7 due to "paucity of the school environment and poor performance" (p. 365) whereby teachers and students in these schools do not have access to adequate and appropriate instructional materials, thereby priming these students for failure. Similarly, Lewin (2009) reports that marginalized students are at risk of dropping out, repeating grades, having poor achievement compared to regular children, having poor school attendance records, and/or failing to graduate from primary schools.

There seems to be a dearth of research on how the teachers' practices have contributed to increased or decreased access to education for marginalized children. Moreover, there is no research that has considered how teachers' practices have influenced the provision of educational opportunities to marginalized children that is both equitable and of quality. These two gaps in the research provide the impetus for this study. Moreover, the commitment by the Kenyan government to expand access to education for all children, as evidenced by its expenditure for education could be undermined in the long-term if a truly equitable and quality education is not provided for all children.

\section{Purpose of This Study}

The purpose of this study was to examine teacher perceptions on how the Free Primary Education policy in Kenya had influenced access to education for marginalized students. The study first attempts to establish the categories of students whom teachers in Kisii County perceive to be at risk of being marginalized in their classrooms and who exhibit any or a combination of the following characteristics, a) repeating grades, b) low achievement, c) dropping out of school, and d) having low attendance. This information is crucial in highlighting 
the plight of the most vulnerable groups within the school age cohort with regard to accessing education. In addition, an empirical indication of the prevalence of marginalized students in schools will hopefully incite their inclusion in future educational policy deliberations. Categories of students at risk of being marginalized in schools and classrooms could provide useful information for educators that they can use to proactively plan instruction and programs that address their diverse needs.

Secondly, the study examined schooling and instructional practices that contributed to and/or hindered delivery of accessible, quality, and equitable education for marginalized children. By focusing on Kisii County in Western Kenya, results from this study provide useful information to guide educators and reformers when creating educational policies at the devolved county system of governance.

Thirdly, results and discussions from this study contribute to the literature and research on access to primary education for marginalized students in the wake of free primary education. Information on how teachers are meeting or not meeting the needs of marginalized students may inform future teacher education program reform; more specifically, on how to educate teachers to meet the needs of marginalized students who are at risk of dropping out of school, repeating grades, and/or having low achievement. This is premised on the belief that teachers who meet the diverse learning needs of their students contribute to their retention, adequate progression through grades, and educational achievement.

Fourthly, there is no study to date in Kenya that has examined how teachers' philosophical orientations and/or beliefs influence their pedagogical practices. By examining teachers' philosophies and/or beliefs with regard to providing equitable education through 
differentiated instruction, this study provides results that may highlight possible areas for the jobembedded professional development of teachers.

\section{Research Questions}

A sequential mixed methods study (QUAN-qual design) was used to examine access to primary education for marginalized students in Kenya through the lens of critical theory. Specifically this study was guided by the following questions:

1. How do teachers' perceive Free Primary Education in Kenya influences access to primary education for marginalized students?

2. What do teachers perceive to be at risk categories for marginalized students?

3. How do teacher practices influence the retention of marginalized students in education in Kenya?

4. To what extent do teacher beliefs influence their desire to differentiate instruction for marginalized students?

The study was conducted in Kisii County, an administrative region located in the western part of Kenya (see Appendix A). The study was conducted in two phases: quantitative and qualitative. In the first phase, a survey with Likert-scale items was administered to collect quantitative data that was used to answer the first, second, third, and fourth research questions. In addition, the information from this survey was used to determine and recruit participants for the second phase of the study. In the second phase, qualitative data was collected through interviews, and focus groups. This data was used to answer the first, second, and third research questions of this study and also corroborate findings from the first phase. 


\section{Chapter Summary and Organization}

The sections that follow in this dissertation are organized as follows: chapter two discusses literature related to access to education in Kenya in four distinct periods, a) precolonial, b) colonial, c) post colonial, and d) post Free Primary Education. In addition, the chapter reviews literature on categories of children in Kenya who are at risk for marginalization and identified zones within which they have higher risks of being excluded from the basic education system. Literature is also used to provide the legal underpinnings of education as a human right and discuss meanings of access, equity, inclusion, and differentiated instruction. Chapter three discusses the theoretical framework guiding this research, the mixed research methodology used in this research, the rationale for using mixed methods, and limitations of this methodology. Chapter four presents and discusses the research findings (quantitative and qualitative). Chapter five provides the conclusions drawn from this study, the policy as well as practice implications and/or recommendations of this study. Chapter five concludes with a forecast for further research. 


\section{Chapter 2: Review of Related Literature}

\section{Introduction}

Kenya, a former British Colony, attained its independence in 1963. As of 2009, Kenya had a total population of $38,610,097$, out of whom $19,192,458$ are male while $19,417,639$ are female (Republic of Kenya, 2010). About 26 million Kenyans live in the rural areas which represents about 68 percent of its total population. Moreover, 42.88 percent of the Kenyan population is between ages 0 and 14. Specifically, 24.48 percent of Kenyans are of the ages 6 and 14 (see Appendix B), while those in age 5 and below comprise of 18.4 percent of the total population. This population demographic shows that there is a sustained demand for access to primary education.

\section{Overview of Education in Kenya}

A review of literature covering education in Kenya between the late $19^{\text {th }}$ Century, the $20^{\text {th }}$ Century, and early $21^{\text {st }}$ Century indicates that Kenya's education has evolved through the years. In the literature there are four distinct educations periods: 1) the indigenous and/or pre-colonial education (Akama, \& Maxon, 2006; Bogonko, 1992; Sifuna, 1980; Sifuna \& Otiende, 2006; Sheffield, 1973); 2) colonial education (Bogonko, 1992; Schilling, 1976; Sifuna, 1980; Sifuna \& Otiende, 1994, 2006; Sheffield, 1973; Urch, 1971); 3) post-colonial education (Bogonko, 1992; Eshiwani, 1993; Godia, 1987; Republic of Kenya, 1964, 1966, 1970, 1976, 1981, 1991; Rharade, 1997; Sifuna, 1980; Sifuna \& Otiende, 1994, 2006); and 4) post Free Primary Education era (Amutabi 2003; Omwami \& Omwami 2010; Sifuna, 2006; Somerset, 2011). The sections that follow are discussions of education in Kenya in each of the four periods with a focus on the goals of education, the issue of access, the challenges and the reforms within the education system. 
Indigenous/pre-colonial education in Kenya. Before the coming of European

missionaries, settlers, and colonialists, each tribal community in Kenya had both formal and informal education for its members. Formal education involved instruction delivered to children by specialists such as herbal medicine men and priests in formal settings. Informal education on the other hand, was ubiquitous as it happened in playgrounds, at fire sites, in gardens, grazing fields, and at homes.

The mode of instruction for indigenous education involved both direct and indirect instruction. Direct instruction occurred when children were given direct orders or guidelines on a specific chore or trade. Indirect instruction incorporated use of poems, riddles, proverbs, myths, legends, fables, and songs that were laden with messages of wisdom and wit. The content of precolonial education included: character building, inculcation of morals, social skills, trade skills and societal customs and/or traditions (Bogonko, 1992; Sifuna \& Otiende, 2006). Elders were the main instructors and it is through this education that the society perpetuated and conserved its institutions, laws, and language (Sifuna \& Otiende, 2006).

In the Gusii community, indigenous education was a life-long process that started at birth and continued up to death (Akama and Maxon, 2006, LeVine, Dixon, LeVine, Richman, Leiderman, Keefer, \& Brazelton, 1994). In the pre-colonial Gusii, there were no schools dedicated to instruction and indigenous education was aimed at transmitting social, political, and economic values of the community (LeVine, et al. 1994). For young children, learning was largely through observation, role-play, and receiving corrective feedback from their mothers or older siblings. For the teenagers and young adults, the elders were the main transmitters of knowledge as they actively participated in productive activities within the community. Direct 
instruction only occurred during initiation ceremonies ${ }^{4}$ (LeVine, et al., 1994). In every aspect, the Gusii indigenous education was pragmatic in orientation as it was aimed at transforming the youths into productive members of the society (Akama and Maxon, 2006). In general, the Kenyan indigenous education was accessible and available to all children except in the specialized trades such as herbal medicine where only a select few were trained. In many respects the education was also gendered since the girls received different education from the boys.

Introduction of western education occurred in mid- $19^{\text {th }}$ Century with the coming of missionaries. However, even with the onset of missionary led education, indigenous education continued to be the most common form of education accessible to all. The section that follows examines education that was offered by missionaries as a harbinger for colonial education.

Early Christian missionaries. Christian missionaries preceded the establishment of British Colonial rule. The earliest missionaries who made an impact in education were John Krapf and Johan Rebmann of the Church Missionary Society (CMS) in 1844 and 1846 respectively (Sheffield, 1973). By 1844, Krapf had established a mission at Rabai in the coastal region of Kenya. Between mid- $19^{\text {th }}$ Century and early $20^{\text {th }}$ Century, western education that was offered by missionaries was localized to the coastal region of Kenya. The missionaries at the time had to woo indigenous Kenyans into their classrooms that also acted as churches. Influence of the missionary activity hinterland was established after the completion of the Kenya-Uganda Railway line in 1902 . The table 1 below summarizes the early mission centers that had been set up by 1915 .

\footnotetext{
${ }^{4}$ The common initiation ceremony was circumcision for boys and clitoridectomy or female genital mutilation for girls. During these ceremonies, the candidates (boys or girls aged 10 years) were secluded from the community for an average period of a month.
} 


\section{Table 1:}

Earliest Mission Centers that had Been Set Up in Kenya by 1915

\begin{tabular}{ll}
\hline Name of mission & Location \\
\hline Holy Ghost Fathers & Bura (among the Dawida people) \\
Church Missionary Society & Rabai, Kikuyu, Embu, and Maseno \\
Church of Scotland Mission & Kibwezi, Kikuyu, Tumutumu, Chogoria \\
Gospel Missionary Society & Kambui and Ngenda in Kiambu \\
Italian Consolata Catholic Mission & Limuru, Kiambu, Mangu \\
Mill Hill Mission & Yala, Kakamega, Kisii \\
\hline
\end{tabular}

It can be deduced from table 1 above that by 1915, modern day Nyanza (home province for Kisii County), Western, Coastal, Central, and Eastern Provinces had missions. These missions established some of the best schools to date in these regions. The early missionary education was aimed at equipping indigenous Kenyans with 3Rs (writing, reading, and arithmetic) so that they may read the Bible and work for the colonial administration that was taking root at the time. Missionary education was a precursor to colonial education.

Colonial education. As the colonial government was taking root in Kenya in the early 1900, the missionaries were the main providers of formal education that was modeled along the British education system. The Colonial government established the department of education in 1911. The clash between missionary values and cultural values held by indigenous communities resulted in resistance to missionary education by the mid 1920s (Sheffield, 1973, Sifuna \& Otiende, 2006). In particular, the leaders in Kiambu in modern day Central Province complained on the Missionary ban on female circumcision, and as a reaction, they formed Kikuyu 
Independent Schools. The discontentment of Africans to missionary education received attention of the colonial government which responded by establishing the District Education Boards (DEB), through the District Education Ordinance of 1934 (Bogonko, 1992; Sifuna \& Otiende, 2006). The role of the DEBs was to "allocate grants, fees and scholarships, salary scales, the leasing of plots for school development, and maintaining a register of school" (Sifuna \& Otiende, 2006, p. 206) within their jurisdiction.

The colonial policy to education was marked by ordinances such as the Education Ordinance of 1931 which established different advisory councils for European, African, Arabs, and Indian education (Sifuna \& Otiende, 2006). Besides the ordinances, there were educational commissions whose recommendations influenced education provision and policy during the colonial period. For instance, the Phelp Stokes Commission of 1924 impacted the curriculum by recommending that education given to Africans be tailored to meet their agricultural and industrial needs. In addition to this, it recommended that all missionary schools be registered, closely monitored, and receive grants-in-aid according to grades (Sheffield, 1973). Another notable educational policy document was the Sessional Paper of 1956/1957. Passed during Mau Mau insurgency, this paper recommended creation of African education standards, a raise in Asian Education standards, and maintaining of standards of education offered to children of European descent.

In respect to the Kisii region, Christian missionaries were the first to introduce western education during the colonial period. However, the missionaries' efforts to educate children and adults in Kisii region during this period were hampered by Kisii resistance to Western education due to "missionaries looking down upon many aspects of the Gusii culture and traditional education" (Maxon, 1989, p. 82). The Gusii people were particularly incensed by the 
missionaries' attitudes towards the Gusii culture and were wary of the influence of the Western culture. Unlike central Kenya, Kisii region did not have African Independent Schools, instead, there was clamor for more public funded schools run by District Education Boards (DEB) and funded by Local Native Councils (Maxon, 1989).

Access to education during the colonial period. Education in the colonial period was markedly segregated and grossly unequal as evidenced in funding, policy, infrastructure, curriculum, and staffing (Somerset, 2011). Children of European descent attended white only schools that were well staffed and built relative to those attended by children of African descent. In terms of policy, there was an enforced universal access to education for children of European descent while children of African descent were not covered by this policy. The grants-in-aid to the white only schools were higher compared to Asian and African schools. For instance, "from 1947 to 1957, European education was allocated $£ 670,000$, the Asian $£ 636,000$, and the African education $£ 806,000$; or $\mathrm{Ksh}^{5} 583$, Ksh.174, and Ksh.4 per capita respectively” (Bogonko, 1992, p. 110). The white only schools also had highly qualified teachers who received higher salaries than their black or Asian counterparts with similar qualifications. There were remarkable differences in curriculum taught, the whites only schools received education that was "complete and comprehensive" (Bogonko, 1992, p. 110). On the other hand the curriculum for African pupils was non-academic whereby the focus was on religious and moral instruction as well as manual and practical activities (Sheffield, 1973; Somerset, 2011).

Low enrollment of girls in education was a major issue during the colonial era. For example, the Annual Report on Education of 1949 reported that there were low percentages in girl enrollments and high student dropout rates (Sheffield, 1973). The low number of girls in

\footnotetext{
${ }^{5}$ Ksh. Kenya Shilling is the official Kenyan currency
} 
schools during this colonial period was attributed to cultural factors and insecurity posed by the risk of walking long distances in bushes (Eshiwani, 1993).

Despite the initial resistance to western education that was offered by missionaries and the colonial government, there was a gradual acceptance to this education as it offered clear alternatives to subsistence and sedentary living. In addition, the western education at the time was seen as being in tandem with the new economic models that had been introduced by the colonial government. Therefore, by 1950 s the demand for access to primary education by indigenous Kenyans exceeded the capacity of existing schools at the time. This demand triggered a massive expansion of primary schools by District Education Boards under the auspices of the Local Native Councils ${ }^{6}$ (LNCs) through use local taxes (Schilling, 1976, Sifuna \& Otiende, 1992). Local Native Councils that had been formed by the colonial government in 1924 to give Africans more voice in decision-making on taxes collected within their districts; were comprised of elected leaders, but it was the district commissioner, a colonial appointee, who retained the ultimate authority in decision-making (Maxon, 2009). In Kisii, the LNC had led to the establishment of the prestigious African Government School in 1934 (Bogonko, 1992). Christian Missionary schools were also places that offered access to education for people in the Kisii region.

The return of Indigenous Kenyans, who had conscripted to fight WWII alongside the Royal Army Forces of Britain, resulted in reinvigorated nationalism that clamored for equality and equity in social, economic, and political spheres in Kenya. In central Kenya in particular,

\footnotetext{
${ }^{6}$ Local Native Councils (LNCs); were regional bodies formed by the colonial government as a tool for indirect rule. They were established in 1924 by the colonial government under the Amendment of the Native Authority Ordinance. Development and expansion of the education sector was one of the areas that the LNCs have been credited during the colonial period.
} 
there was Mau Mau insurgency. This insurgency prompted the colonial government to declare a state of emergency.

During the period when the colonial Kenya was under the state of emergency (19521959), access to education suffered a major set back as the Independent African Schools that had began in the 1920s were banned. Most of the Independent African Schools were located in central Kenya. The colonial administrators perceived these schools as training grounds for subversive activities. However, the demand for education continued to increase as more and more Kenyans had started to take their children to school. The section that follows discusses issues related to access to education during the post-colonial Kenya.

Post-colonial education in Kenya. Kenya attained its independence from the British Colonial rule in 1963. Preceding independence had been a tumultuous decade marked by the state of emergency and fervent clamor for independence. Equal access to education for indigenous Kenyan children was intertwined with other social, economic, and political reasons driving nationalism and fight for independence at the time. In this literature review on access to education in a post-colonial Kenya is discussed under four distinct periods: 1) primary education in the first decade (1963 -1970); 2) primary education in the second and third decades (19711980); 3) primary education in the third and fourth decades (1981 -2002); and 4) primary education in Free Primary Education era (2003 to present).

Primary education in the first decade (1963-1970). At independence, the number of primary school children rose 900,000 in 1963 to 1.4 million in 1970 (Sifuna, 1980). This was due to high population growth rate, desegregation of schools, and the belief that education was a guarantor for economic success (Sifuna \& Otiende, 1994; Burnett, 2008). After independence, all primary schools in Kenya were deemed inclusive. For instance, the manifesto of Kenya African 
National Union (KANU), the party which formed the government of Kenya at independence, advocated for universal basic education to ensure access to all children. In line with this, the government formed the Kenya Education Commission Education of 1964, popularly known as the Ominde Commission, to lay out principles that were to guide post-colonial education in Kenya. The Ominde Commission reiterated KANU's clamor for universal basic education. In particular, the commission recommended free universal basic education to start in 1965 and to be completed in 1971 (Republic of Kenya, 1964). In addition, the commission identified the problems that bedeviled education at that time as segregation by class, lack of finances, uncoordinated curriculum, and unemployment of primary school graduates (Republic of Kenya, 1964). The Ominde Commission report was the first comprehensive policy document on education after independence and as such, some of its recommendations formed the basis for on future policies on education in Kenya.

Besides the Ominde Commission of 1964, universal basic education was equally stressed in the Five-Year Development Plan of 1966. According to this Five-Year Development Plan, one of the objectives of the government was to provide free access to primary education for all children of school age (Republic of Kenya, 1965). Despite high emphasis for free education in these two documents, the government failed to bring free primary education to fruition due to lack of funds. In addition, segregation of schools continued to exist as the former white only schools admitted children of the bourgeoisie class while children of the commoners attended regular public schools that were poorly equipped, funded, and staffed. This system whereby some schools are better equipped and staffed than others continue to exist in the present day Kenya as evidenced by blatant acts of giving more funds to 'National Schools' especially at the secondary level while district schools which are in dire need of funds get less. The establishment 
of the Kenya School Equipment Scheme (KSES) in 1969, a department within the ministry of education that was charged with the purchase and supply of instructional materials to all schools in Kenya (Abenga, 2009), was another significant development in education during this period.

Primary education in the second decade (1971-1980). The first concrete steps to provide universal access occurred in 1973 when the then president of Kenya; Jomo Kenyatta, through a presidential decree, made education free for the first four years of primary education (Bogonko, 1992). In the same vein, the Five-Year Development Plan of 1970 - 1974 (Republic of Kenya 1970) recognized the need for free universal basic education. In addition, an education commission called the Gachathi Report of 1976 (Republic of Kenya, 1976) recommended the removal of fees for the full seven years of primary. Following this report, a newly elected president Daniel A. Moi, decreed that milk be supplied to all primary schools and that education from standards V - VII be free, effectively making the entire primary education cycle. This resulted in an increase in enrolments. However, lack of funds for purchasing milk at the time, resulted in diversion of funds from the Kenya School Equipment Scheme (KSES) resulting in its demise by early 1980s.

Primary education in the third and fourth decades (1981-2002). Universal free primary education had been attained in Kenya by 1982 (Bogonko, 1992). Despite this achievement, there were challenges that hindered delivery of quality education to students enrolled in public primary schools. One such challenge was the shortage of trained teachers which forced the government at the time to employ more untrained teachers ${ }^{7}$. This group of untrained teachers comprised $30 \%$ of the teaching workforce (Republic of Kenya, 1991). The second challenge that faced the implementation of universal free primary education was constraints in classroom space and lack

\footnotetext{
${ }^{7}$ Untrained teachers were individuals who were employed to teacher in public primary schools and who did not have any qualification other than secondary education. These individuals had therefore not gone through any formal training on teaching in a teacher training college.
} 
of instructional materials. As Bogonko (1992) notes, "the general growth ratio of primary schools to pupils was 1:383 in 1980 and 1:370 in 1985" (p. 116), which indicated the classroom space in schools had been outpaced by the enrollments. This was due to the high population growth rate at the time. To cope with the problem, the government abdicated the role of classroom construction to school committees, Parent Teacher Associations (PTAs), local communities and municipalities through levies and Harambees ${ }^{8}$.

The third and fourth decades after Kenya's independence saw changes in the education system in Kenya. First, following the recommendations of the Presidential Working Party on the Second University in Kenya in 1981 commonly known as the McKay Commission (Republic of Kenya, 1981), the 7-4-2-3 ${ }^{9}$ system of education was changed to the current system of 8-4-4 (see Figure 1 below). The McKay Commission stressed the inclusion of technical subjects in the curriculum. The rationale given by the commission was based on the concern that a majority of young people joining the job market and who had received primary as well as secondary education did not have requisite technical skills for paid employment (Rharade, 1997). In addition to this the commission argued that exposing students to technical education early on would equip them with skills for self employment in trades such as masonry, carpentry, and welding (Eshiwani, 1993; Rharade, 1997). Thus from recommendations of the McKay Commission of 1981, the 8-4-4 system was born. Figure 1 below shows a basic structure of the 8-4-4 system from primary ( $1^{\text {st }}$ grade) to university. It also includes a description of pre-primary or early childhood education years (ages 3-5).

\footnotetext{
${ }^{8}$ Harambee is a Swahili word which literary means "pull together". At independence the Kenyans started pooling their resources together through fundraisers to build or complete various projects. The harambee tradition still flourishes in Kenya.

${ }^{9}$ The 7-4-2-3 system of education involved 7 years of primary education, 4 years of lower secondary education, 2 years of higher secondary education, and 3 years in university. Whereas the 8-4-4 system of education that was established following McKay Commission involved 8 years of primary education, 4 years of secondary education, and 4 years of university education.
} 
Figure 1:

Structure of the 8-4-4 System in Kenya

\section{Pre primary education}

- Entrance to pre-primary education is at age 3 years

- children graduate from pre-primary at age 5 years

- total number of years in pre-primary is 3 years

- Enrollment in pre-primary is voluntary

\section{Primary education}

- Children enroll in primary education at age 6 yearsand graduate at age 13 years.

- Students sit for national exams - Kenya Certificate of Primary Education (KCPE) at the end of their Standard VIII (Eight Grade).

- Enrollment in primary is compulsory.

- Covers Grades 1-8

\section{Secondary education}

- Students enter secondary school typically on their $14^{\text {th }}$ year and spend four years in secondary school.

- Students sit for national exams - Kenya Certificate of Secondary Education (KCSE) at the end of their fourth year in secondary (Form IV an equivalent of $12^{\text {th }}$ Grade)

- Admission to secondary schools is competitive and not all students who graduate from primary schools are guaranteed.

- Covers Grade 9-12

\section{University education}

- Admission is competitive and students are admitted based on their performance in Kenya Certificate of Secondary Education (KCSE).

- Students spend four years in university education for most degrees. Some degrees such as Medicine and engineering take six years. 
Figure 1 above gives a brief description of each level in the system of education in Kenya starting from pre-primary to university. After completion of $8^{\text {th }}$ grade (standard 8), students can matriculate into mid level colleges such as vocation technology centers and youth polytechnics, after graduating from $12^{\text {th }}$ grade (form 4), students can matriculate into university.

Implemented in 1985 with no advance preparation, the 8-4-4 system of education resulted in shortages in classroom facilities to accommodate pupils who were in their eight-year in primary schools. All primary schools at the time had only room to accommodate students from first grade through seventh grade. Another problem was shortage of teacher instructors for the technical subjects. To address these issues, the government encouraged local communities to fund construction of extra classes through harambees and levies.

The second change that occurred within the education sector in the third and fourth decades was the introduction of the cost-sharing policy in the late 1987. The cost sharing policy required both parents and the government to bear the cost of schooling at the primary and secondary levels. The parents became responsible for the cost of developing school infrastructure, instructional materials and any other expenses, while the government only covered the costs for teacher salaries. Cost-sharing; an austere fiscal policy that was part of the Structural Adjustment Programs (SAPs) the government of Kenya had to implement as a conditionality to receive financial aid by the World Bank and the International Monetary Fund, resulted in restricted access to education and a precipitous decline in student enrollments from 91\% in 1980 to $65 \%$ by1997 (World Bank 2001, in Omwami \& Omwami, 2010). This was because children from poor families and whose parents would not raise the required fees to access education. 
Summary. Based on the discussion on the historical development and reform in education, it can be argued that while it was the Kenyan government's goal to actualize access to free primary education as from 1964 onwards, it was not until 1980s when primary education became free for all school age children. This however did not last for long because of the introduction of cost-sharing policy in the late 1980s which led to a precipitous decline in primary school enrolments at the turn of the millennium. This decline in enrolments also suggested that there were a large group of school age cohort who did not access primary education.

Primary education in Kenya between 2000 and 2010. The reversal of decline in percentages of school age children enrollments and restricted access to education occurred after the government declared Free Primary Education $(\mathrm{FPE})^{10}$ in 2003. This declaration was a fulfillment to a campaign promise made by the National Alliance and Rainbow Coalition (NARC), whose party leader won the 2002 Kenyan Presidential general election, and in part it was a response to the United Nations Education for All (EFA) initiative of 2000 and a fulfillment of the Kenya's Children Act of 2001. The Free Primary Education (FPE) guaranteed that all children between the ages of 6-14 years would attend public schools free of charge. Thus in 2003, there was an upsurge in enrollments by 1.3 million children who had previously been left out of the public education system due to their parents' inability to pay the required fees.

In the first year of FPE enrollments, there was a $75 \%$ increase in government expenditure in education. For instance the total development expenditure on education increased from Ksh.

\footnotetext{
${ }^{10}$ The objectives of Free Primary Education include the following: 1) To reverse the declining enrollments at the primary level; 2) To enhance access, retention, quality, and relevance at the primary level; 3) To improve participation, progression, and completion rates at the primary level; 4) To implement sector policy goal, including universally accepted conventions on the provision of education (to which Kenya is a signatory); 5) To reduce the cost of education, previously borne by parents in the provision of primary school education; 6) To streamline and rationalize the use of educational resources; 7)To Implement the provisions of the (Kenyan) Children's Act of 2001; 7) To improve on learning achievements
} 
4.8 billion in 2002/2003 economic year to Ksh. 8.4 billion in the 2003/2004 economic year. In the same period, the number of public primary schools slightly increased by $2.7 \%$ from 51,123 in 2002 to 52, 522 in 2003 (Republic of Kenya, 2004). The number of new schools was small compared to the large number of new students who enrolled in schools and this caused overcrowding in classrooms. During the same period, the teacher pupil ratio worsened from 34:1 in 2002 to $40: 1$ in 2003 . While the government recognized the need to hire more teachers in its economic survey report released in 2004, it acknowledged that any such effort was curtailed by lack of revenue at the national level (Republic of Kenya, 2004).

Throughout the implementation of FPE, the government recognized the need to purchase learning materials to students and schools for equity reasons. The target was to achieve a child textbook ratio of 2:1 in upper primary $\left(5^{\text {th }}\right.$ grade $-8^{\text {th }}$ grade $)$ and 3:1 in lower primary $\left(1^{\text {st }}\right.$ grade to $4^{\text {th }}$ grade) with the first three years after FPE implementation. The section that follows discusses the evolution of education as a human right.

\section{Education as a Right}

The fervent movements to universalize basic education in sub Saharan Africa and Kenya in particular is rooted in the Universal Declaration of Human Rights (UDHR) that was passed by the United Nations in 1948. Specifically, Article 26 of the UDHR (United Nations, 1948) stipulates:

1.Everyone has a right to education. Education shall be free, at least in the elementary and fundamental stages. Elementary education shall be compulsory. Technical and professional education shall be made generally available and higher education shall be equally accessible to all on the basis of merit. 2. Education shall be directed to the full development of the human personality and to the strengthening of respect for human 
rights and fundamental freedoms. It shall promote understanding, tolerance, and friendship among all nations, racial or religious groups and shall further the activities of the United Nations for the maintenance of peace. 3. Parents have a prior right to choose the kind of education that shall be given to their children (Article 26).

Article 26 of the UDHR clearly emphasizes the need for education in the elementary stages to be free. Moreover, it recognizes that this education should lead to the full development of human personality. The historical context in which UDHR was passed (right after World War II) is reflected in this article as it identifies education as the key to understanding and tolerance of diversity. The influence of UDHR on post-colonial educational policy documents in Kenya is evident. For instance, the Educational Report of 1964, which is the earliest policy document that guided education and training in Kenya, identified the provision of free and compulsory primary education to all children (Republic of Kenya, 1964).

Besides Article 26 of the UDHR, the passage of the Convention of the Rights of the Child (CRC) $)^{11}$ in 1989 (United Nations, 1989), reiterates the child's right to education. Ratified by 189 countries, the CRC stands out as the most accepted law in the world (Burnett, 2008). Article 28 of CRC specifically states: "States (should) recognize the right of the child to education" in particular, "make primary education compulsory and available free to all...(and) take measures to encourage regular attendance at schools and the reduction of dropout rates". Unlike the UDHR, the CRC is more specific since it emphasizes that primary education be free and compulsory as well as the need to increase participation through regular attendance and

\footnotetext{
${ }^{11}$ Convention on the Rights of the Child (CRC) 1. States Parties recognize the right of the child to education, and with a view to achieving this right progressively and on the basis of equal opportunity, they shall, in particular: (a) Make primary education compulsory and available free to all; (b) Encourage the development of different forms of secondary education, including general and vocational education, make them available and accessible to every child, and take appropriate measures such as the introduction of free education and offering financial assistance in case of need; (c) Make higher education accessible to all on the basis of capacity by every appropriate means; (d) Make educational and vocational information and guidance available and accessible to all children; (e) Take measures to encourage regular attendance at schools and the reduction of dropout rates
} 
reduction in dropout rates. Both the UDHR and the CRC are foundational legal instruments that obligate countries to comply with the call to universalize basic education.

At the global level, the strongest push for universal primary education that is free and compulsory occurred during the 1990 World Conference on Education for All at Jomtien, Thailand (UNESCO, 1990). In this conference, participating countries including Kenya signed the Education for All (EFA) initiative. EFA initiative had six goals ${ }^{12}$ which laid benchmarks for attaining universal primary education. In particular, EFA goal number one emphasized the need for universal access to basic education for all school age children in all countries. At the turn of the century, the goals of EFA had not been attained. Thus in the year of 2000, a World Forum on Education for All at Dakar, Senegal, yielded a more concrete framework for action which readjusted the attainment dates for the EFA goals (United Nations Educational Scientific and Cultural Organization - UNESCO, 2000). The Dakar Framework for Action, as it was known, reiterated the EFA goals but emphasized the targets for their attainment. The specific framework included:

1) Expanding and improving comprehensive early childhood care and education, especially for the most vulnerable and disadvantaged children.

2) Ensuring that by 2015 all children, particularly girls, children in difficult circumstances and those belonging to ethnic minorities, have access to and complete free and compulsory primary education of good quality.

3) Ensuring that the learning needs of all young people and adults are met through equitable access to appropriate learning and life skills programs.

\footnotetext{
${ }^{12}$ EFA goals: 1. Universal access to learning; 2. A focus on equity; 3. Emphasis on learning outcomes; 4. Broadening the means and the scope of basic education; 5. Enhancing the environment for learning; 6. Strengthening partnerships by 2000
} 
4) Achieving 50 percent improvement in levels of adult literacy by 2015, especially for women, and equitable access to basic and continuing education for all adults.

5) Eliminating gender disparities in primary and secondary education by 2005 , and achieving gender equality in education by 2015 , with a focus on ensuring girls' full and equal access to achievement in basic education of good quality.

6) Improving every aspect of the quality education, and ensuring their excellence so that recognized and measurable learning outcomes are achieved by all, especially in literacy, numeracy and essential life skills. (UNESCO, 2000: p. 15-17)

The focus for Education For All (EFA) framework number one in the Dakar Declaration was on expanding early childhood educational access to marginalized groups through adaptive educational programs. The EFA framework number two in this declaration set 2015 as target date for attaining the universal access to education. This framework also emphasized the need for interventions to mitigate environmental and social conditions that constrain girls, children from difficult circumstances, and ethnic minorities from fully participating in education. Framework number three demanded increased access to young adults for continuing education so as to actively participate in their economies. The fourth framework focused on improving levels of adult literacy, while achievement of gender parity is the central idea in the fifth framework. The sixth framework for action focused on the quality of education in all spheres including highly skilled teachers, well-motivated students, adequate materials and facilities, and relevant curriculum (UNESCO, 2000).

Alongside the EFA framework for action passed in Dakar, Senegal, was the passage of the Millennium Development Goals (MDGs) of 2000 (United Nations, 2000), which reinforced the need for attaining of universal basic education by the year 2015. Through the MDGs, the 
United Nations through UNESCO constantly monitors member countries in their progress towards attainment of both MDG goals and EFA goals. Since 2002, the UNESCO has been giving out EFA reports on the progress that countries are making towards the attainment of EFA goals. For each year, the EFA report has focused on a particular issue. The 2010 EFA report (UNESCO, 2010), which focused on marginalization, brought to the forefront the plight facing the students who are at risk of dropping out or not being enrolled in schools.

It can be concluded that the events at the global stage, starting with the passage of Universal Declaration of Human Rights (UDHR) and later Convention of the Rights of a Child (CRC), as well as the passage of EFA goals and MDGs, had a great influence in shaping the educational policy in Kenya. For instance, chapter four of the recently promulgated Constitution of Kenya covering the bill of rights emphasizes the right of the child to free and compulsory basic education. In particular, section 43 of this constitution indicates the right of every person to education, while section 53 underscores the right of every child to free and compulsory basic education (Republic of Kenya, 2010). This recognition of free basic education within the constitution, demonstrates the government's commitment to the attainment of the universal access to education by 2015 for all its school age children as stipulated by the Education for All goals of 2000 and the Millennium Development Goals of 2000.

\section{Zones of Exclusion}

Research conducted by the Consortium for Research in Educational Access, Transitions, and Equity (CREATE) ${ }^{13}$, extensively identifies general factors that underlie exclusion from access to basic education for at risk students in developing countries. Based on its research in

\footnotetext{
${ }^{13}$ CREATE is a research program based in Sussex University in the United Kingdom has done extensive studies that aim at increasing knowledge and understanding of the reasons why so many children fail to access and complete basic education successfully in Developing countries and sub Saharan Africa in particular. The CREATE program is funded by the United Kingdom Department for International Development (DFID)
} 
sub-Saharan Africa, CREATE has developed a model that identifies zones in which children between the ages 5-15 are vulnerable to be excluded from educational participation. In CREATE's model, there are three zones of vulnerability and/or exclusion at the primary (Grades 1-8) school level (refer figure 2 below). Zone 1 represents children who never attend school due to wars, livelihood style (e.g. nomadic) or health issues such as HIV/AIDS (www.create-rpc.org; Lewin, 2009). Zone 2 includes children who are excluded after initial entry due to dropping out. Lewin identifies the precursors for dropping out as "repetition, low achievement, temporary withdrawals, low attendance, overage enrollment, poor teaching, degraded facilities, high teacher pupil ratio, household poverty and poor health and nutrition” (p. 156-157). Zone 3 focuses on those who are at risk of dropping out. These include low achievers, repeaters, and low-attenders (Lewin, 2009).

Figure 2:

\section{CREATE's Zones of Exclusion in primary schools}

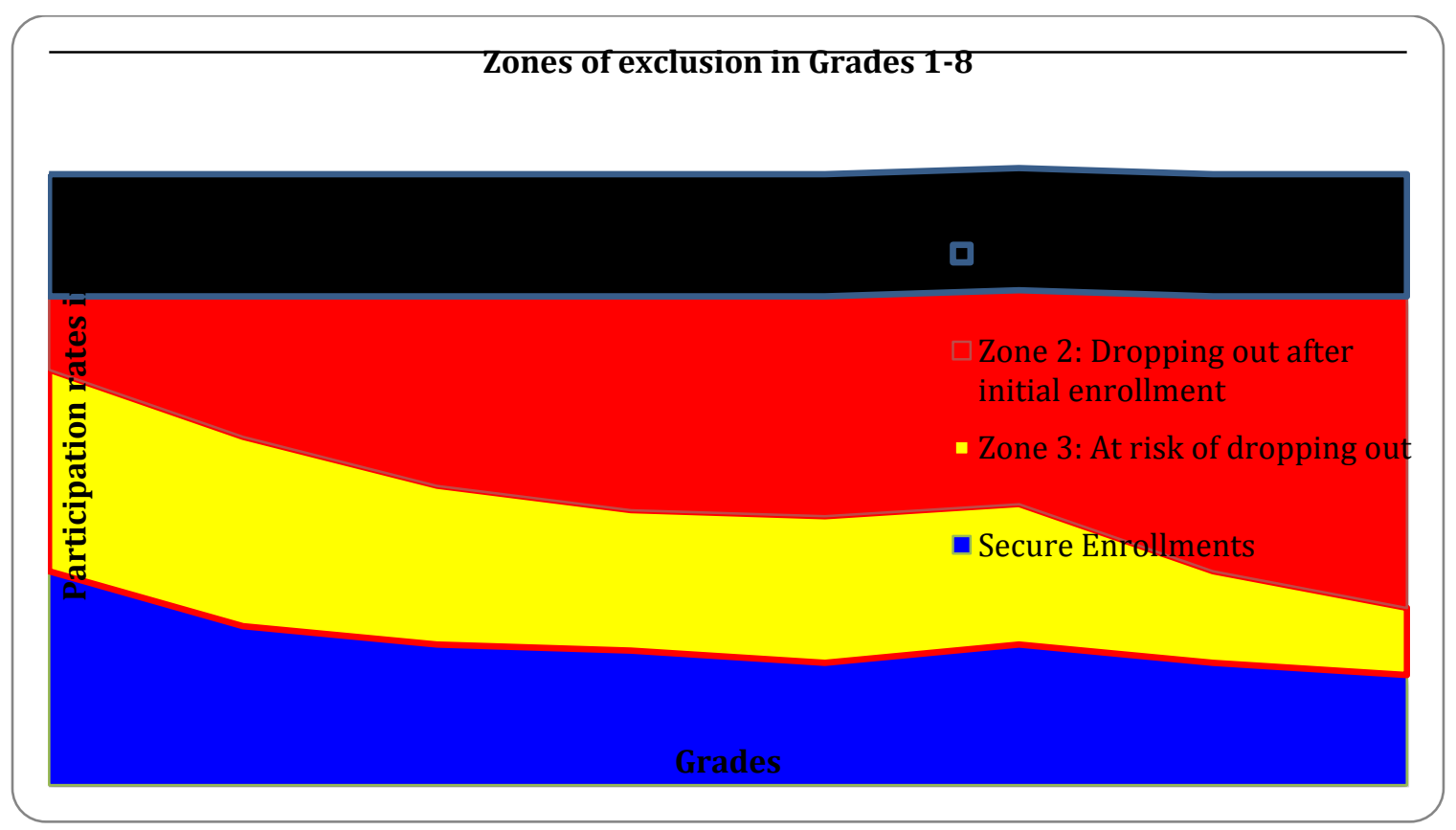


Sources: Adapted from Lewin, K.M. (2009). Access to education in sub-Saharan Africa, patterns, problems, and possibilities. Comparative Education, 45(2), 151-174.

This study focuses on CREATE zones 2 and 3 for the primary reason that this is where schooling and teacher characteristics have a potential of playing a major role in influencing access. In addition, the problem of initial access to education appears to have been addressed through the declaration for Free Primary Education (FPE), recognition of the right to free basic education for every child by the Constitution of Kenya, and a terse declaration by the Ministry of Education of Kenya, in which all parents and/or guardians who fail to send their children to school would be sued by the state (Daily Nation, 8/16/12). In the sections that follow, this paper will attempt to review related literature on children who are still excluded and those who are at risk of being excluded after initial enrollment in primary education in Kenya.

\section{Children Still Excluded From Full Benefits of FPE}

Despite the Free Primary Education initiative in Kenya, universal access to primary education has not been achieved (Republic of Kenya, 2009). This assertion was confirmed by Kenya's 2009 census report that indicated that about 1.9 million school age children were not enrolled in the formal education system. This was a staggering number of children since they represented 23 percent of the school age cohort. Various studies have identified reasons for exclusion of these children from formal schools. These include: a) child labor, b) children infected and/or affected by HIV/AIDS, c) children from pastoralist communities (Sifuna, 2005), d) children with disabilities (Ananga, 2011; Birger \& Crassati, 2009; Burnet, 2008; GithithoMuriithi, 2010; Ministry of Education Science and Technology, 2005; Munene \& Ruto, 2010; Mutua \& Dimitrov, 2001; Nyambedha, Wandibba, \& Aagaard-Hansen, 2000; Sifuna, 2005; UNESCO, 2010), e) the girl child (Glick, 2008; Kane, 2004; Lloyd, Mensch, \& Clark, 2000; 
Southern and Eastern Africa Consortium for Monitoring Educational Quality-SACMEQ, 2011; Shabaya \& Konadu-Agyemang, 2004), and f) children whose basic needs are unmet (Kristjan, Mango, Krishna, Radeny, \& Johnson, 2010; Republic of Kenya, 2007)

Child labor. Child labor is widespread in Kenya and limits children's access to as well as participation in primary education (Ananga, 2011; Githitho- Muriithi, 2010; Munene \& Ruto, 2010). A study by Ananga (2011) that sought to determine the typology of school dropouts, reported that child labor led to high incidences of lateness, irregular attendance, and seasonal withdrawal all of which culminated into permanent withdrawal from schools. Though the study by Ananga was conducted in Ghana, its findings help in highlighting the impact of child labor on education.

The International Labor Organization (ILO) defines child labor, ${ }^{14}$ as any work that involves children who are aged between 5 and 17 years and that this work interferes with the child's education, deprives them from their childhood, and that it is harmful to their physical and mental development (http://www.ilo.org./ipec/facts/lang-en/index.htm). Child labor is distinct from child work (Hartjen \& Priyadarsin, 2012) in that child work is any work that takes place outside the school hours and within the household including but not limited to family activities such as weeding, harvesting, or any other local economy. Within the African context, child work is valued and is an integral part of their cultural experience. While child work may affect schooling, Githitho-Muriithi (2010) reports that about 34\% of children engaged in child work attend school. Specifically in Kisii community child work, which involves completing domestic chores, heavily affects the girls as most of their after school hours are devoted to collecting firewood, fetching water, and cleaning. On the other hand, child labor denotes children who are

\footnotetext{
${ }^{14}$ According to the International Labor Organization (ILO), child labor encompasses any work that involves children who are aged between 5 and 17 years and is likely to be hazardous or interfere with the child's education, or be harmful to the child's health, or physical, mental, spiritual, moral, or social development.
} 
forced to work out of necessity due to poverty, survival or to fend for themselves and/or other dependents (Hartjen \& Priyadarsin, 2012). This labor unlike child work interferes with the child's schooling by depriving them the opportunity to attend school, leave school prematurely or require them to attempt to combine school attendance with excessively long and heavy work (Diallo, Hagemann, Etienne, Gurbuzer, \& Mehran, 2010).

In Kenya, children participating in child labor are predominantly engaged in the domestic and commercial sectors (Githitho-Muriithi, 2010; Munene \& Ruto, 2010), which may include being employed as a domestic worker (e.g. maid, farmhand, etc.), porter, shepherd, or hawker. All these activities limit the affected child's participation in education hence qualifying as child labor. In Kenya, as in most developing countries child labor is associated with poverty, whereby children have no choice but to engage in labor to supplement household income or risk starvation (Githitho_Muriithi, 2010). Oftentimes, when such children enroll in schools, their attendance is irregular hence they become part of the marginalized students who are at risk of dropping out. While the studies by Munene and Ruto and that of Githitho-Muriithi give good information on the causes of child labor, they fail to track how teachers perceive this vulnerable group of students and any school practices that help keep students in schools. This gap in research offers a good avenue for further research.

HIV/AIDS. Besides child labor, HIV/AIDS is another factor that contributes to the exclusion of children from the free primary education in Kenya. The sociological and economical impact of HIV and AIDS on education is devastating not only to Kenya, but also in many countries in sub-Saharan Africa (Burnett, 2008). For instance, a child's participation in school is affected when his/her parent dies of AIDS. The Education for All Global Monitoring Report of 2010 (UNESCO, 2010) asserts: 
In some sub-Saharan African countries, including Ethiopia, Kenya, Malawi, and Tanzania, children whose mothers died (of AIDS) were more likely to move to another household and less likely to stay in school. Death of a mother reduced involvement among both boys and girls by around 20 percent and disrupted attendance by enrolled children (p.184).

This statement suggests that children orphaned due to HIV and AIDS are at risk of dropping out of schools if enrolled or risk being excluded altogether. The risk is higher when the mother is involved since she is assumed to be the primary caretaker of the family when she dies, older children are forced to assume the caretaker role and thus drop out of school (Birger \& Crassati, 2009; Swadener, Kabiru, \& Njenga, 2000).

Despite the high rates of HIV/AIDS infection and cases in Nyanza, there is a lack of organized support systems by both the government and communities to cater for needs of children orphaned by HIV/AIDS (Nyambedha, Wandibba, \& Aagaard-Hansen, 2001). Focusing on support systems for these vulnerable children in Nyanza region in western Kenya, Nyambedha et al's (2001) study revealed that, "majority of orphaned children are cared for within the patrilineal set-up with maternal relatives also getting involved in their support to some extent" (91). Indicative in Nyambedha et al study are the four main "problem areas" (89) which orphan children encounter and these are schooling, medical care, food, and clothing. Out of these four problem areas, schooling was reported to be the most serious and the study attributed this to limitations in resources that characterize orphan households.

In other instances, HIV/AIDS orphans who are taken in by their guardians who in most cases are members from their extended family, normally experience a drop in reading and writing (Himaz, 2009). The finding by Himaz does indicate the influence of HIV/AIDS on a 
student's learning. This may be due to the psychological impact of losing their mother or a guardian's lack of interest in the child's education. In addition to this, school children that have been infected with HIV (normally at birth) encounter direct and/or indirect stigmatization (UNESCO, 2010), which in turn affects their participation and fuels their marginalization. In addition to this, children infected with HIV/AIDS are likely to miss school due to health related issues for a lengthy period of time thereby affecting their access to education.

In Kenya, the effect of the HIV/AIDS pandemic is well summarized in the Kenya Education Sector Support Program (KESSP) 2005-2010, a document that was developed by the Ministry of Education Science and Technology. On the chapter that covers HIV/AIDS, the document states:

In the education sector, the HIV/AIDS pandemic affects the sector in several ways. First, most of the children infected with HIV/AIDS at birth do not live to enroll in school. Second, the number of orphans in schools will increase as parents dies from HIV/AIDS, thus without appropriate interventions, the orphans will most likely drop out of school. Third, some children will be forced to stay at home to care for sick family members. Fourth, there are teachers dying from HIV/AIDS while others are too sick to work thus denying the sector vital skilled human resources (Ministry of Education Science and Technology, 2005, p. 59)

KESSP rightfully emphasizes the need for schools to adopt appropriate interventions and measures that will create safe learning conditions for orphans to continue attending school. Such proactive interventions have to be reflected in the school ethos, right from the school administration to classroom instructional practices. Therefore, any discourse on the challenges facing the delivery of education, which is accessible, equitable, and of quality in the $21^{\text {st }}$ Century 
to all children in Kenya must include a discourse on educating HIV and AIDS orphans. More so because it is projected that by the year 2020, about 11.8 percent of all children in Kenya below 15 years will be orphaned mainly because of AIDS (Birger \& Crassati, 2009). Hence, examining schooling conditions, teacher practices and perceptions in regard to how they handle these students becomes a moral imperative.

Children from pastoralist communities. Children from pastoralist communities ${ }^{15}$ are another group that is at risk of failing to enroll or regularly attend schools due to their migratory nature from season to season (Sifuna, 2005). Since schools in Kenya are fixed structures, children in these communities that are migratory oftentimes encounter discontinuous schooling experiences as they miss school for a long period while migrating with their livestock from place to place in search for pasture. Increasing access to basic education for such children and migratory communities require innovative schools. In his study that looked into the ways of increasing access and participation in education by pastoralist communities, Sifuna (2005), concluded that the traditional delivery modes of education in regular classrooms was not compatible with the way of life of these communities nor does it meet their needs and demands. As such he recommended the use of adaptable methods of education for instance using "mobile schools to cater for the nomadic nature of the communities. These schools could employ collapsible classrooms that can be assembled or disassembled within a short notice and carried conveniently by donkeys or camels" (Sifuna, 2005, p.515). Poor teacher staffing is another problem encountered by schools in regions occupied by pastoralist communities in Kenya.

\footnotetext{
${ }^{15}$ Pastoralist or nomadic communities are communities whose main economic mainstay is livestock keeping. These communities, who normally live in arid and semi-arid areas, migrate from place to place with their livestock in search for green pasture and water from season to season. The young boys within these communities normally shepherd the livestock and are therefore away from schools most of the time
} 
Children with disabilities. Another group of students who are vulnerable and do not participate fully in free primary education are children with disabilities. In Kenya, about four percent of its population is comprised of persons with disabilities (Republic of Kenya, 2010). However, this is a conservative figure, as it does not capture the full extent of the numbers of people with disabilities. That is why the census report of 2009 acknowledges that, "Disability is not a phenomenon that can easily be described with a binary classification of yes/no. In this regard, this aspect is particularly difficult in a census where the number of questions asked is restricted" (Republic of Kenya, 2010, p.28). Moreover, poor identification as well as record keeping (Kochung, 2003), cultural factors and /or superstitions (Mukuria \& Korir, 2006), and lack of awareness (Bore, Mukuria, \& Adera, 2007), all hamper the identification process of children with disabilities. Nevertheless, the children with disabilities who this study assumes to be four percent of the school age cohort (based on the census report) and are classified as marginalized warrant examination of whether they are receiving appropriate education.

The factors that influence decision making on enrolment of children with disabilities in public schools is an issue that has received attention by researchers on education in Kenya. For instance, an empirical study by Mutua and Dimitrov (2001) that sought to determine factors predicting the enrolment of children with intellectual disabilities in Kenyan schools reported four significant predictors. These predictors were: parents' level of education, parents' expectations about social acceptance of a child, parents' belief about the appropriateness of the child's school education, and parents' bias against educating children with intellectual disabilities. It is important to note here that this study focused only on children with disabilities who are totally excluded from the education system and therefore does not account for the educational 
experiences of children with disabilities in schools. However its findings undergird the sociocultural practices that contribute to the discrimination of children with disabilities.

The educational attainment of children with disabilities in Kenya is another area that has been studied. In a national survey on the condition of persons with disabilities in 1982, Nkinyangi and Mbindyo (1982) reported that most persons with disabilities remained illiterate or became progressively illiterate after their primary education. Though this survey was conducted in the era when schools required parents to pay fees, its findings help reinforce the notion that individuals with disabilities have higher illiteracy rates than those of the normal population. This also raises concern on the appropriateness of the education afforded to students with disabilities. Perhaps the concern on appropriateness of education for students with disabilities is illustrated better by Bore, Mukuria, and Adera (2007) who indicate that the "needs of children with emotional and/or behavior disorders are still not being appropriately addressed"' (p.54). In their study which focused on Educating of children with emotional and/or behavioral disabilities in Kenya, they report that the lack of explicit government policy on special education, inadequate funding, and lack of public awareness and support for special education have negatively impacted the quality of education for this group of children. Since this study only based its findings on a survey from pre-service teachers who had prior but limited interactions with children with disabilities, there is need to gather data from practicing teachers. This study however, uses an umbrella/inclusive term of marginal students to represent all those students who are at risk of dropping out of schools after initial entry, repeating grades, are overage in respect to their grades, exhibit poor performance, and have low attendance.

A study by Lynch et al (2010) focusing on the role of itinerant teachers in mainstreamed schools that have students with visual impairments indicated that there is a lack of resources for 
teaching students with visual impairments. This study also emphasized the role of itinerant teachers in providing appropriate education for these students. Perhaps clear pointers to endemic problems that bedevil special education delivery in Kenya are best highlighted in the Ministry of Education Science and Technology-MOEST (2005) in a Kenya Education Sector Support Program (KESSP) ${ }^{16}$ document, which states:

Lack of clear guidelines on the implementation of an all inclusive education policy, lack of reliable data on children with special needs, inadequate tools and skills in identification and assessment and curriculum that is not tailored to meet special needs ( $\mathrm{p}$. 28).

The Kenya Education Sector Support Program clearly delineates the five barriers to equitable access to education for children with special needs. These barriers are: 1) lack of comprehensive policy and guidelines for special needs education, 2) lack of data of special needs children, 3) inadequate tools and skills to teach students with special needs, 4) inadequate tools and skills to identify children with special needs, and 5) curriculum that is not tailored and adaptable to the learning needs of children with disabilities. The above excerpt from KESSP document clearly augments the notion that the learning needs of students with disabilities are not equitably met in Kenyan classrooms.

The girl child. Various studies that have focused on gender disparities with regard to access to basic education have found that girls or female students are at risk for marginalization (Glick, 2008; Kane, 2004; McMahon, Winch, Caruso, Obure, Ogutu, Ochari, \& Rheingans, 2011; Shabaya \& Konadu-Agyemang, 2004; United Nations, 2000). This section examines gender disparities and factors that influence these disparities.

\footnotetext{
${ }^{16}$ KESSP - Kenya Education Sector Support Program 2005 - 2010. In this document, the Ministry of education describes the areas within special education that have to be improved within a five year period
} 
Disparities in initial educational enrollments, continued progression, retention, and achievement that exist between boys and girls in developing countries is an issue that has received considerable attention in both international and state educational policy declarations. For instance goal number three of the Millennium Development Goals (United Nations, 2000) that focuses on promoting gender equality and empowerment of women stipulates elimination of gender disparities in education by 2015 . Gender disparities are common in developing countries and Kenya is no exception (Ministry of Education Science and Technology-MOEST, 2005).

Various strategies have been given to advance equal educational attainment for both girls and boys. For example, Glick (2008) reported that "girl child education" has ripple effects on improved child nutrition, schooling, reduced infant mortality, reduced maternal mortality, reduced fertility and more women in the workforce. This implies that a nation that has higher girl-child literacy is healthier and wealthier thus the urgency to ensure that access to education is equitable to all children irrespective of their gender.

In Kenya, though initial enrollment in the first grade (standard one) indicates near attainment of gender parity (MOEST, 2007, SACMEQ, 2011), there still exists gender disparities in continued access, progression through grades, and retention rates as manifested in the number of children who enroll in the $8^{\text {th }}$ grade Kenya Certificate of Primary Examinations. In addition, there are disparities with regard to achievements in national examinations. Various reasons have been given to explain gender disparities in education. These reasons within the Kenyan context are better illustrated by the Kenya Education Sector Support Program (KESSP) 2005-2010 document that states:

Access has (to education for the girl child) been hampered by factors such as cultural and religious attitudes and practices, infrastructural, inadequate policy guidelines, poverty, 
HIV/AIDS, community awareness, as well as lack of adequate role (female) models especially in the rural areas (Ministry of Education Science and Technology, 2005, p. 249).

In addition to the reasons given by the Ministry of Education of Kenya, there are some research that have focused on reasons for gender disparities, these are: a) cultural beliefs and practices (Glick, 2008; Kane, 2004; Shabaya \& Konadu-Agyemang, 2004), b) school environments (Lloyd, Mensch, \& Clark, 2000; Southern and Eastern Africa Consortium for Monitoring Educational Quality-SACMEQ, 2011), c) teacher stereotypes (Lloyd, Mensch, \& Clark, 2000), and d) poverty (MOEST, 2005). The section that follows briefly discusses each of these factors in relation to access to education in Kenya.

Cultural beliefs and practices. Cultural beliefs and practices in some African communities have been identified as one of the factors that inhibit initial enrollment, retention, and progression of female students (Glick, 2008; Kane, 2004; Shabaya \& Konadu-Agyemang, 2004). For instance, Kane (2004) identified the customary laws that disbarred women from inheriting property in Kenya as a contributing factor to low female enrollments in schools. Though sections 27(3), 40(1), and 60(1) Kenyan constitution stipulates that all persons irrespective of their gender have a right to own and inherit property and prosper, there still exist retrogressive cultural factors that continue to hamper fully realization of women's right to own property. For instance, the cultural practice amongst the Kisii community that involves transfer of family property (in most cases land) to boys and not girls typifies economic disempowerment and alienation of women in this community. This practice of brazen gender preference is further illustrated by the choice of families with limited resources to invest in educating the boys over girls. Other cultural factors that inhibit fully participation of girls include early marriages, female 
genital mutilation and/or female circumcision (which "prepare" girls for adulthood/marriage roles), and domestic chores overload when compared to chores performed by their male counterparts (Glick, 2008).

School environment. Some studies have reported that the school environment and the school policies do have a great effect on girl child participation in education. Physical and psychological school safety has been found to influence girl child participation in education (Lloyd, Mensch, \& Clark, 2000; McMahon, et al., 2011SACMEQ, 2011). Physical school safety involved provision of separate toilet facilities for boys and girls and having school fences (SACMEQ, 2011). The condition of toilets in primary schools in Kenya was reported by McMahon, et al., (2011) as a factor that influenced female students' level of comfort in schools. In A comprehensive study on primary school quality and its effect on educational participation of Kenyan girls and boys, Lloyd, Mensch, and Clark, (2000), reported that the characteristics of school environment such as teacher quality, teacher attitudes to students (girls or boys), staff composition (the proportion of female teachers to male teachers), school fees/school price, and distance from home to school had a significant effect on girl-child participation in education than the boy-child. Lloyd, et al (2000), further argued that proactive school policies that favored girl child education such as targeted subsidies for girls schooling and active public campaigns to encourage girls' schooling have a positive impact in female enrollments in schools.

Teacher stereotypes. Lloyd et al (2000), in their study on female participation in Kenya education, also reported that poor teacher attitudes towards the ability of females undermined the female students' efforts in education. These teacher attitudes, a clear manifestation of negative stereotyping, resulted in girls being excluded in classroom activities or being reduced to 
spectators, thus creating an environment that favored male students. Hostile school/classroom environments for female students thus create a recipe for gender inequity.

Another area that has been researched on gender inequity is on performance on examinations (educational attainment). A close examination of Kenya National Examination Council results for the past few years indicates that male students perform better than their female counterparts in science subjects (KNEC, 2009, 2008). In a study by Githua \& Mwangi (2003), it was found that male students were highly motivated to study mathematics than their female counterparts. This was partly attributing to teacher and classroom environment. Also Glick (2008) found out that girls' exam performance unlike boys' was impacted by unfavorable teacher evaluations on their abilities. However, the 2009 Kenya Certificate of Secondary Examination (KCSE) shows that in some provinces/regions such as Nairobi, Eastern, Rift Valley and Western Provinces gender parity has almost been realized (KNEC, 2009 report), while the remaining four regions, Nyanza included, have higher gender disparities in KCSE registration.

Children whose basic needs are unmet. A careful examination of the characteristics of students who this study deems to be marginalized illustrates what Abraham Maslow (1943) would state as human needs unfulfilled. The theory of human needs as posited by Abraham Maslow $(1943,1970)$ maintains that all human beings regardless of culture have five needs that can be arranged in a hierarchy. These needs are physiological needs, safety needs, love and belonging needs, self-esteem needs, and lastly self-actualization needs (see figure 3 below). Under Maslow's hierarchy of needs, human beings have to fulfill the lower level needs which he considered powerful or pre-potent before they strive to fulfill the next level of needs. For instance, the physiological needs (food, shelter, and clothing) are more pre-potent than the safety needs, while the safety needs are more powerful than the love and belonging needs. However, 
Maslow also recognized the role of context, immediacy of situations, and individuality as driving forces for different needs. In addition, Maslow acknowledged that at no time will a particular need be met $100 \%$, rather different needs are sometimes are pursued simultaneously.

\section{Figure 3:}

\section{Maslow's Hierarchy of Human Needs}

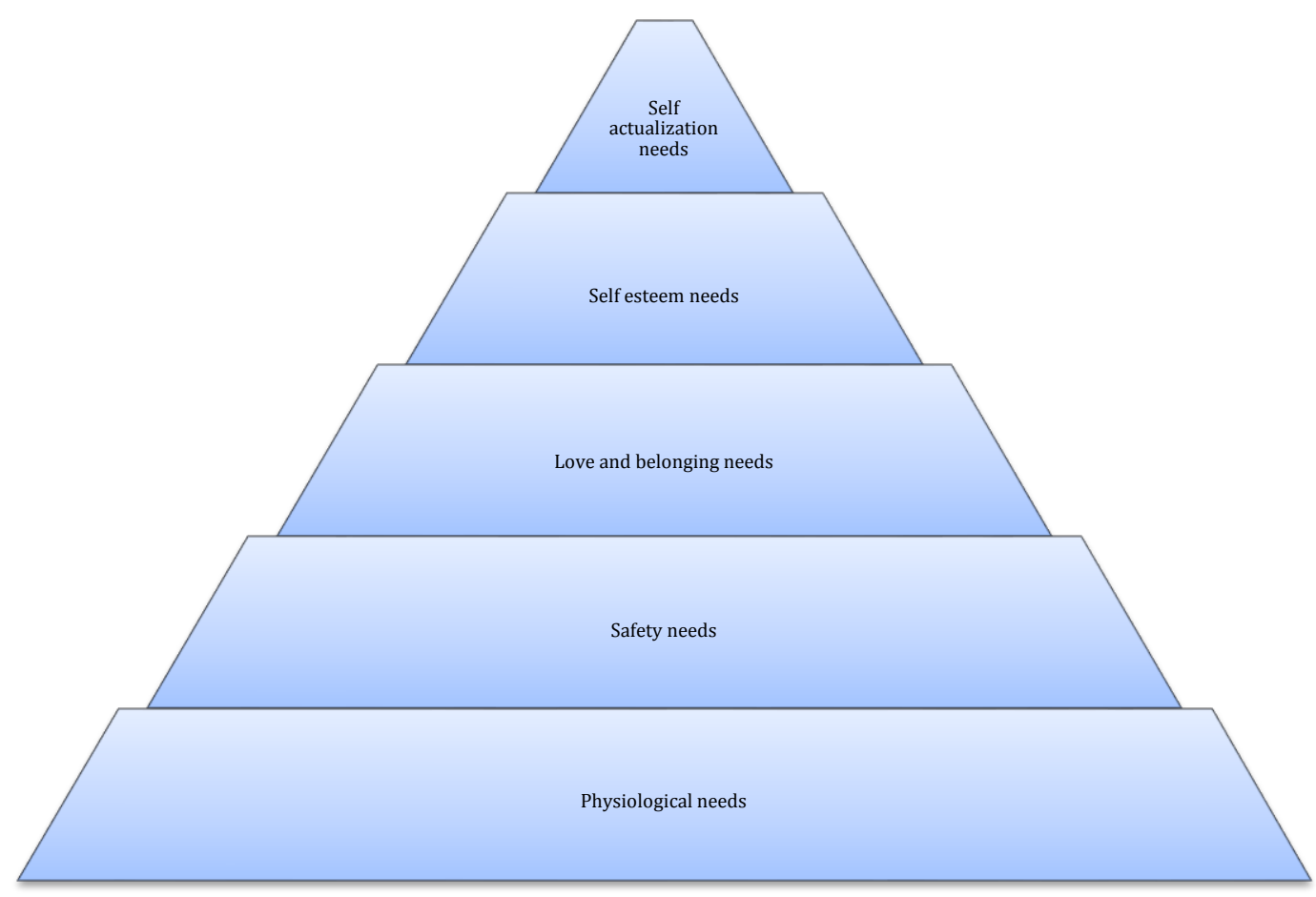

Maslow identified physiological needs as life-sustaining necessities of food, shelter, clothing, and sex (for reproduction). The safety needs include security, stability, dependency, protection, and freedom from fear, anxiety, and chaos. For school going children, these needs are expressed as the desire to live in a safe and an orderly world (both at home and school), undisrupted routines, consistency in parenting as well as schooling. In love and belonging needs, Maslow indicated that human beings have a natural tendency to love and to be loved as well as desire to 
belong and/or be accepted in a group. On self-esteem needs Maslow posited that people have the need a) to be positively evaluated and complimented by others, and b) to gain self-respect and self-esteem. In self-esteem, human beings are reinforced by attention, recognition, and prestige. Maslow suggests that when self-esteem needs are satisfied an individual becomes self-confident, but when unmet, they produce feelings of inferiority, self-doubt, and helplessness. Finally, Maslow indicated that when all the lower level needs have been met, people strive to selfactualize by achieving their unique potential and talents.

In educational settings, the theory of human needs as suggested by Maslow has a lot of potency in understanding student motivation as well as learning. It therefore becomes an imperative for classroom teachers, school counselors, and school administrators to conscientiously observe and interrogate their students for conditions that suggest unfulfilled needs. Harper, Harper, and Stills (2003) state:

That teachers should observe conditions that suggest unfulfilled needs in students. These conditions include: a) signs for insufficient food and poor nutrition (physiological needs), b) indication of abusive homes or bullying in schools (safety), c) evidence of rejected or isolated students (need for belongingness and love), d) tendency for teachers to disrespect and physiologically reject students (self-esteem), and e) a pattern of not encouraging or even discouraging students from developing a natural talent of ability (p. 17).

Instructive in Harper et al (2003) argument is the idea that teachers should not only monitor student behavior for the unfulfilled needs but also observe their own instructional as well as administrative practices within and without classrooms which may inhibit students from fulfilling their needs. While no need can be understood in isolation, schools should be responsible for physical needs, social needs, role of social development in learning, achieving 
status in changing social groups, growing gradually from dependence to independence, security and satisfaction, receiving and giving affection, developing appropriate communication skills, learning to face reality, and intellectual needs (Shepherd and Ragan, 1982).

In Kenya, challenging economic and social factors predispose millions of children in failing to fulfill their basic needs. These factors include poverty, HIV and AIDS, severe malnutrition occasioned by famine and hunger (Kristjan, Mango, Krishna, Radeny, \& Johnson, 2010; Republic of Kenya, 2007). In particular, the effect of poverty is more widespread since $56 \%$ of the Kenyans live under the poverty line (Achoka, Odeboro, Julius, \& Nduku, 2007). Based on Maslow, it can be argued that conditions of hunger, malnutrition, disease (HIV and AIDS) and are significant barriers to access to universal basic education for marginalized students.

In sum it is important to know the perspectives of teachers on marginal group of students whose issues have not been adequately addressed in Kenyan education policy documents. The section that follows will define the concept of marginalized students and outline the characteristics of marginalized students within the context of Kenyan education.

\section{Marginalized Students}

The ratification of Universal Declaration of Human Rights (UDHR), Convention of the Rights of the Child (CRC), and Education For All (EFA), underscores the need for education to be accessible, equitable, and of quality to all children. For instance Article Four of the expanded vision of EFA 2000 (UNESCO, 2000) requires:

An active commitment must be made to removing educational disparities. Underserved groups: the poor; street and working children; rural and remote populations; nomads and migrant workers; indigenous peoples; ethnic, racial, and linguistic minorities; refugees; 
those displaced by war; and people under occupation, should not suffer any

discrimination in access to learning opportunities (paragraph 4 of Article 4 of EFA).

It is evident from the above statement that the categories of persons enumerated are often categorized as the marginalized ones within most communities in the world. Article 4 of EFA goes further to encourage non-discriminatory practices in schools and classrooms that ensure equitable access to learning opportunities for marginalized students.

UNESCO (2010) defines marginalization in education as "a form of acute and persistent disadvantage rooted in the underlying social inequalities" (p. 135). In sub-Saharan Africa and Kenya in particular, the social inequalities affecting educational access and equity include family socio-economic status, ethnicity, remoteness, and individual characteristics. This is a narrow focus since it omits the role of teacher practices and school conditions that marginalize some students. Whereas the central focus of this study is teacher and school practices, it also explores social inequalities and how individual teachers are addressing these inequalities in their schools and classrooms.

For this study marginalized students refers to students who come from marginal groups within society (which include: students from families that are extremely poor, children who are homeless, children who are orphans, children engaged in child labor, and children who have disabilities), and who exhibit or are at risk of exhibiting one of the following characteristics: accumulate fewer years in education, high risk of dropping out of school, poor attendance, low achievement, and/or repetition of grades.

Learners who are marginalized exhibit some characteristics that set them aside from regular students. The first characteristic is that they accumulate fewer years of education. UNESCO (2010) indicates that "marginalized individuals do not just accumulate fewer years of 
education when they are in school; they often receive a poor quality education leading in turn to low levels of learning achievement” (p. 137). In Kenya, children engaged in child labor, orphans, and street (homeless) children have a high risk of accumulating fewer years spent in education due to taking time off school to attend to their survival needs (Birger \& Craissati, 2009; GithithoMiriithi, 2010).

The second characteristic is that marginal students have a high risk of dropping out of schools. In Kenya, the number of children who enroll but fail to complete primary schools ranges between 43-46 percent (Acker, Migoli, \& Nzomo, 2001). This high percentage underscores the notion that an initial enrolment in primary schools is not the most difficult challenge, but that of retention and completion of schooling. Ackers, Migoli, and Nzomo (2001), report that significant dropouts occur between first and second grades, as well as sixth and seventh grades. This study assumes that students who are at risk of dropping out are those identified with disabilities, orphans, repeaters, and children engaged in child labor due to poverty. As a result of dropping out of schools, the marginal students eventually accumulate fewer years of education.

Marginalized students also have high risks of repeating grades, which is a common shortcoming of education in Kenya. A study by Bauchmann (1999), which conducted a survey of 759 school age children, reported that 64 percent of the respondents had repeated a grade at least once. Though forced repetition of grades is outlawed in Kenya, parents and teachers force children to repeat grades with the hope that their performance and skills will improve (Ackers, Migoli, \& Nzomo, 2001). This is a function of an exam driven education system and due to limited access to secondary school places. It must be noted that every year, about $10 \%$ of primary school graduates do not get access to secondary schools due to lack of space. For instance out of 811, 930 students who had completed their Kenya Certificate of Primary 
Examination (KCPE) in 2012, about 100, 000 or $12 \%$ of them did not get admission to Kenyan public secondary schools (The East African Standard, 2/4/2013).

Marginalized students are also at risk of exhibiting low achievement in the Kenyan education system due to the administration of national examinations at the $8^{\text {th }}$ grade (Standard 8 ) and $12^{\text {th }}$ grade (Form IV). The pressure that accompanies these examinations bears a heavy toll both on teachers and students. The examinations are actually a hindrance to access especially to secondary and university education as a large number of students are involuntarily excluded from the education system.

Performance in the national examinations is not even across Kenya. Based on the "now defunct" ranking system, some regions within Kenya have consistently ranked in the bottom 10. Though some of these regions are from Arid and Semi Arid Areas (ASAL), there are regions that are highly productive but are within this category. For instance, a study by Bagaka (2010) showed that two districts that make up the now Kisii County were among the poorest performing districts in KCPE for seven years in a period spanning from the year 2001 to 2007. While this information is important in pinpointing disturbing educational trends within these regions, it does not account for the underlying factors that contribute to this low performance. However, in a different study by Hungi and Thuku (2010), individual factors (such as SES, age, and gender) as well as school factors (such pupil-teacher ratio and teacher competency) were reported to influence student performance on mathematics in national examinations.

In summary, the literature provides evidence that children engaged in child labor, children affected by or infected with HIV/AIDS as well as orphans, children with disabilities, children from pastoralist communities, the girl child, and children whose basic needs are unmet, form a cluster of children who are at risk for marginalization in classrooms. Moreover, these 
groups of children exhibit symptoms such as low achievement, dropping out, repeating grades, and accumulating fewer years of education compared to their peers.

The section that follows defines access as well as equity as used in this study. Defining these terms is important since it will delineate my understanding and discussion of these two terms, therefore laying a foundation on their subsequent uses within this study. In addition, the section discusses inclusion of marginalized students as one of the practices that has been identified to promote access to education for marginalized students. The section concludes with the discussion of differentiated instruction, a key pedagogical practice that ensures equitable and quality education for vulnerable groups in classrooms.

\section{Access}

In a definition adopted from the Consortium for Research on Educational Access, Transitions, and Equity (CREATE), Lewin (2009) states that access to education "should include admission and progression on schedule for age in grade, regular attendance, achievement related to national curricular exams, appropriate access to post primary opportunities, and more opportunities to learn" (p.154). In this definition of access, there seems to be an emphasis on the actual progression of a student after initial enrollment.

In this study access to education refers to the opportunity for all school age children (ages 6-17) to enroll, progress through grades and meaningfully gain from the learning process. From this working definition, there are three distinct dimensions of access: the first dimension is opportunity for initial enrollment which is a function of availability of actual spaces in schools, cost of schooling (which includes but not limited to instructional materials, fees and levies, as well as school uniforms), family socio economic status, and individual characteristics. Bedi, Kimalu, Manda, and Nafula (2002) in their study on "Decline in primary school enrollment in 
Kenya," reported that cost, school inputs and curriculum, school availability, family expected benefits of schooling, and the spread of HIV/AIDS as potential predictors of level of primary school enrollment in Kenya. This study by Bedi et al., used the district as a unit of analysis. In this dimension of opportunity for initial enrollment, the government policy on education plays a big role in influencing access. The second dimension of access is progression through grades after initial enrolment. In this dimension access becomes meaningful if children who are enrolled in schools can advance from one grade to another. The third dimension is gainful learning for the individual students. Both the second and third dimensions of access are influenced greatly by school culture as well as social structure, which in turn influence the social interactions and learning processes that take within schools. Educational access for marginalized students cannot be discussed in isolation from educational equity and inclusion movement as well as differentiated instruction as school practices that can contribute to increased access.

\section{Equity}

Different people have defined equity in different ways. Nieto (1996) defines equity in education as opportunity or equal outcomes, including the contexts in which students participate in educational experiences and the extent to which those experiences enable their academic growth. This definition seems to be aligned with the definition offered by the Illinois State Board of Education (http://www.isbe.net/accountability/html/equity.htm), which has described equity as equal access, equal treatment, and equal educational outcomes for both genders and all racial/ethnic subgroups identified within the school population. These two definitions lay emphasis on equality in all spheres (outcomes, input, opportunity, and experiences). However, there lies a fallacy of likening equity to equal opportunity. Grant and Ladson-Billings (1997), argue that "equal opportunity is necessary, but not a sufficient step for educational equity to 
occur" (p. 101). For Grant and Ladson-Billings, equal opportunity is the first step towards educational equity. Equity thus does not denote equality or "sameness of result or even identical experiences" (Bennett, 2011, p.5); rather, any description of equity must be viewed through the lens of equality, inequality, fairness, and justice.

Equity in education means providing equal opportunities for all students to attain their fullest potential (Bennett, 2011). This however should be approached judiciously, as different students are treated differently due to their diverse needs. This form of equity does not demand equal results, rather the emphasis is on the educational inputs and educational processes. However, what is equitable largely depends on both the dispensers and receivers of equity. To understand equity, there is a need to analyze broader social forces that cultivate inequality throughout society, that is, unemployment, poor or lack of housing, criminal justice, et cetera. Thus when examining equity, it becomes imperative to situate, describe and examine equity within the context in which it occurs (Jordan, 2010). Therefore, educational inequity is part and parcel of the overarching social ills.

In this paper educational equity involves allocation of resources, instructional time, pedagogy, and treatment of all students in a fair, just and humane manner, thereby increasing equal participation for all students in a democracy. Therefore, achieving equity requires dismantling of structures and policies that foster inequality and alienation of a section of the student populace regardless of their culture, race/ethnicity, socioeconomic status, or color.

In Kenya, over the past decade, there have been significant changes both in policy and in schools towards actualizing educational equity to all children. One such change is the shift towards inclusion of children with disabilities in regular classrooms (Ministry of Education, 2009). The Ministry of Education specifically identifies inclusion as one way in which the FPE 
has "increased access" to children with disabilities. The section that follows traces the global inclusion movement in general and Kenya in particular.

\section{Inclusion of Learners with Disabilities in Regular Classrooms}

The inclusion movement for children with disabilities in regular classrooms can be traced to landmark court decisions in the US Supreme Court such as Brown v. Board of Education of 1954, Pennsylvania Association of Retarded Children (PARC) v. Commonwealth of Pennsylvania of 1971, Mills v. Board of Education of 1972; the Civil Rights movements of 1960s and 1970s, as well as the passage of important legislative acts in the US Congress in the second half of the $20^{\text {th }}$ Century. Specifically the 1954 decision by the United States Supreme Court in Brown v. Board of Education Topeka 347 U.S. 483 (1954) which ruled against legal segregation in the school system, citing the Equal Protection Clause in the Fourteenth Amendment of the US Constitution. The Brown v. Board ruling overturned the "separate but equal" doctrine established 1896 in Plessy v. Ferguson ruling which constitutionally legitimized segregation. The Brown v. Board decision, served as a catalyst for the inclusion movement by establishing a legal and constitutional basis for equality of opportunity for all individuals in education.

Further, the passage of the Civil Rights Act of 1964 P.L 88-352 in the United States augmented the quest for equal opportunity. The specific law that heralded provision of education for the student with disabilities was the 1975 Education for All Handicapped Children Act P.L. 94-142. Later reauthorized as the Individuals with Disabilities Education Act in 1990, 1994 and 2004, the law set regulations that ensured that children with disabilities were educated in their Least Restrictive Environment (LRE), received a FAPE, learning was personalized according to their IEP, and were accorded the due process. 
On the global stage, equalization of opportunities is the focus of the United Nations Standard Rules document under "Target Areas for Equal Participation”. Rule Six of this document requires all nations; Kenya included, observe the principle of equality in primary, secondary and tertiary educational settings for children, youth and adults with disabilities in integrated settings (United Nations, 1993). In addition to the United Nations Standard Rule Six, the world Conference on Special Needs Education that was held Samalanca, Spain urged the development of inclusive education as an integral part of all education programs (UNESCO, 1994). In rationalizing inclusion, the Samalanca Conference on Special Needs Education stated: Regular schools with this inclusive orientation are the most effective means of combating discriminatory attitude, creating welcoming communities, building an inclusive society and achieving education for all; moreover, they provide an effective education to the majority of children and improve the efficiency and ultimately the cost effectiveness of the entire education system (UNESCO, 1994, iv)

From the above excerpt, it is evident that the Samalanca Conference argued for inclusive schools as a way of providing enabling environments that would actualize equal opportunity for the children with disabilities. The Jomtien1990 World Conference on Education for All heralded the Samalanca conference on special needs education and it had laid target dates for all countries to achieve universal basic education

In Kenya, the inclusion movement is an issue that has been featured in recent educational policy speeches and policy documents. In 2009, in a speech delivered during the launch of the Special Needs Education policy (Ministry of Education Science and Technology, 2009), education for children with disabilities was recognized as being crucial in accelerating the 
attainment of the goals Education for All and the Millennium Development Goals. In reference to inclusion the minister ${ }^{17}$ said:

Successful implementation of this policy framework is expected to improve the quality and access to education provided to children with special needs. It also addresses issues of equity and improvement of learning environments in all schools. This will ensure that inclusive education becomes a reality and consequently improves participation and involvement of people with special needs in national development in general (Ministry of Education, 2009, p. 8)

The above statement by the minister and the Special Needs Education policy framework is the strongest push yet towards inclusion. Implied in the minister's statement is that equity, access, and provision of a quality education to students with disabilities could be achieved through inclusive settings. The major purpose of Special Needs Education policy framework is to provide guidelines and regulations that will govern provision of special education in Kenya. In addition it will ensure that children with disabilities fully participate and are treated equally in learning activities at all levels.

The shift to inclusion and integration of children with disabilities in regular classrooms and the presence of marginalized students in Kenyan primary schools, demands a shift in the pedagogical practices by Kenyan teachers. In Kenyan classrooms, the challenge then becomes addressing the diverse learning needs of students. The best approach to achieve this is through differentiated instruction.

\footnotetext{
${ }^{17}$ The minister of education was Professor Sam Ongeri. He delivered this speech in July of 2009 during the launch of the Special Needs Education Policy document.
} 


\section{Differentiated Instruction}

Differentiated instruction is a philosophy and approach to teaching where a teacher proactively plans for varied assessment and instructional approaches to meet the diverse learning needs of students. In differentiated instruction (DI), students are offered multiple options for taking in information, making sense of ideas and expressing what they learn (Tomlinson, 2001). As a student-centered approach, DI takes cognizant of student learning needs, interests, and current ability levels. Therefore to effectively plan for DI, teachers must understand the needs of both advanced and struggling learners.

Differentiated instruction is rooted in cognitive psychology and is based largely on research on student achievement (McTighe \& Brown, 2005; Rock, Gregg, Ellis, \& Gable, 2008). Rock et al (2008) proposes four guiding principles for DI in classrooms:

A focus on essential ideas and skills in each content area, responsiveness to individual student differences, integration of assessment and instruction, (and lastly) an ongoing adjustment of content, process, and products to meet students' level of prior knowledge, critical thinking, and expression styles (p. 33)

Tomlinson (2000) reinforces these four principles but goes further to emphasize the need for teacher awareness of students differences based on their life circumstances, past experiences, and readiness to learn. The student differences have a significant influence on the content and pace of instruction in classrooms. To achieve a rich learning environment that takes cognizance of individual differences, teachers should strive to match content to student real-life experiences, and create feeling of mutual respect, acceptance and valuing of all students. In addition, the teaching strategies used in classrooms should be diverse so as to cater for the diverse learning styles of students. In essence, differentiated instruction is averse to the notion of 'one-size-fit- 
all", instead, it encourages incorporation of multiple strategies during instruction. For instance, during a lesson, a teacher could employ direct instruction when explaining important concepts, cooperative learning and/or group work to utilize the various strengths of students, and one to one tutoring to meet the needs of a struggling student.

Besides differentiating content and the process of instruction, Differentiated Instruction requires differentiation of the product where "learning tasks are adjusted to each student's appropriate learning zone" (Smit \& Humpert, 2012, p. 1153). In differentiating the product, students are allowed to demonstrate masterly of a concept and/or learning through various products besides traditional standardized testing. In this case, formative assessments assist in identifying the next learning sequence and therefore critical in extending as well as adapting instruction.

In practice, teachers who engage in differentiating instruction must embrace the following beliefs: a) that each learner has unique needs, and that the learner shares the responsibility of learning with the teacher; b) that content and/or educational goals must be aligned with the prior knowledge as well as learning profiles of individual students; c) that learning tasks must be aligned with student's interest and allow students to work at their own pace. In addition, they should allow for expression of learning in various forms; and d) the role of the teacher is to facilitate a student's learning processes (Smit \& Humpert, 2012). In the present day Kenya, these beliefs are necessary as classrooms are becoming more heterogeneous in student make up due the shift towards inclusion.

In Kenya, the Kenya Education Sector Support Program 2005-2010 (KESSP), a policy document that highlighted concrete steps that had to be taken by the education sector so as to achieve Education for All by 2015, there is emphasis on inclusive education. While inclusive 
education is highly visible in KESSP document, there is little or no research that has examined the role of differentiated instruction in the era of Free Primary Education in Kenya. This gap in research provides some of the impetus for the study.

\section{Summary of Literature Review}

Based on the literature review on access to education in Kenya, it is evident that there were attempts in the 1960s, 1970s and 1980s to initiate free universal basic education in Kenya with limited success. Furthermore, there is evidence of external influence on the Kenyan education policy, specifically the adoption of Free Primary Education as a vehicle of ensuring universal access to basic education, which is a key goal in the United Nations Millennium Development Goals of 2000 and the Education For All goals of 2000. Previous research conducted on educational access has focused on identifying characteristics of children left behind from fully participating and benefiting from free primary education in Kenya such as children from nomadic communities, street children, orphans, children with disabilities, children affected and/or infected by HIV/AIDS pandemic, the girl child, and children whose basic needs are unmet. This then demands an alternative dimension of research on the education of marginalized students that might better be directed at understanding the institutional character of schools, and in particular teachers practices and how these practices affect provision of education that is accessible, equitable, and of quality to marginalized students. 


\section{Chapter 3: Methodology}

This chapter is organized as follows, the theoretical framework and how it influences my research, the rationale for using the sequential mixed method, the context of the study, description of participants, quantitative and qualitative data collection methods, trustworthiness, data credibility, and data analysis.

\section{Theoretical Framework}

This study is premised on the belief of critical pedagogy, a school of thought within the critical theory paradigm that is concerned with the study of how school and society in general is influenced by dominant social, political, economic, and ideological forces. Critical pedagogy derives its roots from the neo-Marxists of the Frankfurt School, who included Theodor Adorno, Jurgen Habermas, Max Horkheimer, Herbart Marcuse, and Walter Benjamin. Geuss (1988) contends that critical theory consists of three theses:

(First) Critical theories have special standing as guides for human action in that: a) they are aimed at producing enlightenment in the agents which hold them, i.e. enabling those agents to determine what their true interests are; b) they are inherently emancipatory, i.e. they free agents from a kind of coercion which is at least partly self-imposed, from self frustration of conscious human action. (Second) Critical theories have cognitive content, i.e., they are forms of knowledge. (Third) Critical theories differ epistemologically in essential ways from theories in the natural sciences. Theories in natural science are objectifying, critical theories are reflective (pp. 1-2).

Inherent goals amongst agents of critical theory are critical emancipation, critical enlightenment, and critical consciousness. Geuss (1988) continues to argue that critical theory through reflection 
should make subjects within society aware of their own origin and the context that has created their present conditions. This happens through heightened consciousness.

Just like critical theory, critical pedagogy embodies the concept of emancipation and/or liberation (Freire, 2007), critical enlightenment (Freire, 2007; Kincheloe, 2008), the concept of immanence (McLaren \& Kincheloe, 2007), hegemony (Gramsci, 1971), the concepts of politics and power (Apple, 1986) and social justice (Giroux, 1986). Kincheloe (2007) delineates six identifying characteristics inherent in critical pedagogical practices. These include the vision of social and educational justice as well as equality, the belief that education is inherently political, commitment to the alleviation of human suffering, a pedagogy that prevents students from being hurt, the use of generative themes in educational settings, and commitment to social change.

This vision of social and educational justice demands that critical educators reconceptualize power inscription within the society and the ways in which schooling organization, as well practice, affects the lives of students from marginalized groups (Kincheloe, 2008). The imperative for critical pedagogists is to understand how education is used to perpetuate the dominant knowledge, values, and practices as prescribed by the ruling class or the holders of power. One way in which teachers and other educators who are critical can deconstruct the dominant knowledge serving the aspirations of those with power is by helping to create safe spaces in which the marginalized students can learn and be empowered and by adopting texts, language, and pedagogies that are inclusive.

The view of education as being political is the second characteristic of critical pedagogy. In this view, critical educators contend that education is a political act (Apple, 1986) in that it occurs in social, political, and economic settings, which influence the goals and objectives of 
education, funding, the nature of textbooks, access, and decision-making. Therefore, the purpose of the school is shaped and influenced by the political context (Kincheloe, 2008).

The third characteristic of critical pedagogy is that it is committed to the alleviation of human suffering. This is perfectly aligned with Freire's call for critical emancipation and/or liberation. In this aspect, critical pedagogy is committed to developing a school culture that supports and empowers marginalized students. In addition, critical pedagogy embraces instructional practices that are both equitable and democratic.

The fourth characteristic is that it propagates a pedagogy that prevents students from being hurt. The most common area that is hurtful to marginalized students is measurements and assessments (Kincheloe, 2008). Critical pedagogy strongly contests technical or instrumental rationality (Darder, Baltodano, \& Torres, 2009), which creates dichotomies and characterizes students as capable or incapable of academic work. Instead, critical pedagogy advocates for inclusiveness and differentiation of products. In particular, allowing students to demonstrate mastery of a concept or content through multiple products and representations.

Critical pedagogy also embraces the aspect of generative themes (Freire, 2007). The notion of generative themes was advanced by Freire who, while growing up in Recife, Brazil, observed and experienced firsthand the effects of poverty. He advocated the use of generative themes so as to tap into issues that were important and relevant to students in his class. Core to the use of generative themes is problem posing, whereby teachers and learners actively engage in a critical analysis of the forces that shape the world around them (Freire, 2007). Problem posing is diametrically opposite to the banking concept of education which dehumanizes and encourages docility. In problem posing, students are co-creators of knowledge and the student-teacher relationship in the classroom is dialectic. Critical teachers are not mere technicians (Freire, 2007) 
and students are not mere receptacles of knowledge. Freire in his seminal book Pedagogy of the Oppressed states:

In problem-posing education, people develop their power to perceive critically the way they exist in the world with which and in which they find themselves; they come to see the world not as static reality, but as reality in process, in transformation. (p. 83)

Education for increased human possibilities is a theme in Freirian ideas which emphasize the need to recognize that the education and learning acts influence and in turn are influenced by the wider social, organizational, and political contexts in which they occur. This demands teachers to be always critically aware of their actions in-side and outside classrooms

Critical pedagogy is interested in advocating for social change and cultivating the intellect, which reinforce each other, as the human intellect cannot be cultivated without changing the unjust social context (Kincheloe, 2008). Closely aligned with this is the idea that critical educators are opposed to social, economic and educational determinism. The principle of determinism holds that individuals have little ability to change the flow of events and therefore they are condemned to their present states. In this principle, a poor child will continue living in poverty and misery throughout his/her life. This is a defeatist principle as it does not factor in the human potential and ability to overcome.

This list delineating the core characteristics of critical pedagogy is not exhaustive due to the evolving nature of the critical theory paradigm (Kincheloe, 2008; Ozmon \& Craver 2007). However, it is evident that the central concern for the critical educator is the marginalization of particular students in school and those policies that ensure they remain marginalized.

Rationale for Critical pedagogy. In conclusion, it can be argued that this study is aligned with an issue that is of central concern to critical theorists, that is, access to education for 
marginalized students. The lenses of a critical pedagogy paradigm are suitable for this study since they provide an appropriate theoretical basis for examining the issues of the marginalized and the underprivileged in the any society.

\section{Sequential Mixed Method}

A mixed method is a design that utilizes both qualitative and quantitative research techniques in data collection and analysis (Tashakkori \& Teddlie, 2003). The mixing of quantitative and qualitative data collection and analysis can occur either concurrently (parallel) or in sequential phases. A principal tenet of mixed methods design is that researchers should mindfully create designs that effectively answer their research question as opposed to choosing only from a restricted menu of designs prescribed by quantitative or qualitative only methods (Johnson \& Onwuegbuzie, 2004). This means that the mixed methodologist avoids taking a purist quantitative (postpostivist) or qualitative (interpretivist) position.

Various purposes or rationales have been advanced for using the mixed methods approach. The first purpose of mixed methods is triangulation (Greene, Caracelli, \& Graham, 1989; Creswell, 2003). In this case the intent of utilizing mixed methods is to validate or corroborate responses to a single phenomenon through the use of multiple methods.

Complimentarity (Greene, Caracelli, \& Graham, 1989; Rossman \& Wilson, 1985) is the second purpose that has been advanced for the use of mixed methods. In complimentarity, qualitative data is utilized to elaborate or clarify the findings from quantitative data and vice versa, with the view of gaining a deeper understanding of the phenomenon under study. The third purpose is

development (Greene, Caracelli, \& Graham, 1989; Creswell, 2003) whereby the results from one method form the basis on which the instruments for the other method are developed. The fourth purpose is initiation (Rossman \& Wilson, 1985) in which the results from one method are used to 
recast new perspectives. Finally, the fifth purpose is expansion, in which the breadth and range of research is expanded through use of different methods on different inquiry components.

This study utilized a sequential mixed methods design shown in the figure 4 below

\section{Figure 4:}

Phases of the Sequential Mixed Methods Research

\section{QUANTITATIVE}

- Data is collected through Likert_Scale surveys

- Information from the surveys is used to design the protocol for qualitative interviews

\section{Qualitative}

- Data is collected through:

- Focus Groups

- Interviews

The model shown in figure 4 denotes that this study occurred in two distinct phases that were sequential. In the first phase of this research, quantitative (QUAN) data was collected in the form of a survey. This data sought to determine whether teachers' philosophical orientations were correlated to their provision of differentiated instruction for marginalized students. The findings from the quantitative data were used to guide the design of interview questions for the second phase of the study. The data from the first phase was also used to determine the participants for the second phase - Qualitative (Qual), which involved interviewing and focus groups. The role of the second phase was to elaborate, corroborate, and seek deep understanding of the phenomenon under study. This aligned with the rationales for conducting mixed methods of triangulation, complimentarity, and development (Greene et al., 1989). 


\section{Research Context}

This study was conducted in Kisii County (see Appendix A), an administrative unit located in the western part of Kenya near Lake Victoria. The county, recently formed under the new constitution, was formerly comprised of Gucha, Kenyenya, Kisii Central, Marani, Masaba South, Nyamache, Sameta, and South Kisii Districts (as of 2011), has a total population of 1,263,599 people of whom, 284,274 (23\%) are children aged 5-14 years (Republic of Kenya, 2010). The population density is 861 persons per square kilometer with small scale farming for both subsistence and cash crops (such as coffee, pyrethrum, and tea) as the main economic activity. The county has seven political units: Kitutu Chache, Nyaribari Chache, Bonchari, Bomachoge, Nyaribari Masaba, Bobasi, and South Mugirango. To meet the educational needs of primary school age children (6-13 years), the county has over 700 primary schools. Kisii County was chosen as the focus of this study based on the following four reasons:

1. Poor performances in Kenya Certificate of Primary Examination $(\mathrm{KCPE})^{18}$ (Bagaka, 2010), which suggests existence of underlying problems of not meeting the learning needs of students.

2. High population density in the region, with schools in close proximities. This offered convenience for this study

3. The region is highly agricultural, which is typical of the majority of Kenyan rural communities. The results may be extrapolated to represent the face of rural Kenya.

4. By focusing on a county, the study is poised to provide an in-depth view of issues that are particular to the county.

\footnotetext{
${ }^{18} \mathrm{KCPE}$ is a terminal examination given at the end of the $8^{\text {th }}$ Grade in primary school and is used to determine admission of a student into high school.
} 


\section{Participants}

The participants for the first (quantitative) phase of this study were classroom teachers drawn from a stratified purposeful sample (Patton, 2002) of 28 public primary schools within Kisii County ${ }^{19}$. In Kisii County, there are seven political units called constituencies (see Appendix C) with over 700 primary schools. Each public primary school (first grade through eight grade) had at least 8 teachers. Therefore, 4 public primary schools were purposefully selected (Patton, 2002) from each of the political units within Kisii County. The total number of schools used in this phase of the study was 28 and a total of 304 surveys were distributed; 217 surveys garnered responses (female $=107$; male $=88$; the number of those who did not identify their gender=22). This represented a high $71.3 \%$ return rate. Each school received a varying number of surveys depending on the number of teachers who were present during the administration of the surveys as well as their willingness to participate. The least number of surveys given to a school was 4 while the school with the highest number of surveys had 20 .

Participants who self reported their teaching qualifications in the survey instrument (see Appendix D) showed an eclectic group (see table 2 below). Majority of the teachers who participated in this survey $(\mathrm{n}=107)$ had attained their teaching certification from two-year teacher education colleges in Kenya. Forty-six participants had attained certification from three-year colleges (diploma colleges), while only 29 participants indicated they attained certification from four-year colleges. Only one participant had post-graduate qualifications at the master's level. There were 11 participants who had no teaching certification, 10 of whom had either attended a three-year or four-year college. A total of 11 teachers or $5.5 \%(n=217)$ had no teaching certification, of these, four of the participants had only a high school qualification, one had a

\footnotetext{
${ }^{19}$ Public primary schools are maintained and/or assisted out of public funds, which include but not limited to government funds for Free Primary Education (FPE).
} 
diploma or three years of college, and six had degrees or four years of education in a college.

Table 2 below characterizes the participants by their professional qualifications

Table 2:

\section{Professional Qualifications}

\begin{tabular}{lll}
\hline $\begin{array}{l}\text { Highest Level of Teaching } \\
\text { Qualification }\end{array}$ & Number of participants & Percentage \\
\hline Untrained with degree & 1 & 0.5 \\
Untrained with diploma & 6 & 3 \\
$\begin{array}{l}\text { Untrained without degree or } \\
\text { diploma }\end{array}$ & 4 & 2 \\
$\begin{array}{l}\text { Certificate (Two years in a teacher } \\
\text { training college) }\end{array}$ & 106 & 49 \\
$\begin{array}{l}\text { Diploma (Three years in a teacher } \\
\text { training college) }\end{array}$ & 46 & 21 \\
$\begin{array}{l}\text { Degree (Four years in college with } \\
\text { teaching certification) }\end{array}$ & 29 & 13 \\
Masters & 1 & 0.5 \\
No answer & 24 & 11 \\
Total & 217 & 100 \\
\hline
\end{tabular}

Note: In Kenya, the minimum requirements for primary school teacher certification is two years of post secondary education in an accredited teacher college.

In terms of age, participants for the Teacher Survey were an eclectic group drawn from 28 primary schools. From table 3 below, it can be deduced that the modal age group of participants was $35-39$, with $26.3 \%(n=217)$ of participants reporting in this category. About $49.7 \%$ of participants reported that they were between $20-39$ years, which indicated that Kisii County had a young teaching workforce. Table 3 below displays number of teachers in various age groups. 
Table 3:

Participants by Age Group

\begin{tabular}{lll} 
Age bracket & Number of participants & Percentage \\
\hline $\mathbf{2 0 - 2 4}$ & 3 & 1.4 \\
$\mathbf{2 5 - 2 9}$ & 8 & 4 \\
$\mathbf{3 0 - 3 4}$ & 40 & 18 \\
$\mathbf{3 5 - 3 9}$ & 57 & 26.3 \\
$\mathbf{4 0 - 4 4}$ & 42 & 19 \\
$\mathbf{4 5 - 4 9}$ & 18 & 8 \\
$\mathbf{5 0 - 5 4}$ & 31 & 14.3 \\
$\mathbf{5 5 +}$ & 10 & 5 \\
No answer & 8 & 4 \\
Total number of surveys & 217 & 100 \\
collected & & \\
\hline
\end{tabular}

On teaching experience, there were a total of 209 teachers who responded to this item. The average teaching experience was 16.2 years with the highest number of years of teaching experience being 38 years, while the lowest was 2 years (See table 4 below). The modal group for teaching experience was $15-19$ years and this represented $25 \%(n=209)$ of the total number of teachers. In addition, $72 \%$ of teachers reported to have a teaching experience of more than ten years. This is important because, it shows they were in the profession in the pre- and post FPE. Table 4 below displays clusters of years for teaching experience of participants. 
Table 4:

Cluster of Years of Teaching Experience

\begin{tabular}{lrr}
\hline $\begin{array}{l}\text { Cluster of Years of } \\
\text { Teaching Experience }\end{array}$ & Frequency & \multicolumn{2}{c}{$\begin{array}{l}\text { Percentage } \\
(\%)\end{array}$} \\
\hline 0-4 Years & 17 & 8 \\
5-9 Years & 41 & 20 \\
10-14 Years & 34 & 16 \\
15-19 Years & 52 & 25 \\
20-24 Years & 27 & 13 \\
25-29 Years & 28 & 14 \\
30-34 Years & 7 & 3 \\
35-39 Years & 3 & 1 \\
Total & 209 & 100 \\
\hline
\end{tabular}

Note: The retirement age of teachers is at 60 years.

Participants for the second (qualitative) phase of the study were purposefully selected (Patton, 2002) based on the feedback from the survey instrument. The survey instrument (see Appendix D) administered during the first phase of the study (quantitative phase) had a section that required participants to indicate their willingness to participate in the focus group interviews. Based on the responses to items $10,11,21,60$, and 61 (see table 5 below) of the survey protocol (see Appendix D), an initial list of possible participants was generated. There were 127 participants who indicated their willingness to participate in focus groups, based on their response to items 60 and 61 in the survey. This list was further narrowed down to 88 based on responses to items 10,11, and 21 in the survey instrument (see also Table 5 below). The possible participants were further contacted by phone and subjected to a focus group screening protocol (see Appendix E) to generate the final list of participants. The focus group screening protocol resulted in a total of 12 participants per focus group. Of these, 30 were female and 18 were male. However, only 30 participants showed up for the four focus groups held on four different days. 


\section{Table 5:}

\section{Survey Items Used in the Initial Screening of Focus Group Participants}

10. Do you have marginalized students in your class?

\section{Are you aware of the objectives of Free Primary Education Policy?}

21. Did you teach in primary schools before the implementation of Free Primary Education?

60. Would you be willing to participate in a focus group interview for this study?

61. If yes, please provide your phone number?

Note: The above questions which were part of the survey protocol (see Appendix D), were used to screen the possible participants for the focus groups.

The three participants for the administrator interviews were purposefully selected from three schools in Kisii Municipality. These schools were chosen based on unique issues that emerged from focus group two and four discussions regarding access to education.

\section{Data Collection}

Permissions for the study. Permission to conduct this study was acquired through the Institutional Review Board (IRB) of West Virginia University to ensure that the ethical standards for research as well as the rights of participants were respected (see Appendix F). In Kenya, the research permit for this study was acquired from the National Council for Science and Technology (NCST), a department within the Ministry of Higher Education Science and Technology in Kenya in charge of research permits (see Appendix G). Additional permissions were obtained from the Local Educational Authorities at the district level for the researcher to conduct research within public schools (see Appendix H).

Quantitative data. During the first phase of the study, quantitative data was gathered using an instrument that was developed by the researcher after an in-depth review of literature on common teacher philosophies and styles of differentiating instruction (Tomlinson, 2001; Tomlinson \& McTighe, 2006; Gregory \& Chapman2002). There were ten items on Teachers' 
Philosophies (TP) and nine items on Teachers' willingness to Differentiate Instruction (TWDI), both of which were contained in section two of the survey instrument (see Appendix D).

The survey was hand delivered to schools by the researcher and a research assistant. At each school, the researcher and/or the researcher assistant introduced themselves and provided the research permits needed to gain access to the school. They then briefly described the purpose of the research to the school administration - the head-teacher, deputy or senior teacher (whoever was in charge). We requested a school administrator to introduce us to one teacher who then acted as a lead participant. After talking to the lead participant (explaining the purpose and rationale for the study), the lead participant was given the survey packets that had the letter of introduction (see Appendix I), the survey questions, and a return envelope. The letter of introduction informed the participants of their right to voluntarily participate or discontinue from participating at any time, and that the survey was completely anonymous confidential. The number of survey packets left with each lead participant corresponded to the number of teachers present on that day in the school. In sixteen schools, upon the request of the lead participant and permission from the administration, the researcher introduced himself to the teachers (in teacher lounges) and explained the research.

The lead participant then distributed the survey packet (survey questions, letter of introduction, and return envelope). After two weeks, the lead participant then collected the surveys and kept them safe until the researcher or the researcher assistant collected them. The first survey was conducted during the week of June 6, 2011. Two weeks after their administration, lead participants collected completed surveys and who then forwarded them to the researcher. In nine out of the twenty-eight schools surveyed, due to in-school activities such as music festivals, teacher meetings, and even teaching practice, the researcher collected 
completed surveys after the agreed date. The last survey response was collected on June 24, 2011.

Qualitative data. Information that was collected from sections one and three of the survey was used to design the interview questions for both the focus groups and one to one interviews. The survey was also used to recruit participants for the interviews and focus groups. Qualitative data was collected during the second phase of the study that involved interviews and focus groups.

Interviews. Interviewing as a data collection tool is based on conversation (Kvale, 1996) in which meaning making is co-constructed by both the interviewer and interviewee (Gubrium \& Holstein, 2002). Patton (2002) states that interviews "begin with the assumption that the perspective of others is meaningful, knowable, and able to be made explicit" (p. 341). For this study interviews were conducted on a purposefully selected sample of school administrators to clarify, confirm, and/or extend information. The three school administrators chosen for the interviews were selected based on the information gathered from the surveys that indicated unique issues related to their schools within Kisii Municipality (their schools being in urban setting and being affected by the open air market at Daraja Mbili). An interview protocol (see Appendix J) was used to gain the perspectives of the interviewees. Extensive notes taken during informal conversations with school administrators, as part of my field notes while delivering or collecting completed surveys from the schools complemented the interviews.

Focus groups. Focus groups were formed to collect data and extend discussions on prominent issues identified from surveys and interviews. A focus group is "a carefully planned group discussion and/or interview designed to obtain perceptions on a defined area of interest in a permissive and non-threatening environment" (Krueger, 1994, p. 6). Unlike individual 
interviews, focus groups utilize group dynamics, whereby a member of the group is sometimes forced to defend and /or clarify his opinion to other members. Its role is not consensus building; rather, it is to obtain a range of opinions about issues (Vaughn \& Sinagub, 1996) and this trait renders the focus group as a unique tool for collecting qualitative data. The focus groups interviews were used for this study because of their convenience in collecting data from a large group of teachers and their potential of generating constructive discussions amongst teachers on the issue of student marginalization.

Krueger (1994) states that focus groups should be composed of seven to ten participants who share homogeneous traits but are unfamiliar with each other. In addition, three to seven focus groups should be conducted in a series so as to overcome internal and external influences. In conducting focus groups, Morgan (1998) suggests three different approaches with regard to moderator involvement that is: more structured groups, less structured groups, and funnel based interview. In a "more structured focus group, the moderator takes a visible role and uses a standardized interview" (Morgan, 1998, p. 41) for all the focus groups. In less structured format, the moderator is less involved in the discussion. The funnel based interview, which is a combination of less and more structured approaches begins with broad discussions and ends up with more focused discussions.

For this study, there were a total of four focus groups comprised of between five to ten classroom teachers per group. The first focus group had nine members, the second had ten members, the third focus group had five, and the fourth had six members. Participants for the focus groups were recruited during the administration of the survey. In conducting the focus group, a funnel based interview approach (Morgan, 1998) following a standardized interview protocol (see Appendix J) was used. The funnel-based approach was chosen to allow 
participants to engage in discussions without feeling confined to protocol-defined questions. To overcome the motivation problems associated with focus groups, a token $(\$ 12.5)$ was given to each participant to encourage their participation. An interview protocol (see Appendix J) was used to ensure that all the pertinent issues relevant to the research topic were covered and also to maintain focus.

The invitation letter (see Appendix K) and the interview protocol (see Appendix J) for the focus groups was hand delivered to all recruited participants at least a week prior to the date of the focus group meeting. A text message reminder was sent to these participants two days prior to interview. The locations for the focus groups were secured early and prepared for the meetings. Three of these locations were conference halls in hotels in Kisii Town and Keumbu, the third location was a classroom at a public secondary school.

Prior to conducting the focus group, each participant was asked to read and sign an informed consent form (see Appendix L). Also all the members were provided with stationery and refreshments. Before beginning of each focus group session, we discussed the ground rules that were part of a brief introductory packet describing the topic and the intent of the focus group. The interview protocol was then used to facilitate discussions. The proceedings of each focus group were audio recorded and my assistant researcher took detailed notes. At the end of each focus group, the assistant summarized the salient points participants discussed during the session and asked whether or not the focus group participants agreed with the assistant's assessment of their discussion. This served to act as member checking. At the close of the interviews/discussions, the participants were asked whether or not they could be contacted later for clarification. All participants in the four focus groups agreed. 


\section{Instrument Reliability}

Reliability is the consistency of a measure (Fields, 2005). In this study, the reliability of items on Teachers' Philosophies Scale (TP), Teachers' Willingness to Differentiate Instruction Scale (TWPI), Teaching Materials scale (TM), as well as Accommodations scale, were established through the Cronbach's Alpha $(\propto)$ statistic (see Table 7 below). In the Cronbach's Alpha, internal consistency of an instrument is calculated by establishing "the variance within each item, and the co-variance between a particular and any other item on the scale" (Fields, 2005, p.667).

The Cronbach's Alpha for each scale (see table 6 below) was Teaching Philosophies $\propto=$ $0.769(\mathrm{~N}=10)$, Differentiated Instruction $\propto=0.859(\mathrm{~N}=9)$, and Accommodations $\propto=0.794$ $(\mathrm{N}=10)$, while the Cronbach for Teaching Materials scale was $\propto=0.646(\mathrm{~N}=6)$.

\section{Table 6:}

Reliability Statistics

\begin{tabular}{lllll}
\hline & $\begin{array}{l}\text { Teaching } \\
\text { Philosophies } \\
\text { Scale }\end{array}$ & $\begin{array}{l}\text { Differentiated } \\
\text { Instruction Scale }\end{array}$ & $\begin{array}{l}\text { Teaching } \\
\text { Materials Scale }\end{array}$ & $\begin{array}{l}\text { Accommodations } \\
\text { Scale }\end{array}$ \\
\hline Valid cases & 182 & 181 & 185 & 186 \\
Cases excluded & 35 & 36 & 32 & 31 \\
Total cases & 217 & 217 & 217 & 217 \\
Cronbach's & 0.769 & 0.858 & 0.646 & 0.794 \\
Alpha & & 9 & 6 & 8 \\
No of items N & 10 & 9 & & \\
\hline
\end{tabular}

Table 6 above shows that the Cronbach's Alpha for the Teaching Philosophies, Differentiated Instruction, and Accommodations scales had high internal consistency and therefore these scales were considered reliable as the alpha was greater than 0.700 . On the other 
hand the Teaching Materials scale recorded a below par internal consistency as the Cronbach Alpha less than the 0.700 . This was noted as a weakness for the instrument and the results from this section of the instrument were not used to corroborate information collected from the interviews. Participants who did not complete all items in each scale were excluded from the calculation of the Cronbanch's Alpha.

\section{Trustworthiness}

Trustworthiness or data credibility was established through the use of Lincoln and Guba (1985) three constructs of member checks (i.e., getting feedback from participants immediately after the focus groups and interviews on the correctness of recorded information), a fairly prolonged engagement in the field mid-May through end of July, and triangulation. The use of multiple sources to collect data (surveys, interviews, and focus groups) were used to triangulate the data

\section{Data Analysis}

Different methods of data analyses were applied to quantitative data that was collected in form of surveys and qualitative data collected through one to one interviews and focus group interviews. During each analysis, the focus was on relevant information that was used to answer the research questions.

Quantitative data analysis. All collected surveys were assigned numbers to maintain privacy and then all responses from each survey section was entered in an excel file for easier management and retrieval. The collected survey scripts were then kept under lock and key in a safe box. During the study (starting from the time of obtaining permissions and consent for the study) the researcher kept a detailed journal with an account of all the processes of data collection and coding. 
The data entered in the Excel file was then copied to the SPSS program for analysis. Descriptive analysis was applied for section one of the survey instrument (see Appendix D) to describe the demographics of the participants and how teachers perceive their schools have attained the objectives of Free Primary Education.

Using the SPSS software, the Spearman's Rho $\left(\mathrm{r}_{\mathrm{s}}\right)$ analysis was done to determine the relationship between teacher beliefs and/or philosophies, their willingness to differentiate instruction (content, process, and product), the use of variety of teaching materials, and the accommodations they make in their teaching so as to create a learning environment conducive for marginalized students. The rationale for using the Spearman's correlation coefficient is because the data violates two assumptions of parametric tests that require the data to be normally distributed and to be interval level. In this study, the data set is at the ordinal level (ranks) and does not meet the normal distribution criteria.

Qualitative data analysis. Qualitative data analysis procedures were used in this study guided by the work of Grbich (2007), Patton (2002), Strauss and Corbin (1998), as well as Hsieh and Shannon (2005). The analysis of qualitative data began with verbatim transcription of audios recorded during interviews and focus group discussions. After transcription, the names of participants were replaced by pseudonyms to maintain their privacy. The transcripts were then crosschecked alongside the notes taken during the interviews and focus groups proceedings to add any information that was missed or not clear during transcription.

After transcription, the transcripts were first read and reread to get a general trend of the issues discussed by the interviewees and participants of the focus groups. In the third reading through an iterative process, segments of the transcripts (sentences, phrases, or passages) that were thematically cohered or contained salient information critical in answering the research 
questions were highlighted. The highlighted segments were then assigned open codes based on the relevant concepts and examples of those concepts within the segments. Coding was done to help differentiate the segmented data for easier comparison of the data sets and easier retrieval of the data for interpretation (Strauss \& Corbin 1998). Throughout the coding, a code-book was kept that contained a list of all codes with an accompanying excerpt from the segments that represented the best description for each code.

The next stage of analysis involved going through all the codes and their descriptions to develop categories or themes. At this stage, using strategies suggested by Strauss and Corbin (1998), I checked the categories or themes to make sure that they were internally consistent with each other but externally distinct from one another. A tally of all codes that comprised each category was kept to establish the dominance of an issue within the interviews and focus group discussions.

The last stage of analysis involved crosschecking the categories across the focus groups and one to one interviews for any emerging patterns. In every stage of the qualitative analysis of segmenting, coding, categorizing, and searching for emerging patterns, careful attention was paid to maintain the original meaning contained in the transcripts through an audit trail back to the original texts. The major categories or themes and the emerging patterns served to illustrate major perceptions of teachers on who they perceive as marginalized students in their classrooms as well as their practices within and outside the classroom that influenced access to, and retention of, marginalized students in primary schools in Kisii County. In addition, themes and patterns were used to develop explanations of phenomena (Patton, 2002; Strauss \& Corbin, 1998). 


\section{Limitations in the Methodology}

Data for this study was collected through the survey instrument (see Appendix D) that was distributed to classroom teachers from 28 schools. Though the percentage of the returned surveys was high $(71.3 \%)$, the percentage of return was not the same from all participating schools, for instance, from seven schools the responses were below 50\% while in two schools there was zero response. In both schools where there was a zero response, teachers who had received the survey in this particular cited heavy work. In addition to the surveys, the small number of interviews with principals was a limitation for this study. In that the three principals were drawn from schools located Kisii Municipality, the only large cosmopolitan area in the Kisii County and therefore shared experiences that were unique to their schools. 


\section{Chapter 4: Findings and Discussion}

\section{Introduction}

In this section findings from both quantitative and qualitative data are used to discuss the research questions. In each instance, the quantitative findings are first presented and corroborated by the qualitative findings. How well the findings are aligned to previous research in each issue or research question is also discussed. Based on the quantitative data, from the teacher survey instrument (see Appendix D), there is evidence that Free Primary Education has to a great extent influenced access, retention, and progression rates for all students. However, from the same survey, teachers indicated that Free Primary Education had only influenced to a moderate extent declining enrollment rates as well as quality of education for marginalized students. Teachers also identified the orphans, children with low incidence disabilities, children from single parents, and homeless children as the groups they considered vulnerable to repeating grades, dropping out, having low achievement, or missing school at least 10 times within a ninety-day period.

In regard to teacher practices, the quantitative data from the survey indicated that about $59.1 \%(n=217)$ of classroom teachers had not received any training at all on how to instruct marginalized (vulnerable groups) within their classrooms in equitable ways. These findings from the quantitative data were supported by the perceptions of teachers who participated in focus groups and interviews that they were not well prepared and/or trained to adequately meet the educational needs of marginalized students in their classrooms.

Analysis of Spearman Rho of Correlation coefficient indicated that there was a significant correlation between Teachers' Philosophies and Teachers' Willingness to Differentiate Instruction for marginalized students $\left(r_{s}=0.43, p<0.05\right)$. On the other hand, there 
was a significant correlation between Teachers' Philosophies and their willingness to use a variety of teaching materials for marginalized students $\left(r_{s}=0.15, p<0.05\right)$.

The findings from the qualitative data showed mixed results in regard to how Free Primary Education had influenced access to education for the marginalized students. The results from the focus groups and one to one administrator interviews indicated that the FPE program had guaranteed access to all students through open admission policy, provision of instructional materials, support for the Most Vulnerable Children (MVC) in some schools, reduction in levies charged on students, reduction in dropouts, improved learning standards, and renovation of school infrastructure. However, there was also evidence of factors constraining access to universal education for marginalized students. These factors included school levies, high teacherpupil ratio, lack of room, as well as lack of appropriate instructional facilities, and lack of teacher awareness on how to promote the learning of marginalized students in their classrooms. The qualitative findings also identified the girls, the orphans, children from extremely poor families, children from single parents, and children with low incidence disabilities as the most vulnerable groups in their classrooms. From the qualitative findings, the themes that emerged regarding teacher and school practices influencing learning of the marginalized students included appropriate use of culturally responsive pedagogy, care, remedial teaching, as well as guidance and counseling. From the focus groups and one to one interviews, the data was inconclusive as to whether participants were differentiating instruction for the diverse groups in their classrooms. The section that follows provides a detailed discussion of the findings for each research question. 


\section{Research Question \# 1: How Teachers Perceive FPE has Influenced Access to Primary Education for Marginalized Students.}

Teachers have been at the forefront in the implementation of Free Primary Education (FPE) since its inception in 2003; yet, policy makers disregard their perceptions on the success of this program. Utilizing survey data collected from 217 primary school teachers drawn from 28 schools in Kisii County, as well as 30 participants from four focus groups interviews, and three one to one administrator interviews, the findings from this study underscore the perception of teachers on the influence of FPE on access to education for the marginalized students.

Quantitative findings. From the survey (see Appendix D), 99.5\% ( $\mathrm{n}=206)$ respondents indicated that they were aware of the Free Primary Education objectives. In this survey (see Appendix D), item 11 required teachers to report the extent to which they believe the broad objectives of Free Primary Education had been met in their schools. Results for this item are displayed in table 7 below. 


\section{Table 7:}

Teacher Perceptions on the Extent to Which FPE Objectives have been Met.

\begin{tabular}{|c|c|c|c|c|c|}
\hline To what extent has FPE: & 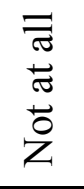 & 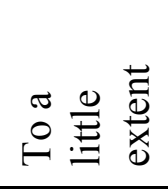 & 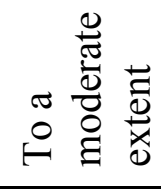 & 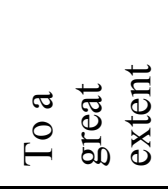 & 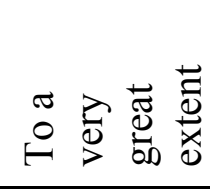 \\
\hline $\begin{array}{l}\text { Reversed the declining } \\
\text { enrollments }(n=201)\end{array}$ & $7 \%$ & $15 \%$ & $32 \%$ & $33 \%$ & $13 \%$ \\
\hline $\begin{array}{l}\text { Enhanced access at the primary } \\
\text { level }(n=201)\end{array}$ & $0 \%$ & $5 \%$ & $24 \%$ & $43 \%$ & $28 \%$ \\
\hline Increased retention $(n=199)$ & $1 \%$ & $13 \%$ & $28 \%$ & $42 \%$ & $16 \%$ \\
\hline $\begin{array}{l}\text { Increased quality of education } \\
(n=213)\end{array}$ & $5 \%$ & $13 \%$ & $35 \%$ & $37 \%$ & $10 \%$ \\
\hline $\begin{array}{l}\text { Improved participation rates } \\
(\mathrm{n}=208)\end{array}$ & $2 \%$ & $12 \%$ & $37 \%$ & $39 \%$ & $10 \%$ \\
\hline $\begin{array}{l}\text { Improved progression rates } \\
(\mathrm{n}=206)\end{array}$ & $3 \%$ & $14 \%$ & $31 \%$ & $41 \%$ & $11 \%$ \\
\hline $\begin{array}{l}\text { Reduced cost of education } \\
(n=206)\end{array}$ & $1 \%$ & $7 \%$ & $17 \%$ & $45 \%$ & $30 \%$ \\
\hline $\begin{array}{l}\text { Streamlined use of educational } \\
\text { resources }(n=206)\end{array}$ & $2 \%$ & $8 \%$ & $24 \%$ & $46 \%$ & $20 \%$ \\
\hline $\begin{array}{l}\text { Improved learning achievements } \\
(\mathrm{n}=206)\end{array}$ & $2 \%$ & $13 \%$ & $28 \%$ & $40 \%$ & $17 \%$ \\
\hline
\end{tabular}

Note: The responses in this table were collected through a survey administered to 217 teachers from 28 schools in Kisii County.

The nine items featured in the above table focused on the objectives of Free Primary Education of Kenya. From table 7 above, participants reported that eight out of the nine of these objectives had been met from a moderate to a very great extent by $80 \%$. The specific objectives met included enhanced access to education at the primary level $(95 \%, n=201)$, increased quality of education $(82 \%, \mathrm{n}=213)$, improved participation rates $(86 \%, \mathrm{n}=208)$, improved progression rates $(83 \%, n=206)$, reduced costs of education $(92 \%, n=206)$, and streamlined use of instructional resources $(90 \%, \mathrm{n}=206)$ for marginalized students. However, $22 \%$ of the teachers $(n=201)$ reported that Free Primary Education had only to a little extent or not at all reversed the 
declining enrollments of marginalized students in their schools. On item-by-item analysis, teachers reported high ratings that FPE had led to the reduction of the cost of primary education, increased access to marginalized students, and streamlined use of educational resources in a combined percentage of $76 \%, 71 \%$, and $66 \%$ respectfully in the categories of "to a great extent" and "to a very great extent". These results are displayed in table 8 above

Qualitative findings. Both the focus groups and interviews had two specific items in the interview protocol (see Appendix J) that required participants to discuss how free primary education has influenced educational access for marginalized students. Specifically they were to respond to: a) How has free primary education influenced access to primary education for marginalized students? And b) What are the benefits of Free Primary Education? Analysis of focus group and interviews' descriptions of the influence of FPE on access to primary education for marginalized students yielded six themes that are illustrated in table 8 below:

\section{Table 8:}

Themes from Focus Groups and Administrator Interviews on FPE influence on access

Theme Frequency

\begin{tabular}{ll}
\hline Access to instructional materials & 39 \\
Reduction in levies & 18 \\
Increased access to basic education & 16 \\
Improved educational standards & 16 \\
Improvements in school facilities & 9 \\
Reduction in dropouts & 6
\end{tabular}

In table 8 above, in a higher number of instances, participants identified access to instructional materials as a single most way by which Free Primary Education had influenced 
access to basic education for marginalized students. Reduction in levies paid to schools by parents, increased initial access, improved educational standards, improvements in school facilities, and reduction in dropouts were other ways in which FPE had influenced educational access. Each of these themes is discussed and elaborated in the following sections.

Access to instructional materials. All focus groups and interviews, participants in 39 instances identified the provision of instructional materials in the form of textbooks and writing materials as one of the ways in which Free Primary Education (FPE) had influenced learning in schools. They reported that with the introduction of FPE, children from vulnerable groups as well as children from ordinary families have had equal access to learning materials. For instance Josiah stated:

...Here the government has really assisted especially those marginalized pupils...If you come to schools or if you go to schools, there are many textbooks which are just bought for these particular pupils. So they are able to get textbooks free.

In highlighting the provision of instructional materials to schools, Josiah underscores one of the major achievements of Free Primary Education. This is particularly important since access to adequate and appropriate instructional materials in Kenyan schools was elusive during the first four decades of Kenya’s independence (1963 - 2003). Between 1963 and 2003, there was only one major attempt to properly equip schools with learning materials through a program initiated by the government in 1969, the Kenya Schools Equipment Scheme - KSES (Abenga, 2009; Rotich, 2004, Sifuna, 2007). The KSES was a department within the ministry of education that was charged with providing instructional and learning materials to primary schools in Kenya (Sifuna, 2007). However, the KSES collapsed in the late 1970s due to diversion of funds intended for the purchase of learning and instructional materials to school milk programs. This 
diversion of funds implied that schools were left with minimal instructional resources. The resultant effect was that only children from middle to high socioeconomic statuses could afford books and relevant educational materials.

The teachers from the focus groups acknowledged the impact of access to adequate and appropriate instructional materials on quality of student learning and performance. Specifically they felt that this access had led to improvements in student performance. For instance, Mary stated:

We are now able to purchase charts, stationery, to name but a few. As a result of purchasing these instructional materials, it has really facilitated learning. It has boosted performance because all that we need is in place; because of that it has even improved performance. (It has also) ...reduced cases of inferiority complex among learners, because each and every learner has access to these instructional materials.

It can be inferred from the Mary's statement that the provision of instructional materials had influenced learning of all students including those who were marginalized. Another impact of the direct impact of provision of instructional materials through Free Primary Education was the reduction in the textbook-pupil ratio, which in turn could have a direct influence on the quality of learning and instruction. However, the child textbook ratio varied from school to school. Some schools had attained a ratio of 1:2 (one book for two children), while others were teetering at a ratio of 1:3 (one book for three children). In terms of the writing materials (pens, pencils, and exercise books), participants shared that students were given these items only once in three months and this was identified as an obstacle to learning for students from extremely poor families. For instance Linet a participant in one of the focus groups said: 
You know many students have come to school, we give them writing material and sometimes when it is over (used up), because you know it is kind of limited...exercise books which we buy are not so much that they can last them throughout the year...so we give them about 12 exercise books, when they are filled up, ok, the parents have to buy. But for the poor ones...still because we require that they write, so the teachers still volunteer to buy for those ones who are not able to buy extra books. I am actually saying that FPE money is not enough to make books run throughout the year

Linet raised one major concern related to the adequacy of Free Primary Education funds, that the funding is not enough. The current funding per child stands at about $\$ 44$ per year and it covers instructional materials, development of infrastructure, payment of support staff and activity fees. The funding for children with special needs is slightly higher but not enough. For sustainability and actualization of the full intent of the Free Primary Education, these funds should match the reality of the day; that is, funding schooling for all students that is adjusted for inflation and reflects the realities as well as needs of individual schools and students.

While the adequacy of Free Primary Education (FPE) funding is contentious, there was consensus between focus groups participants (qualitative data) and the survey responses (quantitative data) that this program has enabled primary schools to have adequate and quality instructional materials. For instance, from the quantitative survey, $90 \%(\mathrm{n}=206)$ of the respondents indicated that FPE "to a great extent and to a very great extent" had streamlined the use of instructional resources. This is aligned with the assertions made by participants in focus group and one to one interviews who indicated that due to FPE, schools now have adequate access to instructional materials such as books and writing materials for students. This finding 
supports research by Somerset (2011) which also indicated that FPE had led to increased access to instructional materials.

Reduction in levies. Reduction in levies students are charged to access education was a major theme highlighted by participants in focus groups and interviews. In the focus groups and administrator interviews, participants described the theme reduction in levies as 'elimination of tuition and levies,' 'reduced fee payments,' 'as a government subsidy,' or 'reprieve in fee payments.' Participants in focus group and administrator interviews shared that this reduction had eased the burden on poor parents who could not afford to pay the tuition as well as other fees charged in schools. The participants also reported that the government's move in 2003 to make primary education free provided increased access to basic education for learners from marginalized groups in society. Mary a participant in one of the focus groups stated:

About school levies, FPE grants or gives money to each learner irrespective of the background where he or she has come (from) and because of this, FPE has reduced cases of sending learners away to go and collect school fees among other levies. Therefore they have enough time in school. So it has reduced absenteeism.

Through FPE, the government disburses funds to schools to finance the learning of all students. These funds, according to Mary, and other participants in the focus groups, mean that no child is sent home because he/she is unable to pay the tuition fees thus reducing absenteeism. Mary's statement was a clear testament of the direct economic impact of Free Primary Education had on households all over Kenya with regard to fee payments by Kenyan parents in public primary schools. The findings from the focus groups and interviews were further supported by the quantitative survey data in which $92 \%(n=206)$ respondents reported 'a moderate to a very great extent' that FPE has led to reduction in the cost of education previously borne by parents. In 
addition, these findings are consistent with research by Mukudi (2004), which reported that fee reduction as an area where FPE has been very successful.

Though the Ministry of Education Science and Technology disburses FPE money to Kenyan public primary schools, the teachers in the focus groups also believed that the capitation per child (the funding for each child) of about $\$ 14$ per year was not sufficient to address the educational needs of all children. Richard a participant in one of the focus groups noted:

In terms of levies, we can only say that the government is subsidizing. Because it is like parents remain with the greater part to play because they are the ones who cater for...examinations, they cater for preps, they cater for (extra) tuition...In that area the FPE has not done well because we have seen even the activity fee which is meant to be the fourth given by the government, in our district - Kisii Central District, the government...the District Education Board has requested the parents to pay and that one has been done formally. So the parents are paying when it is clearly known that it is FPE to cater that but the money is not enough.

The additional costs of schooling in form of: 1) examination fees, 2) extra tuition, and 3) extra curricula activities fees, are not covered by FPE funds and therefore continue to be a hindrance for access to education for children from poor families. Richard's statement provided evidence that tuition fee abolition is not a panacea to wider poverty constraints affecting the demand for education in Kenya. Moreover, Richard's statement illustrated the need to look at the overall cost barriers confronting poor households, rather than tuition fees in isolation. This idea is also reinforced by Education for all Global Monitoring Report (UNESCO, 2010), which identified increased funding to cater for costs of uniforms, textbooks, and other educational costs as the only way to make schools affordable to children from poor households. 
Increased access. Increased access to primary education was another achievement discussed by interview and focus group participants. Access, they said, was evident through increased enrollments of students and all year admission policy. For instance, Joseph, a participant in focus group two states: "Equally they (marginalized students) are accessing education now. They are able to access education and at the same time they are motivated..." In this excerpt, Joseph attributes the increased access to education to Free Primary Education. However, some participants lamented that lack of clear guidelines on admission had led to enrollment of overage students and this was counterproductive. For instance, Rosa, a focus group participant noted:

...another problem is that now children are so many in schools that we have discipline problems because of the different ages in class. Because we have some who had not even come to school, now they waited till they were old it is when they enrolled. Now they are in class with some other small children...you find that these big children may be bullied (taunted) by the small ones because of their age.

Rosa describes discipline as one type of challenge encountered by teachers when they have overage students in their classrooms. Enrollment of overage students in classrooms is also indicative of failure of adult education programs.

Increase in enrollment in basic education has not been paralleled with an increase in physical learning facilities such as classrooms and desks. As a result there is a shortage of desks and classroom space which has led to overcrowding in schools within Kisii County. To illustrate this, Charlie, a focus group participant stated: 
The most acute problem we are having is lack of enough the (physical) structures. The government has not provided enough funds for maybe building new classes...uh making desks for the high number of students to use and chairs for teachers.

Instructive in Charlie's excerpt is that FPE funding is not enough and schools still continue experiencing overcrowding and inadequate learning facilities.

Nevertheless, the overarching goal of FPE was to increase access to basic education to all school-age children. Therefore, the acknowledgment by focus group and interview participants confirmed the notion that perhaps Kenya had made remarkable achievements in increasing access to education for all children. However, challenges such as poverty, overstretched learning facilities, high teacher pupil ratio, and inadequate funding continue to hinder full achievement of the Millennium Development Goals of 2000 (UN, 2000) and Dakar Framework for Education for All goals of 2000 (UNESCO, 2000), which stipulated 2015 as the target date by which all children, in particular girl children and those from difficult backgrounds, should have access to complete and free primary education which is of good quality. In addition, the 1.9 million children whom the Kenya Census Report of 2009 (Republic of Kenya, 2010) identified as being out of school further cast aspersions as to whether Kenya will achieve universal access to basic education for all children.

Improved standards. The participants cited the provision of instructional materials and increase in teacher employment as ways in which Free Primary Education had led to improvements in standards of learning for all students (the marginalized students included). For example Patrick, a participant in the focus group four states: "Now the introduction of FPE has really helped in improving the standards especially in our institution." While this claim by Patrick does not describe what he means by standards, his assertion is supported and/or 
reinforced by Jimmy a participant in one of the focus groups who also stated: "I believe because of this, the quality of education they provide is actually high because they are able now to have these books at hand as they work." Jimmy tried to associate the quality of education delivered to marginalized students with availability and/or access to instructional materials by both the teachers and students.

As stated above, improvements in quality of learning that is occasioned by provision of instructional materials is further supported by results from the survey in which $90 \%(\mathrm{n}=206)$ of participants self-reported that FPE had streamlined use of instructional resources from 'a moderate' to 'a very great extent. Moreover, $85 \%(\mathrm{n}=213)$ of the respondents in the survey indicated 'a moderate' to 'a very great extent' that FPE had increased the quality of education at the primary level. In the same survey, participants indicated by $85 \%(n=206)$ 'a moderate' to 'a very great extent' that FPE had led to improved learning achievements of marginalized students in their classrooms. However, previous research by Bagaka (2010) on Kisii districts schools' (here in referred to as Kisii County) performance in Kenya Certificate of Primary Education (KCPE) examinations administered at the end of $8^{\text {th }}$ grade between 2001 and 2007 found that the districts continued to lag behind in overall performance comparative to other districts in Kenya. While this research contradicts the perceptions by participants in this study that there were improvements in learning outcomes, it can be argued that in individual schools and classrooms; teachers had noted improvements in marginalized students' performance.

In another area of learning and achievement, the focus groups and interview participants believed that through Free Primary Education the literacy levels had gone up. For instance Kevin, a participant in focus group one states: 
It is the other day I had a pupil aged 37 years and he is currently pursuing a course, he finished. He started at class seven, went through secondary and he is now doing a course at Kenya Railways Training Institute.

Kevin's emphasis on students who had previously dropped out of school, but decided to come back to school due to FPE implies that with increased number of years spent in school, there is an increase in literacy levels. It can also be inferred from the example described by Kevin that with increased literacy (herein only referring to the number of years of school) is the increase in human potential through extra training and learning.

Improvements in school facilities. Through the FPE money, the participants reported, most schools were able to construct new classrooms to accommodate more children. In other instances, schools through the FPE funds designated for 'repair and maintenance' were able to improve on existing classrooms thereby providing an environment conducive for learning. This is well illustrated by Chris who opined:

I can also say the government has enabled the schools to have more classes to accommodate the population. Sometimes back, the school was able to accommodate...if it is twenty pupils in class and if there we no classes they learned under trees...it was not conducive, so they ran away.

The funds disbursed to schools have resulted in the construction of new classrooms to accommodate the high enrollment of learners. This contrasts with the pre-FPE era (period before 2003) where there were instances of schools being forced by circumstances to hold classrooms under trees due to inability of communities to fund construction of new classrooms (Sifuna, 2005). Despite Chris's assertion that schools have been able to construct more classrooms (space), the conditions of the existing physical learning spaces in schools is poor. Some 
participants in the focus groups and interviews asserted that their classrooms are unpaved/not cemented, have open windows, and classrooms have no ceilings. For instance, Kevin, a focus group participant states, "in our schools, like me (sic) I have mud classrooms...my children sweep every evening. In the morning they go for water...watering the classrooms." In Kevin's class, the children and teachers have to contend with dust every day thus making it unfavorable environment for learning.

Besides construction of new classrooms, the same portion of the Free Primary Education funds is appropriated for repair and maintenance. This has enabled schools to regularly repair desks, buildings, and even textbooks to ensure their longevity. Bob states, "For example, renovations for classrooms, repair of desks and tables... has been facilitated by FPE." These renovations do ensure that the physical learning space and materials will be available for the next generation of students.

Construction of new classroom space, the continued repair as well as maintenance of existing spaces are areas which have benefitted from Free Primary Education (FPE) Funds. This contrasts with the pre-FPE era in which the construction levies was a cost solely borne by parents (Sifuna, 2007). However, there was also an acknowledgement that FPE funds appropriated to schools for development were not adequate and that the conditions of learning spaces in Kisii primary schools were poor.

Reduced dropouts. In this study, focus groups and interview participants identified reduction in dropout rates as one of the achievements of Free Primary Education. Specifically, they identified the government role in the payment of tuition, as a major factor that helped retain students in schools. For example Leah stated: 
FPE grants or gives money to each learner irrespective of the background where he or she has come and because of this, FPE has reduced cases of sending learners away to go and collect school fees among other levies. Therefore they have enough time to study in school. So, it has minimized cases of absenteeism due to any school levy.

Leah argued that the elimination of school fees has ensured that learners, in particular learners from poor families, are not forced to drop out of school or be absent from school due to nonpayment of fees. The resultant effect of this is that there is increased number of instructional contact hours and thus the likelihood of student success. The assertion by participants in the focus groups and one-one interviews that FPE had led to reduction in dropouts is supported by findings from the quantitative survey where participants had indicated by $95 \%(\mathrm{n}=201)$ and $92 \%$ $(n=206)$ that FPE had enhanced access at the primary level and reduced the cost of education respectively.

\section{Summary}

In describing how Free Primary Education had influenced access to education for marginalized students, both quantitative and qualitative data indicated increased access. Significant in this was the reduction of the fee burden previously born by parents while educating children in primary schools in Kenya. Though participants lamented of the low capitation per child, they acknowledged that FPE had greatly reduced the fees. However, there

still are some extra fees charged in schools not covered by FPE. Increased access is further enhanced by improved school facilities, increased access to instructional materials - notably the purchase of books and writing materials, reduced dropouts, and improved educational standards of students. Each of these factors related and contributed to each other. For instance, increased access to instructional materials could influence improved educational standards, while reduction 
in fees could influence reduction of dropouts. On the other hand, results from this study indicate that FPE funding is not adequate to cater for school development needs and purchase of all required instructional materials for all students.

\section{Research Question \# 2: What do Teachers Perceive to be At Risk Categories for}

\section{Marginalized Students?}

In this study marginalized students were considered to be to those students who come from marginal groups within society, including: (a) students from families that are extremely

poor; (b) children who are homeless; (c) children who are orphans; (d) children engaged in child labor; and (e) children who have disabilities. In addition, students who exhibited or were at risk of exhibiting one of the following characteristics: (a) poor attendance, (b) low achievement, (c) repetition of grades, and (d) dropping out of school were also considered marginalized. This study sought to discover how teachers characterized students they considered to be at risk for marginalization. Results from both quantitative and qualitative data are discussed in the section that follows.

Quantitative data. Item number 10 of the teacher survey instrument (see Appendix D) required teachers to report the number of students in their classrooms whom they perceived to be either orphans, homeless children, children with low incidence disabilities, and those engaged in child labor. Additionally they were required to indicate as to whether the students identified in the above categories were at risk of repeating grades, dropping out of school, having irregular attendance (were likely to miss school for more than 10 days within 90 school day period), and/or were likely to have low academic achievement. Out of the 217 survey responses that were collected, only 167 participants answered this item in the survey. Figure 4 below shows the 
number of teachers who identified to have orphans, homeless children, children with low incidence disabilities and those engaged in child labor in their classrooms.

\section{Figure 4:}

Children identified as marginalized in classrooms

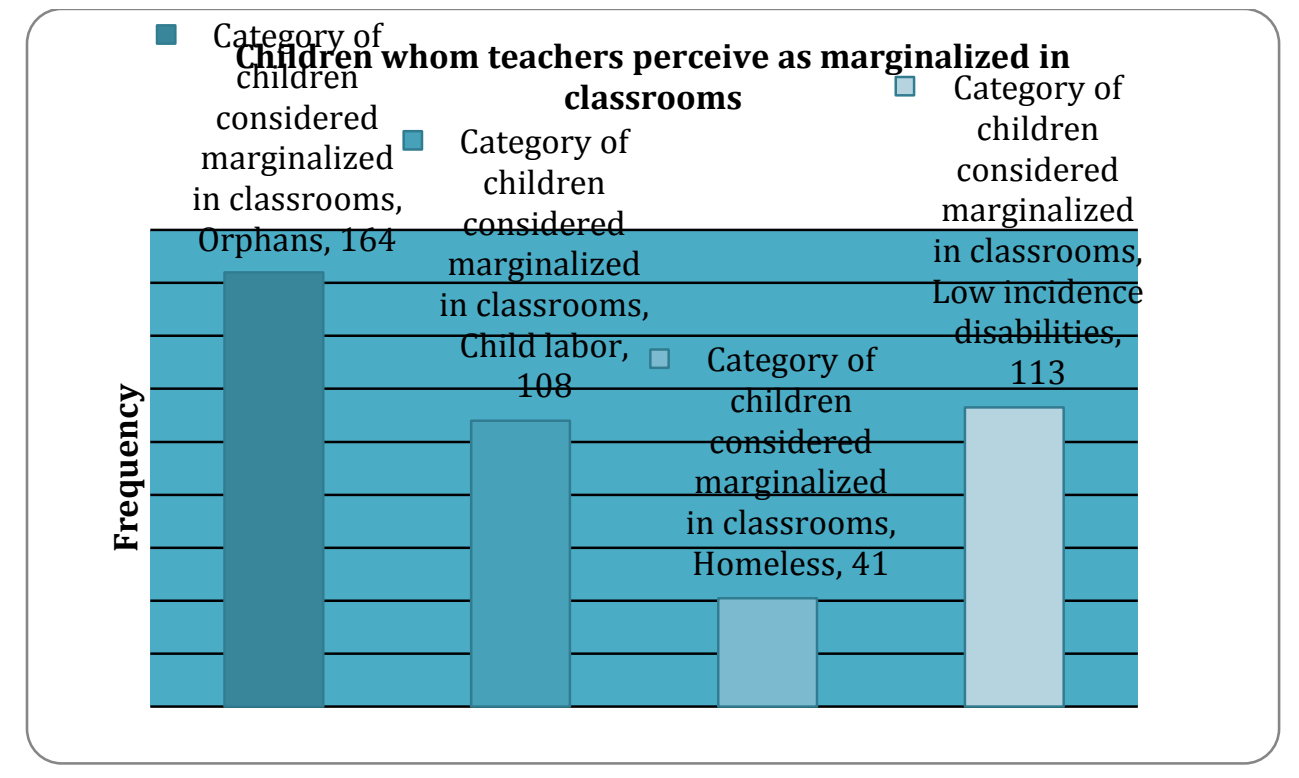

Note: Item \#10 of the survey instrument (see Appendix D) required participants from the 28 primary schools in Kisii County to identify categories of students in their classrooms who were likely to: a) have low attendance (miss school for more than 10 days within a 90 day period); b) have low achievement; c) repeat grades; and d) drop out of school.

In figure 4 above, it can be deduced that the majority of teachers ( $\mathrm{n}=164)$ self-identified to have orphans in their classrooms that were at risk of marginalization. Children with low incidence disabilities (the hard hearing, the blind, and those with mental retardation) and children engaged in child labor were the second and third frequent categories of children ( $n=118$ and $n=108$ respectfully) identified as at risk for marginalization. Only few teachers $(n=41)$ indicated to have homeless children in their classrooms. 
Qualitative data. Qualitative data was gathered through focus groups and administrator interviews following an interview protocol (see Appendix J). Specifically question one and two of the focus group and one to one interview protocol (see Appendix J) sought to garner teacher responses as to which category of students in their classrooms they considered marginalized. Specifically the questions were: 1) Describe to me students you know who have dropped out or stopped coming to school; 2) Who do you perceive as a marginalized student in your school? An inductive content analysis of transcripts of responses for item one and two of the interview protocol (see Appendix J) for the focus group and one to one interviews resulted in twenty-four codes (see appendix M). Further analysis of these codes yielded six distinct categories or themes. These themes or categories, which illustrated how teachers perceived marginalized students were: (a) children from poor families, (b) the orphans, (c) children from negligent parents, (d) the girl child, (e) children with special needs, (f) children with poor health, and (g) children from single parent homes. Table 9 below indicates the number of instances, each of the above themes were mentioned or discussed in the administrator interviews and focus groups interviews.

Table 9:

Categories of Students Identified as 'At Risk' for Marginalization in Classrooms

Category of students identified as 'at risk' in Number of instances mentioned or discussed classrooms

Children from poor families 60

Orphans

52

Children with negligent parents

Girl child 
Children with low incident disabilities

Children with poor health

Children from single parent homes

It can be deduced from table 9 above that similar to the quantitative survey data, qualitative data from the focus groups and administrator interviews distinctly identified children with low incidence disabilities and orphans as categories of students who were 'at risk' for marginalization. While in the survey data children engaged in child labor were identified as a distinct category, in the interviews it was sub-category subsumed in the broad theme of children from poor families (see Appendix M). Unlike the quantitative data, the interviews and focus groups did not identify homeless children as a category of students who were 'at risk' for marginalization. Overall, in a higher number of instances, children from poor families and orphans were cited as being at risk for marginalization.

As evidenced in table 9 above, qualitative data yielded additional categories of students who were 'at risk' for marginalization, including children from poor families, children from negligent parents, children from single parent households, children with poor health, and the girl child. The section that follows, gives a detailed explanation and examples of each theme as identified in the focus groups and administrator interviews.

Children from extremely poor families. Children from extremely poor families were a category of students identified by participants in focus groups and interviews as being at risk for marginalization. Because of poverty some households could not provide basic needs such as good housing, clothing, and even food. Patrick a participant in one of the focus groups stated: 
The major problem that we are having is poverty in that most pupils come to school hungry, you find that some had not even taken super, not even breakfast, so you find them actually dozing in class

Similarly, Gideon, a participant in focus group, suggested that hunger and/or malnourishment as a factor that hinders full access to education for marginalized students when he suggested: ...for example in school we are currently facing what we call starvation or hunger. Most children come from families where there is not enough food, you find sometimes in the afternoons, you find some children are sleeping or they are saying they are sick. If you find something (food) to give them, you find that they are okay. But most of these children when you ask them, they say they don't have anything and later after assessing them, ....6 out of ten have left (school) because of this kind of starvation.

Both Patrick and Gideon argued that poor families, struggled putting three square meals on the table for their children, hence suggesting that the children's basic need of food as suggested by Maslow had not been met. This in turn affected student learning in terms of lacking the energy to learn and malnutrition. The affected pupils ended up dropping out of school or did not achieve well in class.

In the twenty-eight schools surveyed in Kisii County, none had an organized lunch program for all of its pupils and the Free Primary Education funds did not provide school lunches in Kisii County. However, participants from five schools indicated that they had a mandatory lunch program for all students in standard eight (candidate class) that was solely supported by parents. In describing the feeding program in his school Richard a participant in a focus group stated: 
...we have a feeding program in our school for standard seven and eight, but that one is entirely facilitated by the parents. And again, here we have that category of students we regard as marginalized and the school policy on this is that those ones who appear to be totally or completely incapable of meeting the cost of this lunch program, (they) are catered for by the teachers and the school management committee. So we came together with the school management committee and singled...identified those pupils and worked out a way of paying for them.

The above statement by Richard is an example of efforts that were being made by some schools to meet the nutritional needs of students from poor families who have reached standard seven and eight (the last two grades in the primary education). Students who came from poor families and were facing hunger, but were in lower grades standard 1-6, oftentimes they went without lunch. Flora stated:

And another thing is some children because of poverty, once they have gone for lunch they do not find food (at home), and once they do not find food, some they do not come in the afternoon. So, half the day is wasted. And maybe when they come in the next day to school, they are tired and after sometime they will drop away...

The end result is that such children ended up dropping out of school due to this hunger.

Besides hunger, children from poor families were predisposed to engage in child labor to supplement family income. Participants reported that this not only affected their learning due to their irregular attendance, but it also resulted in their dropping out of school. Peter noted:

...you find that even parents encourage their young girls to be babysitters in order for them to raise some little money for the whole family to use. And as a result they make the 
children drop out of school. The casualty is the girl child. Girl children, these are the people who suffer a lot.

Implicit in Peter's statement is that some poor parents forced their young daughters to be babysitters. Hence these children were not able to attend school. Peter's statement shed light on an additional form of marginalization specific to the girl children who lived in poverty.

Orphans. Orphans were the second category of students whom teachers perceived as marginalized. In fact all 30 participants in the focus groups acknowledged having orphans in their classrooms. This category was similar to findings from quantitative data, where $77 \%$ $(n=217)$ of participants identified orphans as one of the categories of children they considered as marginalized and who were at risk of missing school for more than ten days in a school term (three months), having low achievement, repeating grades, and/or dropping out of school. In particular, Mary, a participant from Focus Group 1 states that some children "are orphans because their parents have died of HIV/AIDS.” Mary's statement supports UNESCO (2010) EFA Report and Himaz (2009) study which report HIV and AIDS related deaths as major causes of increase in orphans in sub Saharan Africa, Kenya included.

Teachers perceived orphans as marginalized and their learning was at risk due to irregular attendance dropping out of school altogether as they assumed guardianship of their younger siblings. This assertion was well illustrated by participants in the focus groups and interviews who described various factors that predisposed orphans for marginalization in schooling. Chris a participant from the focus groups stated:

I can call these children the underprivileged children especially those children whose parents have died are categorized in this marginalization. You find that children whose 
parents are dead, they don't have support, they are always miserable. They are not even able to concentrate in the classes.

According to Chris from one of the focus groups, orphans were marginalized. Notable in Chris's argument was his assertion that orphans were not able to concentrate in class, alluding to the psychological impact of losing a parent. This argument was aligned with the Maslow's hierarchy of needs which postulates that for an individual to pursue a higher need (in this case learning), he/she has to satisfy the preceding needs (in this case love, belonging, and security).

Besides the psychological impact on student learning, the focus groups and one to one interviews reported that the learning of orphans was always at risk as they were likely to assume the role of guardianship to their younger siblings, which contributed to irregular attendance, or dropping out of school altogether. Children who suffered the most were those whose parents had died from HIV/AIDS or natural causes and who did not have responsible guardians. James, a participant in one of the focus groups succinctly captured this when he stated that:

I think another reason why these students leave school is because they are orphans. More so when their parents have died, they tend to be alone and they don't have support. So when the pressure in the family... one or two tend(s) to leave school so that he or she may take care of other children. And this is when the parents have died mostly due to HIV/AIDS and it becomes a problem for them to attend school.

James's assertion that children who dropped out to assume sibling care was further reinforced by Josiah a participant in focus group one who observed that:

...I may say of where the parents have died, there is no grandfather, there is no grandmother, and even the uncles are not there, some pupils drop out of school to support their siblings. For example those ones who are old enough, they can go and then take 
maybe a 'kibarua' (casual labor) somewhere and this one will make them at least to get the money to support their siblings.

From Josiah's observation, it can be inferred that some orphans who have assumed 'parental roles' end up dropping out as they looked for employment to support their siblings. In some instances, even when grandparents were alive, they were often too old/frail to adequately provide for these orphans. Peter a participant in one of the focus groups asserted:

I wanted also to comment on this, the dropout issue which comes as a result of bereavement. Uh, like the place where I come from that is Border, that far end of Mosocho Division, in fact there is AIDS menace has brought a big problem because most it has wiped entire families leaving young children at the hands of very old grandmothers. These grandmothers are completely unable to provide for the needs of these children. And that one forces these children to completely drop out of school completely. Peter's description of the living and family conditions facing orphans in Kisii County, is a statement that was aligned to Himaz's (2009) findings which reported that older orphans normally took up the primary care responsibilities of their younger siblings and elderly grandparents.

Children from negligent parents. Participants noted that children from negligent parents, those parents who exhibited poor parenting was another category of students who were identified by participants in the focus groups and one to one interviews as being at risk for marginalization. Negligent parents were characterized as those who showed little interest in a child's social wellbeing and/or education. For instance, Vin a participant in one of the interviews, argued that: 
... (Some) parents do not give actually the required support to their children. They do not make a follow up to school to see how their children are performing, whether the children reached school or not and a result many are forced to drop out.

Lack of parental involvement in the child's learning is at the core of Vin's argument. This influenced a child's well-being in school, especially when a teacher failed to get the parent's assistance in solving issues, such as inappropriate behavior. An example given by Flora, a focus group participant reiterated, “...once we have a problem with a child, maybe it is misbehavior, we want to involve the parents so that we can solve the problem, they hardly come...they hardly come.” By extension Flora's argument suggested that when behavior issues are not solved collaboratively by parents and teachers, it risked those children being marginalized. Lack of parental involvement was a finding consistent with Burnett's (2008) argument that when parents were disengaged from the educational process of their children, it became difficult for teachers to harmonize the school and classroom environment.

The girl child. The data revealed that the girl children in primary schools in Kisii County were predisposed to be at risk for marginalization due to unfavorable school conditions, lack of access to sanitary towels because of poverty, child labor, retention at home to provide child care, and teenage pregnancy. All these factors militated against actualization of universal access to education for the girl child in Kisii County.

Unfavorable school conditions. Unfavorable school condition that participants shared was that the girl child was more susceptible to be marginalized when the school lacked enough toilets. It was reported by the teachers that toilets in schools also acted as changing rooms for girls who are experiencing their menstrual flow. For instance, Alfred, a participant in focus group two argued: 
In my school and I think most of our schools...in an ordinary school setting, there should be a changing room, which we do not have...the ratio of the number of toilets that we have for girls, is not adequate ... So, I think the physical environment is not conducive for some of our girls or a number of our girls.

Alfred observed that the number of toilets (which are normally pit latrines or out houses) in schools were not enough to cater to the bathroom needs of students. The major casualty of this situation was the girl child who had to suffer the indignity of scrambling to use the few that were available. Alfred further illustrates this indignity when he observed that:

...But you see our toilets don't even have doors. So can this girl comfortably walk to the toilet and change her sanitary wear with an open door? So, they have to wait till it is past break time when other children have gone back to class, then one girl has to tell a colleague, 'escort me to go and keep watch for me as I do my thing.'

This kind of indignity may have prompted the girl child to stay away from school during the days when she experiencing her menstrual flow. The onset of menstruation is a landmark event in the life of any girl child and in the Kenyan communities discussions concerning menstruation were considered inappropriate, shameful and/or forbidden (McMahon, Winch, Caruso, Obure, Ogutu, Ochari, \& Rheingans, 2011). The findings from this study were consistent with previous research by McMahon, et al. (2011), which indicated that the school physical environment and in particular the sanitary facilities existing in rural schools made it difficult for a girl (female student) to manage their periods. In McMahon's study, school washrooms were not private and they lacked water. 
Lack of access to sanitary towels. Inability to access sanitary towels due to poverty was a recurring theme and was often cited as a reason for the girl child's discomfiture in schools that led some girls to stay away from schools and/or dropping out, thus marginalization. Grace stated: The girls in lower grades do better in class. But when they reach standard six, seven, and eight, they lose time, they don't come to school regularly. And I have tended to think it is because once they have matured, and have reached the age of ovulation, they now have their menstrual flow. Because the parents...the home background is poor, they are not provided with towels to take care of themselves. They shy off. And you know for a woman, the flow takes 3-4 days a month and if you calculate this, this is 4 times nine months in a school year, this will give you more than a month that a girl misses to come to school. And this makes them marginalized because they don't finish the syllabus. Grace painted a poignant picture on the number of learning days that a girl who did not have access to sanitary pads, was likely to miss, and this absenteeism directly impacted her learning. Based on the discussion in the focus groups, only four out of the 17 schools whose teachers participated in the focus groups stated that they supplied girls in their schools with sanitary towels. Two of these schools were able to provide sanitary towels through a program funded by a non-governmental organization, while the other two schools utilized Most Vulnerable Children (MVC) funds from the Ministry of Education to purchase sanitary pads for girls from very poor households. Only a select number of primary schools in Kenya received the MVC funds through a criterion determined by the ministry of education.

Child labor. In the focus groups and interviews, participants indicated that the school-age girls from poor families were more susceptible to child labor than school-age boys from similar families. In a focus group discussion, Peter stated: 
...Child labor, which comes as a result of poverty. You find that even parents encourage their young girls to be babysitters in order for them to raise some little money for the whole family to use. And as a result they make the children drop out of school. And the casualty is the girl child. Girl children, these are the people who suffer a lot...

While the kind of child labor discussed by Peter above did not fall under the International Labor Organization's description of 'hazardous labor or worst forms of labor' it did however deny the girl child full participation and attendance in schools. Babysitting meant that the girl child withdrew from school and therefore fit the ILO definition of child labor. The ILO defines child labor as:

...child labor refers to: (a) work that is mentally, physically, socially, and morally dangerous and harmful to children and interferes with their schooling by depriving them the opportunity to attend school, obliging them to leave school prematurely; or requiring them to attempt to combine school attendance with excessively long and heavy work (accessed from the ILO website at http://www.ilo.org/ipec/facts/lang--en/index.htm) The major push for this kind of labor was survival; that is the need for the girl child through persuasion or coercion of the parent to engage in babysitting so as to supplement the family income or earn money to buy food for other family members. This was different from the day-today "gender prescribed" chores.

Retention at home to provide child care. Exploitation of the girl child to provide domestic labor was another way identified by focus group participants as an impediment to uninterrupted learning of the girl child. Oftentimes, participants noted, older girls were retained at home during school days to take care of their younger siblings. For instance Sophie a focus group participant stated, "some girls are left home to take care of their younger siblings while their parents are 
away," which suggests that marginalization of girls does not start in schools, rather it starts right from home where parents retain them home at the expense of their education. This is also an indicator of the low premium attached to girl child education in some households.

Teenage pregnancy. Teenage pregnancy was another theme that emerged as participants from focus groups and interviews discussed the children they perceived as marginalized. A teenage girl attending school, who became pregnant, was cited as an example of the children who often dropped out of school thus marginalization. Chris, a participant in focus group two, stated; “...girls who have grown mature, who have indulged in sexual conduct. When they become pregnant, they automatically drop out of school." Apparent in this argument was that some girls in primary schools engaged in premature sex. This sex might be with fellow students or with adults in the communities. Exposure to sex at early ages was given as the reason for sexual promiscuity among teenage girls who came from poor families and lived in urban centers. Jessica a participant in one of the focus groups aptly observed:

I can also add on the relationships between pupils in schools especially from class six, seven, and eight, even to the extent of wanting to marry. But this one is a result of poverty for example, a child that is being brought up by one parent or both parents but they are staying in a single room (a studio or bedroom efficiency). So, you find that the children are exposed to sex early. They know a lot and this one influences them to be involved in relationships at a tender age.

Implicit in Jessica's observation was the idea that poverty; a factor that forced families to live in a single room, played a role. However, in other instances, some girls were driven to engage in sex due to their financial circumstances. Flora stated, "We have early pregnancy whereby some girls tend to go and look for money to support themselves for example buying personal items. By 
so doing they get that they have become pregnant." Teenage pregnancy was one of the major reasons why the girl child dropped out of school.

Children with special needs. Children with special needs were another group commonly identified as marginalized. From the quantitative surveys, $50 \%(\mathrm{n}=217)$ of classroom teachers identified children with low incidence disabilities as one of the categories of marginalized children in their classrooms who were at risk of missing school for more than ten days (in a three month period), low achievement, repeating grades, and/or dropping out of school. This information was corroborated by participants in the focus and one to one administrator interviews in which children with special needs were described as those who were at risk of marginalization in schools and classrooms in 36 instances. In particular, they described special needs children as slow learners, fast learners, and children with low incident disabilities. As Josiah stated, the learning needs of slow learners in schools are often ignored. He noted: ... the slow learners ... can lie under this class of marginalized students or pupils. The reason is that you find every time the teacher goes to class they try to talk good of those children who perform well. So they don't feel settled even if they are in the class. They can lie under the class of marginalized students.

Josiah's assertion clearly indicated that classroom teachers rarely paid attention to the learning needs of the slow learners. Rona who was a participant in one of the focus groups further reinforced this when she stated:

Slow learners can also be under this because in most areas they are left behind. If they are learning the same class with normal children we concentrate more on the normal children than the slow learners. Then we don't cater for them, if we have given work, we move 
along with the quick learners and the slow learners lag behind, so slow learners are also in this group as the marginalized students in our schools.

According to these participants, teachers focused their instruction on students who were on grade level or "fast learners." This focus on "fast learners" resulted in the poor academic performance of students with special needs and these students often ended up dropping out of school. Various reasons were given as to why teachers did not attend the learning needs of students with special needs; chief among them was the pressure to complete the syllabus, as well as the large teacher and pupil ratio. Bob, a participant in focus group four, defended this practice when he stated, "The government says that we are supposed to have 40 , one teacher should handle 40 pupils in a class... so, that kind of ratio is too high to cater for every child." Implicit in Bob's statement was also an example of failed inclusion in Kisii classrooms. Inclusion was required in all schools as indicated in the Kenya Education Sector Support Program - KESSP (Ministry of Education Science and Technology, 2005), and Bob's statement was an indictment of the problems facing inclusion in Kenya.

In three out of the four focus groups conducted, participants also suggested that gifted learners were also at risk for marginalization in classrooms especially when the tasks given in the classrooms were not challenging enough. Josiah, a participant in focus group one addressed this when he argued:

Likewise the quick learners can also fall suit because they go to school and then they find that the work which they are given there, they perform better, there is no challenge which they meet in school. It makes them feel...they can also fall under the class of the marginalized because they may end up performing well and then they feel that the place is not suitable to them. Some have ended up dropping out of school because of finding 
that the task they get up in school is so simple and the teachers are not able to identify

this one and then give them a task which is challenging to them

Josiah's argument was indicative of a lack of attention to students who were identified as gifted in classrooms.

Children with low incidence disabilities were mentioned as one of the groups of children vulnerable to repeating grades and dropping out of school, hence their marginalization. This can be adduced to what the participants in the focus groups referred to as a lack of expertise on the part of teachers to meet the needs of children with disabilities as well as poor referral of students with special needs to schools with special education units. The following interaction (refer table 10 below) between the researcher and Bob a participant in focus group three attested to this:

\section{Table 10:}

\section{Lack of Specialized Teachers in Special Education}

Bob: ....another case was that of...I can call it disability. So, one was impaired and in fact she dropped out of school at standard four because she could not bear...

I: You mentioned that one girl dropped out at standard four and she had a disability?

Bob: Yeah, a disability

I: Do you remember what kind of disability she had?

Bob: Yeah, I remember, in fact she was kind of mentally impaired as well as...it was both mental and physical impairments.

I: So, it was multiple?

Bob: Multiple

I: Did your school make any effort to refer that girl to a school which has special education units where she could have got specialized instruction?

Bob: I don't think or I am not aware

I: In your school do you have any teacher who is trained in special education?

Bob: No

Note: Excerpts from Focus Group 3 showing discourse between the researcher (I) and Bob about lack of specialized teachers in special education 
Based on this excerpt, it can be inferred that many schools in Kisii County did not have special education teachers and majority of regular education teachers did not have any training to handle students with special needs in their classrooms. This information supported data from the Likert - scale surveys where only $0.3 \%(\mathrm{n}=217)$ or six participants self-identified as special education teachers. Lack of enough teachers with skills to teach students with special needs was a finding that supported early findings by Bore, Mukuria, and Adera (2007), which indicated that teachers were not adequately meeting the learning needs of students with special needs. In summary, quantitative and qualitative findings of this study that children with low incidence disabilities were 'at risk' for marginalization corroborates studies by Birger and Craissati (2009), Oriedo (2003), Mukuria and Korir (2006), Bore, Mukuria, and Adera (2007), and Nkinyangi and Mbidyo (1982), all of which reported that children with special needs were still not fully accessing or fully benefitting from basic education in Kenya.

Another group of students who were identified as at risk for marginalization were children with poor health due to lack of access to quality health services and medical care. This situation is compounded when such children had HIV related illnesses. Sophie, a focus group participant, reaffirms this when she stated:

We also have those children who are HIV positive... whose parents are either alive or their parents have died, sometimes they get sick and they have to be away. So, once they get sick for a long time, they drop out of school. Like I have one in standard six, this year she has been away for about three months.

Sophie's excerpt brings forth the idea that some children stay away from school for considerable lengths during the school year due to health related issues. These children eventually drop out of school, hence their marginalization. 
Children from single parent families. Children from single parent families were also identified as a group of students who might be marginalized. Teachers suggested that these children, based on the activities in class and labeling, felt alienated. For instance, Josiah a participant from focus group one alluded to this when he stated:

...marginalized students here are pupils those who have come from single parents families. When children come to school and then they happen to find that others are mentioning about their fathers, others don't even have their fathers that they end up writing the name of the grandfather. These pupils don't feel well. They feel as if they are staying in an environment which is not conducive to them. Sometimes they are ashamed to say their father.

While Josiah made an observation on how peers view these students, Jessica provided an example of classroom activities that alienated these pupils. She stated:

...in some cases, there are children who are brought up by only one parent especially the mother. I can call them the marginalized because when other children are talking about 'my dad', 'my dad', and when especially others know...because I remember there was a case I gave a class a composition to write about "my father", I realized I had made a mistake. 'Kumbe ${ }^{20}$ some don't have fathers. It was so painful they had nothing to write. Others were laughing at them, 'what are you going to write, are you going to write about your uncle?' So, it was painful.

Jessica's example did not state the impact of having single parents, but it put forth some of the issues that these pupils encountered as they got an education. Moreover, this example highlighted the insensitivity of teachers or this practice was not consistent with critical pedagogy which emphasizes culturally relevant teaching.

\footnotetext{
${ }^{20}$ Kumbe is a Swahili word used as an exclamation after somebody has come to a realization of something.
} 


\section{Summary}

It can be summarized that evidence from quantitative and qualitative data of this study suggested that teachers in Kisii County perceived the following categories of students as being at risk for marginalization in their classrooms and/or schools: a) orphans, b) children with low incidence disabilities, c) children from extremely poor families and/or children engaged in child labor, d) the girl child, e) children from single parent households, f) children of negligent parents, g) children with poor health, and g) the homeless child. The focus groups and one to one interviews offered a deeper explanation of the potential triggers of marginalization to include a) poverty, b) teenage pregnancy, and c) unsafe school environments.

\section{Research Question \# 3: How Do Teacher Practices Influence Retention of Marginalized Students?}

After administration of the survey and reviewing the results, data generated did not adequately address the gist of the third question of this research, which is retention. However, analysis of the survey data and qualitative data yielded results on various teacher practices in schools that potentially influenced retention of marginalized students. These practices included professional development activities and instructional practices within the classrooms aimed creating inclusive learning environments where all students felt welcomed and valued.

Professional development. Teacher professional development was reported by participants in the surveys and focus groups as one of the activities that teachers had engaged in as they strived to better meet the needs of diverse learners in their classrooms. The section that follows presents information regarding various teacher professional development activities as reported in quantitative and qualitative data. 
Quantitative data. Items 57, 58, and 59 of the teacher survey instrument (see Appendix D), focused on professional development of teachers and required teachers to self-report all the types and purposes of professional development activities they had attended over a ten-year period. Item 57 (see Appendix D) which specifically required them indicate whether they had received any specialized training to work with marginalized students, and garnered $83.4 \%$ $(n=181)$ response rate. From these responses, only $40.9 \%(n=74)$, indicated that they had received specialized training to work with marginalized students while, $59.1 \%(\mathrm{n}=107)$ said they had not received any training at all. There were 36 teachers who did not respond to this item.

On the other hand, 156 survey respondents indicated that they had attended or participated in professional development activities in form of a seminar, a workshop, in-service training or taken a college course. Out of these, $73.1 \%(n=114)$ indicated that they had participated in only one format of a professional development activity while those who had attended two formats of professional development activities comprised $13.4 \%(\mathrm{n}=21)$. The respondents who indicated they had attended a combination of three or four formats of professional development activities were $10.3 \%(\mathrm{n}=16)$ and $3.2 \%(\mathrm{n}=5)$ respectively. The table 11 below shows the choice of professional development activities in which teachers had participated in the last ten years.

\section{Table 11:}

Choice of Professional Development Activities

\begin{tabular}{lll}
\hline $\begin{array}{l}\text { Format of professional } \\
\text { development }\end{array}$ & Number of attendance & Percentage (\%) \\
\hline Seminar & 81 & 37.3
\end{tabular}


Workshop

College Course

In-service Training
22.6

29.0

11.1

From table 11 it can be deduced that seminar format of professional development had the highest frequency of $37.3 \%(n=81)$. Only $11.1 \%(n=24)$ teachers identified that they participated in professional development that was an in-service training format. There were 61 teachers who did not indicate or respond to whether they had participated in professional development within one year. This accounted for about $28.1 \%$ of the total respondents.

Item 59 of the survey protocol (see Appendix D) required participants to self-report the title and purpose of professional development activities they had attended within the past 10 years that focused on skills of teaching marginalized students. Analysis of these written responses revealed nine distinct categories of purposes of professional development activities attended by participants:

(a) Children with special needs

(b) Gender/vulnerable children

(c) HIV and AIDS

(d) Content area

(e) Instructional strategies

(f) Guidance and counseling

(g) College course,

(h) Early childhood education

(i) Orphans 
Table 12 below shows the frequency to which teachers identified each category above and examples of titles of their professional development activities.

\section{Table 12:}

Categories of Various Professional Development Activities that Teachers had Participated in the Past 10 Years

\begin{tabular}{|c|c|c|}
\hline $\begin{array}{l}\text { Titles of professional } \\
\text { development }\end{array}$ & $\begin{array}{l}\text { Example of purpose of the professional } \\
\text { development activity }\end{array}$ & Frequency \\
\hline Children with special needs & $\begin{array}{l}\text { "for the purpose of assisting learners with } \\
\text { diversified disabilities and needs" }\end{array}$ & 49 \\
\hline Vulnerable children & "to cater for the most vulnerable children" & 23 \\
\hline HIV/AIDS & $\begin{array}{l}\text { "Seminar on HIV/AIDS on how to handle } \\
\text { the children who have been affected and } \\
\text { infected in primary schools" }\end{array}$ & 20 \\
\hline Content area & $\begin{array}{l}\text { "Key resource teacher (KRT) science } \\
\text { improvement" }\end{array}$ & 13 \\
\hline Instructional strategies & $\begin{array}{l}\text { "I attended a seminar for disseminating new } \\
\text { teaching skills" }\end{array}$ & 11 \\
\hline Guidance and counseling & $\begin{array}{l}\text { "guidance and counseling on teaching and } \\
\text { handling of students with different } \\
\text { difficulties" }\end{array}$ & 11 \\
\hline College course & "Special Needs Education degree training" & 9 \\
\hline Early childhood education & $\begin{array}{l}\text { "To understand children in early } \\
\text { development and attend them as } \\
\text { individuals" }\end{array}$ & 7 \\
\hline Orphans & $\begin{array}{l}\text { "to help us understand on how to handle and } \\
\text { give psychological help to orphaned } \\
\text { children" }\end{array}$ & 5 \\
\hline
\end{tabular}

Note: This table contains a summary of responses garnered from the survey (see Appendix D) administered to 217 teachers from 28 schools. Item 58 of this survey required participants to self 
-report the professional development activities they had attended in regard to teaching marginalized students in the past 10 years. Item 59 of the survey required the participants to state the topics/focus of the attended professional development activities.

Evident from table 12 is that professional development activities that focused on children with special needs, vulnerable children, as well as HIV and AIDS, were identified by a modest number of teachers. Though $100 \%(n=30)$ of participants in the focus groups interviews and $77 \%$ $(\mathrm{n}=217)$ of survey participants indicated having orphans in their classrooms, professional development activities attended by teachers with a focus on issues related to orphans was the least identified professional development activity.

Qualitative data. From the focus groups and administrator interviews, all participants reported to have attended at least one professional development activity with 9 out of 30 participants indicating that they had attended a seminar related to HIV and AIDs. However participants reported most of the professional development activities attended was self-funded. Peter, a focus group participant notes:

Another thing that our teachers have mentioned is lack of technical expertise to teach marginalized students. We are lacking that and the government does not seem to set aside monies to train teachers...if a teacher comes out to train, you only come out to do it from your own pocket. So, you find that only a few teachers manage to attend professional development activities and they are too few to handle this big number (of marginalized students).

Peter's excerpt provides evidence of lack of funding for teacher professional development activities. On the other hand, participants noted that the FPE sent to schools for 
professional development activities were either misappropriated or diverted into other uses by the school administration. For instance Gideon, a focus group participant argues,

In our Free Primary Education allotment, we have got what we call quality assurance which I think if we had serious school managers - the administrations - they would come together and organize insets within the school or with neighborhood schools, invite resource persons to come and pass some information...but unfortunately it (the money) goes to the wrong direction.

Gideon illuminates one of the challenges that face FPE which is mismanagement of funds by school administrators.

Instructional practices within the classrooms. From the quantitative data collected through the teacher survey (see Appendix D) participants reported the various instructional practices they carried out in their classrooms with regard to teaching marginalized students. One such practice was providing various accommodations to at risk students, as a way of catering for their diverse learning needs. The accommodations given depended upon the student's special needs and learning needs. In part II, section two of the survey (see Appendix D), participants self-reported the frequency with which they provided accommodations in their classrooms as displayed in table 13 below. 
Table 13:

Frequency with Which Teachers Provided Various Accommodations in Their Classrooms

\begin{tabular}{|c|c|c|c|c|c|}
\hline Accommodations & Never & Rarely & Sometimes & $\begin{array}{l}\text { Almost } \\
\text { always }\end{array}$ & Always \\
\hline Extended test taking $(n=208)$ & $2 \%$ & $19 \%$ & $38 \%$ & $26 \%$ & $15 \%$ \\
\hline Use of guided notes $(n=208)$ & $3 \%$ & $18 \%$ & $23 \%$ & $35 \%$ & $21 \%$ \\
\hline Provision of written notes $(\mathrm{n}=207)$ & $4 \%$ & $10 \%$ & $11 \%$ & $34 \%$ & $41 \%$ \\
\hline Modified tests $(\mathrm{n}=208)$ & $8 \%$ & $13 \%$ & $37 \%$ & $24 \%$ & $18 \%$ \\
\hline Excused absences $(n=202)$ & $3 \%$ & $28 \%$ & $38 \%$ & $17 \%$ & $14 \%$ \\
\hline $\begin{array}{l}\text { Administering verbal tests in place } \\
\text { of written tests }(n=204)\end{array}$ & $12 \%$ & $27 \%$ & $34 \%$ & $16 \%$ & $11 \%$ \\
\hline $\begin{array}{l}\text { Administering shortened tests } \\
(\mathrm{n}=204)\end{array}$ & $6 \%$ & $17 \%$ & $38 \%$ & $24 \%$ & $15 \%$ \\
\hline $\begin{array}{l}\text { Providing a quiet room for testing } \\
(\mathrm{n}=206)\end{array}$ & $5 \%$ & $15 \%$ & $17 \%$ & $17 \%$ & $46 \%$ \\
\hline
\end{tabular}

Table 13 above provided evidence that $60 \%$ of teachers were 'sometimes' to 'always' providing accommodations in the categories listed above. In particular, $75 \%(n=207)$ of teachers self-reported in the category of 'almost always' to 'always' as having accommodated marginalized students by providing them with written lesson notes. Also $63 \%(n=206)$ of teachers were provided a quiet room for testing, and while $56 \%(\mathrm{n}=208)$ self-reported to have given guided notes to marginalized students as a form of accommodation in their classrooms.

Qualitative data. The findings from the quantitative data were supported by focus group and one to one interviews. All focus group participants $(100 \%, \mathrm{n}=30)$ acknowledged providing accommodations for their students as needed. For instance, Bob a participant in the focus groups in response to a probing question as to whether provided extended time for test taking to marginalized students stated: 
We do, those papers (exams) that we have, we try to give them when they go home...they do those problems and then the following day the come, they tell us where they found a problem and then we solve it

The above excerpt provided evidence for how this particular participant accommodated his student with regard to school based examinations.

Beside the specific accommodations, inductive analysis of focus groups and administrator interview transcripts resulted in the following themes of instructional and school practices that specifically targeted the marginalized students. These were a) teacher care, b) remedial teaching, and c) guidance and counseling.

Teacher care. The theme teacher care in this study referred to voluntary acts of kindness or practices of displaying compassion for 'at risk' students, extending financial as well as material help to 'at risk' students in their areas of need, and advocating for 'at risk' students. In the four focus groups and three administrator interviews, teacher care was mentioned and/or discussed 31 times. The dominant example of teacher care was extending financial as well as material help to 'at risk students' and it was mentioned by participants 22 times. On the other hand advocating for at risk students was mentioned only twice, while display of compassion was given as an example seven times.

Extending financial as well as material help to 'at risk' students, involved voluntary acts such as purchasing a school uniform for a needy student, sharing lunch with a child from an impoverished household, and paying the extra fees required by schools. For instance, Vin stated: We realize as per the class where they are learning, these teachers know them ('at risk' students), whenever they realize or know that this kid he or she didn't take breakfast, that teacher takes the initiative of buying a glass of tea and one mandazi (biscuit) so that the 
kid can keep learning for that day. Others have gone to the extent of providing uh...soap

to have them wash their uniforms back at home so that they can come to school clean... Implicit in the above excerpt is that some individual teachers in their own classrooms who were benevolent, took the initiative to purchase breakfast for a student when they realized that such a student was hungry due to lack of food in his/her home. While the voluntary act of kindness was noble, it was not clear whether it happened regularly. It can also be argued that there is a need for organized and publicly funded school feeding programs in Kenyan public day primary schools to offer guaranteed meals for children from impoverished households.

Display of compassion for 'at risk' students was another element of teacher care that was given as an example by focus group participants. Similar to extending financial and material help to 'at risk' students, displays of compassion as teacher care was voluntary. Compassion was displayed through attending funerals to console students whenever they were bereaved and through home visits. The following conversation (see Table 14 below) took place between Leah (a focus group participant) and me (researcher) on home visits as an example of teacher care.

\section{Table 14}

\section{Home Visits as an Example of Teacher Care}

Leah: ...we also need to listen to these children. Also we should love them. Sometimes we visit them at their homes to see how they are staying living. Also when they miss school, we should go seeking them.

Me: Leah, you said that whenever they miss school you make home visits. Can you give us examples of how many such visits you have made in the past year?

Leah: In my class, which is class 4, I have tried to visit their homes. They are around three pupils...in the homes I found out that the father died, so the mother made 
them stay home in order to finish house chores.

Me: Was that one child or three children?

Leah: Two children. The other child comes from a family where he is left alone, an orphan, a total orphan. He has nobody to care for him, so I brought him to school.

Me: Does he now regularly come to school?

Leah: Yes. I started paying for him when he was in class one, even buying him uniform, visiting his home, maybe sometimes helping him in the planting of maize. So, I took a position of a guardian over him.

The conversation above between Leah and me (the researcher) demonstrated how some teachers voluntarily went above and beyond their regular classroom and/or school duties to establish connections with 'at risk' students, thereby ensuring that these students continued to come to school. Taking responsibility for learners' welfare (social and financial) as demonstrated by Leah in the above conversation was supported by Vogt's (2002) assertion that primary school teachers embraced caring as an integral part of their teaching. In this respect, caring was a disposition adopted by these teachers but shaped by 'at risk' students' needs and conditions.

Remedial teaching. Remedial teaching was another practice discussed by participants in focus groups and interviews carried out by teachers in schools as a support to the learning of at risk students in schools. The remedial teaching was carried out in the mornings in what participants called 'morning prep' or after school. Philip, a participant in one of the focus groups stated:

I can say that remedial teaching is just for an individual teacher to arrange on how to assist those learners because the stipulated timetable does not guarantee to go to details 
on how to assist slow learners...therefore we tend to assist them especially during the morning hours, we tell them to come early. Some people (teachers) have gone to the extent of being able to call them to come to school on Sunday afternoon so that they can continue assisting them to reach the standards of others.

From the above excerpt, Philip describes the lengths to which some teachers in his school go to assist what he calls as slow learners. This includes remedial teaching before regular classes begin usually in the morning, and at times on Sunday afternoons.

Guidance and counseling. Guidance and counseling was identified by participants in focus groups and interviews as a practice geared towards addressing the social and emotional needs of 'at risk' students in their schools. In all the 28 schools whose teachers participated in this research, there was no trained counselor or psychologist, rather counseling was conducted by teachers who either attended a seminar on counseling or none at all. Both individual and group counseling was conducted. For instance, Jennifer, a participant in one of the focus groups stated:

We invite Non-Governmental Organizations to come and have some seminars with those pupils especially when they are in standard seven or eight...they address the issue of HIV/AIDS. They also give guidance and counseling to orphans and others who are in need.

As per the above excerpt, one area that was addressed through group counseling and seminars was on HIV and AIDS. This was important due to high number of orphans whose parents had died due to HIV and AIDS.

\section{Summary}

While the data collected did not address the gist of this research question which was retention, it did provide important information regarding teacher practices within and outside 
classrooms that could affect retention. These practices included, a) attending professional development activities geared towards best practices for marginalized students, b) providing various instructional accommodations for marginalized students in classrooms, c) teacher care, d) remedial teaching, and e) guidance and counseling.

\section{Research Question \# 4: To What Extent Do Teacher Beliefs Influence their Desire to Differentiate Instruction for Marginalized Students}

Findings from quantitative data. The Spearman's Rho of correlation analysis was done to determine the relationship between Teacher Philosophies (TP) and Teacher Willingness to Differentiate Instruction (TWDI), to give Accommodations, as well as to Vary Instructional Materials while teaching marginalized students in inclusive classroom settings. The Spearman Rho was chosen instead of the Pearson's correlation coefficient since the data violated the assumptions that it should be normally distributed. The Shapiro-Wilk test of normality indicated a p value of less than .05 in all sub-scales (teaching philosophy, differentiated instruction, teaching materials, and accommodations sub-scales) thus resulting in a rejection of the hypothesis that the data was normally distributed. See table 15 below

Table 15:

Test of Normality

Tests of Normality

\begin{tabular}{|c|c|c|c|}
\hline & \multicolumn{3}{|c|}{ Shapiro-Wilk } \\
\hline & & \multicolumn{2}{|c|}{ Statistic } \\
\hline Teaching Philosophy & .978 & 208 & .002 \\
\hline Differentiated Instruction & .981 & 208 & .007 \\
\hline Teaching Materials & .937 & 208 & .000 \\
\hline Accommodations & .986 & 208 & .038 \\
\hline
\end{tabular}


A Spearman Rho correlation analysis, which is a non-parametric test was conducted to determine the relationship between: a) teacher philosophies and teachers' willingness to differentiate instruction for marginalized students; b) teacher philosophies and teacher willingness to use a variety of teaching materials in their classrooms; c) teacher philosophies and teacher willingness to give various accommodations to marginalized students; d) differentiated instruction and use of a variety of teaching materials; e) differentiated instruction and teacher willingness to give various accommodations to marginalized students; and f) use of teaching materials and teacher willingness to give various accommodations to marginalized students. The descriptive data for teaching philosophy, differentiated instruction, teaching materials, and accommodations is shown in table 16 below.

Table 16:

Descriptive Statistics for Teaching Philosophy, Differentiated Instruction, Teaching Materials, and Accommodations subscales

\section{Descriptive Statistics}

\begin{tabular}{lrrrrr}
\hline \hline & N & Minimum & Maximum & Mean & Std. Deviation \\
\hline Teaching Philosophy & 211 & 2.38 & 5.00 & 4.0513 & .55819 \\
Differentiated Instruction & 209 & 2.22 & 5.00 & 3.6369 & .65217 \\
Teaching Materials & 210 & 2.00 & 5.00 & 4.2103 & .54492 \\
Accommodations & 209 & 1.00 & 5.00 & 3.4018 & .71571 \\
Valid N (listwise) & 208 & & & & \\
\hline \hline
\end{tabular}

Table 16 indicates that a total of 208 cases were the only ones that were valid in all the variables. In teaching philosophy, the mean was 4.05 , while the standard deviation was 0.56 . In regard to differentiated instruction, the mean was 3.6 while the standard deviation was 0.65 . The teaching materials variable had a mean of 4.2 with a standard deviation of 0.5 . Lastly, the accommodations variable had a mean of 3.4 with a standard deviation of 0.72 . 
The Spearman Rho correlation analysis yielded results that are displayed in table 17 below. The analysis only considered participants who provided responses in all parts of section two of the survey instrument (see Appendix D). Table 17 below displays results on the correlation coefficients between teaching philosophy, differentiated instruction, teaching materials, and accommodations.

\section{Table 17:}

Correlation Coefficient between Teaching Philosophy, Differentiated Instruction, Teaching Materials, and Accommodations

\begin{tabular}{|c|c|c|c|c|}
\hline & & \multicolumn{3}{|l|}{ Correlations@ } \\
\hline & & & Teaching Philosophy & $\begin{array}{l}\text { Differentiated } \\
\text { Instruction }\end{array}$ \\
\hline \multirow{8}{*}{ Spearman's rho } & Teaching Philosophy & Correlation Coefficient & 1.000 & $.430^{*}$ \\
\hline & & Sig. (2-tailed) & & .000 \\
\hline & Differentiated Instruction & Correlation Coefficient & $.430^{*}$ & 1.000 \\
\hline & & Sig. (2-tailed) & .000 & \\
\hline & Teaching Materials & Correlation Coefficient & $.147^{*}$ & $.415^{*}$ \\
\hline & & Sig. (2-tailed) & .034 & .000 \\
\hline & Accommodations & Correlation Coefficient & $.342^{*}$ & $.386^{*}$ \\
\hline & & Sig. (2-tailed) & .000 & .000 \\
\hline
\end{tabular}

*. Correlation is significant at the 0.05 level (2-tailed).

c. Listwise $\mathrm{N}=208$

Table 17 above indicated that there was a significant correlation between teaching philosophies and teachers' willingness to differentiate instruction for marginalized students $\left(r_{s}=\right.$ $0.43, p<0.05)$. This correlation coefficient implied that about $43 \%$ of differentiation efforts of product, process, and content were influenced by the beliefs/philosophies espoused by teachers. On the other hand, there was a significant correlation teacher philosophies and their willingness to use a variety of teaching materials while in teaching marginalized students $\left(r_{s}=0.15, p<0.05\right)$. Though the correlation coefficient was weak, it implied that about $15 \%$ of teaching materials used in the classroom are influenced by a teacher's philosophies. 
Similarly, correlation analysis indicated a significant relationship between teachers' philosophies and their willingness to give various accommodations to marginalized students in their classrooms $\left(r_{s}=0.34, p<0.05\right)$. This correlation coefficient shows that about $34 \%$ of teachers who offered accommodations to marginalized students were partly influenced by their beliefs.

On teaching materials and Differentiated Instruction, there was a significant correlation $\left(r_{s}=0.42, p<0.05\right)$. This showed that the use of a variety of teaching materials in the classrooms, $42 \%$ these materials could be influenced by a teacher's willingness to differentiate instruction for his learners. Differentiating Instruction requires that content, process, and product be differentiated. Content differentiation, includes the use of a variety of instructional materials, therefore it would be expected that teachers who differentiate would have scored higher in the teaching materials subscale. Moreover, there was a significant correlation between differentiating instruction and accommodations subscales $\left(r_{s}=0.39, p<0.05\right)$. This implied that about $39 \%$ of various accommodations given by teachers to marginalized students were influenced by teacher's willingness to differentiate instruction for these students.

Similarly, there was a significant correlation between teaching materials subscale and accommodations subscale $\left(r_{s}=0.43, p<0.05\right)$ (see table 18 below). This implied that about $43 \%$ of teachers who self-rated highly on the teaching materials subscale, also self-rated highly on the accommodations subscale. 
Table 18:

Spearman's Correlation Coefficient Between Teaching Materials and Teacher Willingness to Provide Accommodations to Marginalized Students in their Classrooms

Teaching Materials Accommodations

\begin{tabular}{llll}
\hline Spearman's rho & Accommodations & Correlation Coefficient & $.429 *$ \\
& Sig. (2-tailed) & .000 & .000 \\
\hline
\end{tabular}

*. Correlation is significant at the 0.05 level (2-tailed).

c. Listwise $\mathrm{N}=208$

\section{Summary}

Spearman's correlation analysis of teacher beliefs, differentiated instruction, use of teaching materials, and accommodations, revealed that there was a moderate to weak positive correlations. Specifically the moderate correlation between teacher philosophies and their willingness to differentiate instruction (content, process, and product) for the marginalized students suggested the need for reconceptualized teacher mindsets that encourage practices designed to meet the needs of diverse students in inclusive classrooms. Teaching all students for success demands teachers who are not only trained, but also who are willing to assist these students to succeed.

\section{Factors that Contribute to Marginalization}

Horace Mann, an American common school crusader and strong proponent of free schools which are not based in fees, once quipped in metaphorical terms that "education, then, beyond all other devices of human origin, is the great equalizer of conditions of men - the balance wheel of the social machinery" (Horace Mann (1848), Twelfth Annual Report, in Urban, 
W. J., \& Wagoner Jr., J. L. (2004), p. 103). In this metaphor, the goal of schools is to foster public good and prepare students to become productive members of society. In the present day Kenya and Kisii County in particular, the notion of schools as institutions that foster public good and prepare individuals to become productive members of society is contestable as suggested by the evidence from this study. For schools, the ideal is to provide free, equitable, and quality educational experiences to all children, but the reality in Kisii County schools reflects a different picture. In this reality, there still exist societal, school, and individual roadblocks to universal access to education. These roadblocks, which continue to reinforce and perpetuate marginalization of students, were key findings in this research.

Based on the qualitative findings (interviews and focus groups interviews), it is evident that there are three broad factors that contribute to the continued marginalization of students from vulnerable groups in society thus reinforcing this viscous cycle of marginalization. These are a) individual factors, b) school factors, and c) societal factors.

\section{Individual factors}

In this study, the coded segments of data categorized as individual factors were primarily innate characteristics of an individual which included gender and disability. Based on the administrator interviews and focus groups interviews, there was evidence suggesting that classroom teachers and school administrators perceived the girl child from poor families and a child with low incidence disability as categories of students who were 'at risk' for repeating grades, having low attendance, low achievement and dropping out of school. The data appeared to indicate that disability (low incidence disabilities such as deaf and mental retardation) and gender predisposed individual children for marginalization. For the purposes of this study, these were referred to or grouped as individual factors 
Similarly, the issues related to poverty compounded the marginalization of the girl child, more so when they lacked access to sanitary pads. In all five focus groups, and three principal interviews, there was evidence suggesting that the girl child who had no access to sanitary pads was likely to miss school and hence had poor attendance during the menstruation period. In all 14 schools whose teachers participated in the focus groups interviews and the three schools whose principals participated in one to one interviews, only two of the schools had a program for supplying sanitary pads supported by non-governmental organizations (NGO) to the girl child. The remainder of the schools did not have any program supporting girls who had no access to sanitary pads.

In the focus groups and interviews, ninety percent of the participants indicated that orphans in their respective schools were those whose parents have died from HIV and AIDS. The resultant effect of this situation was that some students who were orphans dropped out of school to take care of their younger siblings or ailing parents. This assertion was also reinforced by the quantitative data (survey data) in which $96 \%(\mathrm{n}=175)$ of participants indicated having orphans in their classrooms who were at risk for dropping out of school, repeating grades, and having a low achievement in terms of performance.

In conclusion, it can be argued that marginalized students came to schools with individual factors and/or conditions which handicap full access to basic education. This demands concerted action by schools and the government which should involve establishing conditions and educational practices that will ensure continued and full access to basic education for marginalized students. 


\section{School factors}

The data from this study indicated that there were school factors as well as practices reinforcing and perpetuating marginalization of 'at risk students'. The school factors and/or practices include: a) extra levies charged by schools; b) teaching practices which precluded slow learners as well as those in difficult circumstances from fully benefitting from instruction; c) emphasis on examinations; d) forced repetition; e) labeling; f) failure by teachers to understand how to handle students with special needs in their classrooms; and g) unsafe school environments for the girl child.

From the quantitative survey data, $92 \%(n=206)$ of the teachers reported that Free Primary Education initiative had led to reduction in the costs of education borne by parents. In spite of this, evidence from focus groups and one to one interviews indicated that schools continued to levy extra fees in form of extra curricula activity fees, local examination fees, development fees, and extra tuition fees, among others. These fees and/or levies, participants said, were a burden to children from poor families whose parents or guardians were unable to pay. This meant that children from poor households were oftentimes told to stay away from school until such a time as the fees were paid. The participants indicated that some of these children ended up achieving low grades, repeating grades, and/or dropping out of school altogether.

The requirement for all school children to wear school uniforms was another financial burden discussed by participants as a stressor to children from poor families. For instance, a child from a very poor family, was likely to have no proper school attire or have ill fitting, tattered clothing which exacerbated this child's low self esteem, as well as likelihood of being singled out by other children in the school. For instance, Charles, a participant in focus group 2 
stated: "sometimes these (girls) if they come from poor families, maybe in the manner of dressing, they may become shy because they don't have good dresses especially uniforms. So, they feel shy and drop out of school." Surprisingly, with widespread poverty in the region, only $27 \%(\mathrm{n}=11)$ of schools whose teachers participated in focus group interviews had funding for the Most Vulnerable Children (MVC). The Most Vulnerable Children (MVC) fund, is a government sponsored program which sent monies to schools on a selective basis to purchase basic items such as school uniforms for vulnerable children, who included orphans from extremely poor household and provided sanitary pads for girls from extremely poor families. The low number of schools receiving MVC fund suggested two things: one, school administrators were not applying to secure these funds for their schools; and two, school administrators were not aware of the needs of 'at risk' students within their schools.

Based on the focus group interviews there was evidence to suggest that some teacher practices were precluding vulnerable children from gainfully benefiting from education. These practices included: a) instruction which focused only on the average learners and therefore excluded the slow learners in classrooms, b) labeling, c) teacher perceptions of students that were negative, and d) forced repetition.

In the surveys as well as interviews, participants indicated having a high teacher-pupil ratio in their schools made it difficult to attend to diverse student needs. This meant the diverse challenging needs of students with disabilities, slow learners, overage students, orphans, and children from extremely poor families often went unattended. For instance Alfred, a participant in focus group two argued:

With the introduction of Free Primary Education, we have so many children who now have access to education but the number of teachers is small. So, the ratio (teacher-pupil 
ratio) becomes a problem that even as a teacher you are not able to give individual attention to the deserving children...So, we end up leaving the slow learners and the very fast learners, so we end up concentrating in the middle

This argument by Alfred was corroborated by evidence from the quantitative survey which indicated the average teacher-pupil ratio was 1:39 (one teacher to thirty nine students). The pressure to complete the required curriculum within the academic year exacerbated this situation. As Daniel, a participant in focus group 4 stated, "we need to complete the syllabus within the stipulated time...so, we teach them as equals, those who are clever and those who are weak in class. We don't go back to give them remedial teaching, because there is no time." Both Alfred and Daniel underscored one main challenge facing Free Primary Education, which is a high teacher-pupil ratio in Kisii schools.

In addition to the pressure to complete the required syllabus and curriculum objectives, Kenyan education system's emphasis on examinations and the use of exams as the only measure of student achievement and/or learning has meant that teachers are less reluctant to address the diverse learning needs of special needs children in their classrooms. As a result, 'at risk' children have formed the bulk of students who are low achievers and/or who drop out of schools. For instance, Bob, a participant in one of the focus groups described how forced repetition of students who do make the grade contributed to the student's decision to drop out of school. He stated,

“...so one was (mentally) impaired...I considered that case and in fact she dropped out of school at standard four because she could not bear. So, generally we can say that the main reason for dropouts in our school is repetition." 
From the above excerpt, forced repetition, which mostly affected low achievers and students with low incidence disabilities was a major reason cited by teachers as to why such students dropped out, hence more marginalization. This finding was supported by the research of Ackers, Migoli, and Nzomo (2001) which indicated that most graded repetition occurred between grades 2 and 3, as well as between grade 6 and 7. From the focus groups, as well as the interviews, there was evidence that repetition caused frustration for learners who eventually dropped out of schools. In the quest to post good school averages in the national examination, participants discussed a practice of recommending students to repeat grades despite student wishes. Implied in these repetitions are that students who did not perform well were retained.

Another school factor that was identified as contributing to the marginalization of 'at risk' students was stereotyping. From the focus groups, the language used by some participants reinforced the idea of stereotyping. For instance Daniel, a focus group participant argued: ...we have perceived others as slow learners...we classify them as that...slow learners and we have others who are ...we call them dwarfs, so that now as you teach you find that they are non-performers. So, you tend to sideline them and you go with those who are at least responding in class performance. So, these others we, just see them...we view them as academic dwarfs. So you see we tend to marginalize these others. We don't want to attend to them, but we attend to those who eh...who are at least as we can call...who are geniuses as we can call them...we view them (slow learners) as marginalized because, basically we don't attend to them satisfactorily. Though we have remedial work, which is supposed to be offered, there is no time for that

The above excerpt was an example of a stereotype in which the teacher labeled students who underperformed in the classrooms as 'academic dwarfs'. In this stereotype, Daniel, a classroom 
teacher assumed that the failure of a child to thrive intellectually was due to the deficit in the child rather than a deficit in teaching as well as deficits in the learning environment, and hence he had low expectations for this student. Perhaps more troubling was that the other group participants in Daniel's group made no attempt to correct him, thereby implying that these labels were acceptable and commonplace in their schools.

In addition, when teachers harbored unexamined prejudices about children from poor families or those with special needs, this affected the way they taught students and interacted with these students. For instance, Nick, a participant in focus group one stated, "I also add on teacher negative attitudes towards (students). You find that some teachers when they are in class they use abusive language. (Like) 'You can't make it, you are like your father.' In this quote, there was an element of determinism since Nick assumed student failure was already predetermined by his parent's failure. A comment like this likely made a student feel undervalued and alienated. Moreover, the student may avoid and/or run away from such a teacher's class or lesson, which would interfere with the learning of such a student.

The inclusion policy in most recent Kenyan Education policy related documents, in particular KESSP, has seen an influx of students with diverse needs into regular classrooms. From the qualitative data, there was evidence suggesting that regular education teachers were not well equipped (trained) to handle students with special needs in classrooms. On the other hand, from the quantitative survey, $17 \%(\mathrm{n}=217)$ of participants identified themselves as itinerant or special education teacher designees in 19 out of the 28 schools whose teachers participated in the survey. The low percentage of teachers in Kisii schools with skills to handle special needs students was evidence that these students have been left out of benefitting from education. Hence there is need to train more teachers in this field as well as provide in-service practicing teachers 
with professional development so that they can effectively teach special needs children in their classrooms.

Participants in the focus groups and interviews discussed lack of adequate facilities such as toilets and/or washrooms as a factor that made school environments unsafe. In these discussions and interviews, they noted that lack of adequate facilities was exacerbated by the poor quality of existing facilities. For instance, participants from three schools stated that student toilets in their schools did not have doors thereby threatening the privacy of the girl child. While this was discussed in focus groups and interviews, it did bring to the fore the need to ensure that all schools have adequate amenities to serve all students. Regarding the condition of school buildings, notes taken while delivering surveys to twenty eight schools whose teachers participated in the quantitative phase of this study, indicated that $71 \%(\mathrm{n}=28)$ of these schools had classrooms which were not wheelchair accessible. Out of these schools that were not wheelchair accessible, eight of them were built on unleveled slopes of hills, therefore they had steep inclinations. These slopes effectively made them inaccessible to wheelchair bound children.

\section{Societal factors}

In this study poverty, cultural practices, and policy were grouped as the societal factors that teachers perceived as influencing the marginalization of students. Poverty was identified by the five focus groups interviews as well as three administrator interviews as a factor that was manifested in child labor and lack of basic needs. In particular, participants noted that some students in their classrooms came to school hungry due to their parents' inability to purchase food for them. For such students, their learning and school participation was affected. 
Evidence from the focus groups and interviews also suggested that teachers ascribed to the notion that schools must save the children from their communities rather than work with the communities towards excellence and learning of the children. For instance, some teachers attributed the problem of poor academic performance in schools to alcoholism, community apathy towards benefits of learning, parental neglect, and lack of role models in villages and/or communities where the students came from. For example, Patrick, a focus group participant stated:

Now in my school the main problem that is actually causing dropouts is that we are lacking role models. You find that most of these parents are actually dropouts who actually don't know the importance of education. So they don't advise their children to go to school. So, even if they are called to school to be sensitized on the importance of education, they don't come because they don't see the need and therefore their children don't also see the need of coming to school.

From the above excerpt, it can also be inferred that schools viewed the problem of students dropping out of school as purely a community problem and not a school problem. In other instances, community apathy towards the economic returns of basic education contributed to student dropout. For example, Kevin, a participant in one of the focus groups stated:

...we have seen some students drop out of school because from their home backgrounds they have seen people who have gone to school... may be up to the level of form four $\left(12^{\text {th }}\right.$ grade) and then they have not achieved much. I say that because when we tried to get these pupils, some of them back to school, they even mentioned that, that 'such and such a person has gone up to this level and he has done nothing.' 
In the above excerpt, Kevin alludes to that value of education as per the community, is measured in terms of its economic returns to the individual. This community misunderstanding of the intangibles of basic education is a major hindrance to access to education for school age children. Perhaps what disconcerting is that Kevin did not mention any measures taken by the school to deliberately reach out to the community and work in concert with the community in ensuring that all school age children not only enroll, but also continue coming to school.

In terms of policy, it was apparent that the realities of children from extremely poor families were not recognized in the existing documents. Other than the proclamation for Free Primary Education, which outlined the policy's objectives, participants indicated that they were no guidelines given to schools to guide the implementation of this policy. The quantitative data from the survey indicated that only $81 \%(\mathrm{n}=175)$ of the survey respondents indicated that they were aware of Free Primary Education Objectives while 5\% $(n=11)$ of these respondents self reported that they were not aware of the Free Primary Education Objectives.

In summary, there was a consensus on the idea that schools were uniquely positioned to achieve the Free Primary Education objectives, Education for All goals, Millennium Development Goals, and fulfill mandates of the Kenyan constitution on the rights of a child. In addition, the findings of this study provide evidence of schools as institutions with potential to counter childhood disadvantage and thus break the cycles of marginalization. However, the discourses in the focus groups and interviews indicated existence of individual teacher, as well as school practices and societal factors, that continue have contributed to marginalization of 'at risk' students. 


\section{Chapter 5: Conclusions}

The Kenyan Census Report of 2009 (released in 2010) indicated that there are 1.9 million children of the school age cohort who were not enrolled in the basic education system. This number was an indictment on the efforts that have been made by the Kenyan government to achieve universal access to education for all its children through Free Primary Education. Corroborating this information were previous studies by Githitho-Muriithi (2010), United Nations Educational, Scientific, and Cultural Organization - UNESCO (2010); Birger and Craissati (2009), etc. which reported specific groups of children were still excluded from accessing basic education. In quest of understanding this phenomenon in detail this study was premised on the following: to examine how Free Primary Education had influenced access to marginalized students in Kisii primary schools as self reported by teachers; to identify categories of students whom teachers considered as marginalized in their classrooms; to identify schooling practices that influenced retention of marginalized students in the classrooms, as well as teacher willingness differentiate instruction to meet the diverse learning needs of their students.

To achieve the above purposes, this study was guided by the following research questions: 1) How do teachers perceive Free Primary Education in Kenya has influenced access to primary education for marginalized students? 2) What do teachers perceive to be at risk categories for marginalized students? 3) How do teacher practices influence the retention of marginalized students in education in Kenya? Finally, 4) To what extent do teacher beliefs influence their desire to differentiate instruction for marginalized students? The study was organized as a sequential mixed method conducted in two phases. In the first phase, quantitative survey data was collected first from 217 classroom teachers from 28 primary schools in Kisii County. In the second phase of the study, which was qualitative, four focus group interviews of 
teachers and three one to one interviews of principals drawn from three primary schools in Kisii Municipality were conducted.

With regard to access there were three major findings from this study. First, Free Primary Education (FPE) had influenced initial access to basic education for all children including the marginalized through reduction of fees paid by parents to schools, increased accessibility to instructional materials such as books, improvements in school buildings, reduction in dropout rates, and improvements in educational standards. This finding indicated Kenya as being on track to achieve the United Nations Millennium Development goals of 2000 and Education for All goals, which stipulate that all countries including Kenya should attain universal learning for all children in the school age cohort by 2015. Second, capitation per child was not adequate to cover all the educational expenses. Third, additional fees levied by schools inhibited access to educational opportunities for students from poor families. While these findings highlight achievements made by FPE, they also unmask challenges still facing the full actualization of the objectives of FPE policy.

Nine categories of students were identified by study participants as being 'at risk' for marginalization in their classrooms. These included the girl child, orphans, homeless children, children with low incidence disabilities, children engaged in child labor, children with poor health, children from single parents, children with negligent parents, and children from extremely poor families. The indicators and/or symptoms of these 'at risk' students included low learning achievement, poor attendance (more than ten absences from the school within a 90-day period), malnutrition and/or lack of three square meals, repetition in grades, and dropping out of school. Based on evidence from focus groups and interviews, all these were outcomes of poverty as opposed to student characteristics. 
Teachers described four distinct practices they enacted in their schools with regard to marginalized students. The first practice was care. Teacher care involved planned or unplanned simple acts within and outside school to help these students depending on their need. Planned acts involved creating a school-feeding program in conjunction with parents where students from poor families were exempt from contributing to this program. Providing or buying breakfast and or/lunch for students from poor families, was another example of unplanned act. Other acts whereby teachers demonstrated care to vulnerable children were home visits, purchase of sanitary towels, and participation of teachers in community ceremonies such as funerals to comfort the orphans. The second practice was remedial teaching which provided extra help to struggling students. However, remedial teaching was not entirely free and the associated fees were reported to be a burden to these students. The third practice was guidance and counseling. This was described as a structural support to orphans and the girl children. Despite these practices the data did not demonstrate how each of these practices influenced the retention of marginalized students in primary schools. This was a major limitation for this study.

From the quantitative findings, it was determined that there was: a) a significant correlation between teacher philosophies and their willingness to differentiate instruction for marginalized students $\left(r_{s}=0.43, p<0.05\right)$; b) a significant correlation between teacher philosophies and their willingness to use a variety of teaching materials for marginalized students $\left(r_{s}=0.15, p<0.05\right)$; $)$ a significant relationship between teachers' philosophies and their willingness to provide various accommodations to marginalized students in their classrooms $\left(r_{s}=0.34, p<0.05\right)$; and $\left.\mathrm{d}\right)$ a significant correlation between teaching materials and Differentiated Instruction $\left(r_{s}=0.42, p<0.05\right)$. The section that follows briefly discusses these findings in light of the critical pedagogy framework and the implications for practice. 


\section{Critical Pedagogy}

Critical pedagogy as a framework was used in this study to unpack, shed light on, analyze, and help in rethinking the factors that perpetuated longstanding schooling as well as societal conditions and practices that hindered equitable access to education for marginalized students. In particular, the framework was used to question the false myths of educational equity and access that was supposedly afforded to all school age children (including the students at risk for marginalization) in Kenya. Therefore it is from this framework that the study concluded that: a) access to education as a class issue; b) tests and formal assessments as instruments for marginalization; c) access and retention in education as a critical consciousness issue; and finally d) access to education as a gender issue

Access to education as a class issue. After independence, the racial criterion governing access to education was replaced with the economic ability of the family to pay for education of their children. The review of literature revealed that for decades, Kenyans clamored for more access to education as illustrated in the Education Commission of 1964 commonly known as Ominde Commission. Right after independence, the former white only schools integrated but became enclaves for children from rich families. The issue of access as a class issue became more prominent with the imposition of cost sharing policy in the late 1980's. During this era of cost sharing, only children from families who could afford monies levied by schools could access education all year round. On the other hand, access to basic education for children from poor families was not guaranteed due to parents' inability to pay fees charged by schools.

Though Free Primary Education promises free basic education, evidence from this study indicated otherwise. The extra fees charged by schools in form of examination fees, activity fees, and so forth, continue to deny students from poor families full access to education. Moreover, the 
costs associated purchasing uniforms and sanitary towels (for girls) were another way in which class influenced access to education.

Besides fees and costs associated with education, failure by families to meet the basic needs such as food and clothing (sanitary towels) was another way that class influenced access. In summary, it can be argued that even with FPE, fully access to basic education is not guaranteed to all children.

Tests and assessments as an instrument for marginalization. The use of national examinations as the only measure of learning in Kenya has put a lot of pressure on teachers and parents. In the quest of posting good results every year, schools in collaboration with parents retain students who do not make good grades. From this study, there was evidence that repetition in grades had led to some students to drop out of school and hence an access issue. It can also be argued from the critical pedagogy perspective that national examinations such as Kenya Certificate of Primary Examination (KCPE) administered at the end of the $8^{\text {th }}$ grade, is an oppressive structure. The fixed examination period or seasons is also a source of oppression to those students who may want to take these exams at different periods. In addition, the registration fees charged effectively ensure that children from poor households are not accessing or participating in these examinations.

In a society like that of Kenya oftentimes, examinations are used to preserve the status quo and are hegemonic in nature. Moreover, the use of tests to determine a person's future in Kenya also means that the marginalized who may drop out, or have low achievement, will continue to remain in the low socio-economic status of the Kenyan society thereby effectively reinforcing the cycle of marginalization. 
Access and retention in education as a critical consciousness issue. Critical pedagogy requires that teachers have heightened consciousness of their practices, self, communities, policies, and students they teach. In line with Freire (2007), consciousness is more than simple awareness, instead it implies constant questioning, self-reflecting, and search for more understanding of conditions, practices, as well as policies that continue to oppress and/or alienate that marginalized in the society. Data from this study indicated that participants in the focus groups and interviews were aware of out of school and some school practices contributing to the dropping out of marginalized students but they fell short in recognizing their individual practices that contributed to marginalization.

Access to education as a gender issue. From this study it can be concluded that a cluster of factors militated against access to education for the girl child. These factors included 1) unsafe school environments for instance lack of adequate facilities in schools such as toilets, 2) social problems such as poverty which affected the girls more than it did the boys, 3) cultural practices of early marriages and use of the girl child to provide domestic labor, and 4) sibling care. This then demands targeted programs that address issues specific to the girl child to ensure their continued access to education.

\section{Implications for Practice}

In the following section, implications for practice regarding teacher professional development, providing equitable education and school learning environments that facilitate learning of all students, identification of 'at risk' categories of students for marginalization and need for designating special services needs through state-community partnerships, Free Primary Education funding, comprehensive special needs students policy guidelines, and mitigation of poverty related handicaps in education are discussed. 


\section{Implication \# 1 There is need to ensure that all schools are inclusive, safe, and}

conducive learning environments for all children. Creating learning environments that are inclusive, safe, and conducive in schools requires teachers and school administrators to conscientiously strive to address the basic needs of students in schools. This is an imperative because in Maslow's hierarchy of needs, any unfulfilled basic need of a child potentially overshadows the child quest for learning. For instance, from the qualitative data (focus groups and one to one interviews), it was evident that despite government funding for construction of new classes and maintenance of existing ones, schools still lack adequate and appropriate facilities. For example, from the same data, $43 \%(n=14)$ of schools whose teachers participated in interviews and focus groups reported to have inadequate toilets (out houses) and/or washrooms for their students. Since toilets are a necessity in schools, when student capacity exceeds existing number toilets available for their use, it becomes a public health hazard and a threat to students' safety and comfort in schools. Therefore, the government in partnership with communities should ensure there is clean water in schools, adequate and well-constructed toilets for students' use while in schools, enough classrooms (physical spaces) that are physically accessible to all students, and appropriate facilities for extramural activities.

The vulnerability of the girl child (especially girl children from extremely poor families) in public schools as reported from qualitative data in this research, is exacerbated when they lack access to sanitary towels. This is a basic need for female students. Therefore for universal access to education for all children is to be achieved, the impediments for its realization have to be addressed. Purchasing of sanitary towels to distribute to all schools is one of the steps needed in removing roadblocks to girl child education in Kenya. This is an additional but necessary cost to 
be borne by the government in partnership with manufacturers so as to ensure universal access to education for the girl child.

Creating safe, healthy, and inclusive learning environments also require teachers to pay attention to communities, family backgrounds, and student potentialities in their schools. In particular they have to be aware of student's histories as well as day-to-day realities and use this awareness to develop critical consciousness towards issues of gender, privilege, poverty, and social injustice in schools and societies. This will ensure teacher become advocates for the marginalized students not only in classrooms but also in school boardrooms.

\section{Implication \# 2 There is need to revamp teacher education, teacher professional} development and renewal to reflect current and diverse needs of students. Revamping the teacher education program is the starting point for effective classroom teachers. As a requirement, all the teacher education programs should as a requirement need all teachers take a course in special education and teaching diverse student populations. In addition, such a program should empower teachers with action research skills to enable them deliberately monitor their effectiveness when teaching marginalized students.

In regard to professional development, evidence from this study as discussed in chapter 4 indicate that only forty one percent $(\mathrm{n}=181)$ of teachers within a ten-year period had engaged in professional development activities related to students who have been marginalized. About sixty percent $(\mathrm{n}=181)$ had not participated in professional development activities. This situation was better illustrated by this statement made by a participant in a focus group who stated: "the main problem we encounter when teaching these marginalized students or pupils is that we are not specially trained to handle some of these groups". With the new Free Primary education policy, one would have assumed a majority of teachers had undergone some professional development 
to acclimatize themselves with its mandates and requirements. The below average percentages of teachers who had undergone professional development, necessitate a concerted effort from the Ministry of Education Science and Technology (MOEST), the Kenya Institute of Education $(\mathrm{KIE})^{21}$ and the Kenya Institute of Special Education (KISE) ${ }^{22}$ in coordinating, planning, and conducting professional development activities that are geared towards inducting teachers in best practices such as culturally responsive teaching and differentiated instruction all of which will be aimed at meeting the diverse learning needs of marginalized students in their classrooms.

The urgency for professional development activities reflecting needs of diverse students is also imperative due to influx of children with special needs, orphans, and overage pupils to schools occasioned by Free Primary Education. Specifically, these activities should cover identification of 'at risk' students in their classrooms, differentiated instruction, and administrative practices which may facilitate learning and therefore help in the retention of these students in schools. In addition, professional development activities should focus on culturally responsive pedagogy. This is important to help teachers deconstruct and overcome subterranean prejudices and/or preconceptions they hold regarding students who are at risk for marginalization and therefore raise their own critical consciousness as postulated by Freire. The imperative here is that teachers have to liberate their 'minds' from a prescriptive personal view that hold at risk students as individuals pre-destined for failure. Instead, teachers will be able to view students in terms of their potentialities and what they could do in their classrooms and schools to actualize these potentials. This should be the starting point of creating culturally responsive teachers: that

\footnotetext{
${ }^{21}$ The Kenya Institute of Education (KIE) is a state corporation whose key roles include but are not limited to, conducting research, developing K-12 Curricula and that of middle level colleges that do not offer degrees, developing curricula materials, as well as organizing and conducting in-service and inductions programs for curriculum implementers

${ }^{22}$ Kenya Institute of Special Education (KISE) is a semi-autonomous government agency of the Ministry of Education Science and Technology, whose responsibilities include but not limited to: offer special needs education courses and/programs to teachers handling special needs children, conduct research, conduct in-service to teachers and personnel working with special needs children, etc.
} 
is inducting teachers to practices that may ensure that all learners in their classrooms are benefitting from an education. All these should also aim at preparing teachers who proactively create classroom and school conditions promoting equity.

\section{Implication \# 3 There is need for all teachers to actively identify students who are} 'at risk' for marginalization and ensure that their learning needs are met in their schools

and classrooms. Teacher awareness about the meaning and etiology of students with special needs is crucial in ensuring they receive appropriate education and related services. Hence, this research provides a skeletal outline of symptoms that can be used as a basis for identifying students who are at risk for marginalization in schools. The Ministry of Education should come up with a formal criterion for identifying and documenting the vulnerable groups in schools. Besides the Ministry of Education, any effective classroom teacher should at all times know the different abilities of students and their diversities making up his class. This is imperative as it informs the choice of instructional activities appropriate for each student.

\section{Implication \# 4 The FPE funds should be commensurate to individual student and}

school needs. If FPE is serious about closing the achievement gaps, there is need to allocate more resources to students with the greatest needs. Such a funding should take into account the multiple layers of needs and issues in particular contexts. This recommendation is based on one of the findings from this research was that FPE funds (capitation per child at $\$ 14$ annually) are not enough. The fiscal outlook of Kenyan economy aside, the government should increase capitation per child to reflect current inflation and the cost of living at all times. In addition, the government should promptly disburse the FPE monies to schools to ensure they operate smoothly without disruption. Related to funding, the Ministry of Education should regularly 
audit schools to ascertain that schools funds are utilized for their intended purposes and therefore avoid wastage.

\section{Implication \# 5 There is need for comprehensive policy guidelines for Special Needs}

Children and their education. Though the new constitution of Kenya emphasizes that all children with special needs ought to be taught in inclusive settings, there are no exhaustive guidelines for classroom teachers on how they should instruct these students. A comprehensive legislative guideline for classroom teachers is needed to address: a) assessing students with special needs in classrooms, b) documentation, and c) formulating individualized plans for each student.

In addition, there should be thorough identification of children with special needs with the aim of providing appropriate services and accommodations to their physical, social, and learning needs. This then demands revamping of the Educational Assessment and Resource Centers (EARC), which is the unit within the Ministry of Education tasked with assessment and identification of children with special needs. The EARC in collaboration with classroom teachers should engage in proactive early identification of children with special needs. It is also necessary to provide clear guidelines on special needs child identification and referral processes.

\section{Implication \# 6 There is need to envision schools as full service learning centers.}

Premised on the idea that a school is an extension of a home environment, the government in collaboration with local communities should embark in turning existing schools into full service learning centers, where all students can not only get cognitive nourishment but physical nourishment through provision of lunch and nutritional supplements. In addition, schools should offer health screening services, as well as psychological and counseling services to all students. 
This can this can only be realized if all schools have certified nurses and counselors as part of their staff.

The ultimate goal of full service schools is to create supports for students who are 'at risk' of being marginalized and coordinate services targeting these students. The services envisioned in such schools will help to build partnerships across schools and communities thus ensuring that children are successful.

\section{Limitations of This Study}

The study does not state nor estimate the number of students in the county who are orphans, special needs, from impoverished families, street children, engaged in child labor, or percentage of girl children who drop out from public schools. The study then fails to depict in numerical terms the percentage of age going student populations who are at risk for marginalization as per the study's parameters. This is an inherent weakness within this study.

Failure to demonstrate how teacher practices influenced retention and progression of marginalized students in Kisii County is another limitation for this study. While the study discusses teacher practices deemed unique for marginalized students' success in learning or school attendance, much of this is from a teacher's perspective as it does not show concretely how each practice mentioned influenced retention and progression of marginalized students. Consequently, this research fall short in addressing its central thesis, that teacher practices significantly influence access, retention, and progression of marginalized students in Kisii County

Like any qualitative research, researcher bias is a limitation. The few number of administrator interviews was another limitation. To understand comprehensively FPE, the voice 
of school administrators is critical as it gives a window administrator perspective regarding implementation of FPE in Kenya.

\section{Future Research}

Addressing a fundamental issue of continued access to education for all children regardless of their socioeconomic backgrounds is paramount for a young nation such as Kenya. Arguably, quality universal basic education is still a mirage for 'at risk' Kenyan school age children who often, are invisible within our communities. Stemming from the findings of this research, there is an apparent need to induct all teacher practitioners in professional development activities anchored in best instructional as well as administrative practices geared towards enhancing access to quality educational experiences for students who are 'at risk' for marginalization in Kenyan primary schools. This then explains the need for research studies that focus on teacher professional development activities and their influence on marginalized students. Specifically the nature and structure of professional development activities, and teacher action research as a tool by teachers to monitor their instructional impact on various interventions implemented in their classrooms and schools. In addition, there is need to study the transfer of knowledge from professional development activities to classrooms in a model of theory to practice nexus.

Another avenue for research is on focusing on how specific teacher practices such as care influence continued retention and success of 'at risk' students in Kenyan primary schools. For instance, there is need to garner student perspectives regarding how various teacher practices influence their decisions to continue to attend, identify with, and get attached to their respective schools. This is important to not only policy makers, but also administrators in Kenyan schools. 
In addition, there is need to study how parent perceptions on education influence success of 'at risk' students in Kenya.

There is a need to conduct a longitudinal case studies of students who are at risk for marginalization in schools to better understand their day-to-day struggles both in school and at their homes. In this study, behaviors and practices of teachers teaching these students will also be studied. Such a study will be potential in informing the appropriate interventions and programs suitable to these children. This longitudinal study can also trace teacher 


\section{References}

Abenga, E. S. B. (2009). A systems approach to education in Kenya: implications on educational media program development. Educational Research and Review, 4(8), 371 - 378.

Achoka, J. K., Odebero, S. O., Maiyo, J. K., \& Mualuko, N. J. (2007). Access to basic education in Kenya: Inherent concerns. Educational Research and Reviews, 2(10), 275 - 284.

Ackers, J., Migoli, J., \& Nzomo, J. (2001). Identifying and addressing the causes of declining participation rates In Kenyan primary schools. International Journal of Educational Development. 21(4), 361-374.

Akama, J. S., \& Maxon, R. (2006). Ethnography of the Gusii of Western Kenya: A vanishing cultural heritage. Lewiston, New York: The Edwin Mellen Press.

Alwy, A., \& Schech, S. (2007). Ethnicity, politics, and state resources allocation: explaining educational inequalities in Kenya. In W. T. Pink \& G.W. Noblit (Series Ed) Springer International Handbooks of Education: 1(19), 129 - 144.

Amutabi, M.N. (2003). Political interference in the running of education in post-independence Kenya: a critical retrospection. International Journal of Educational Development, 23(1), 127-144.

Ananga, E. D. (2011). Typology of school dropout: The dimension and dynamics of dropout in Ghana. International Journal of Educational Development, 31(4), 374 - 381.

Apple, M. (1982). Education and power. Boston: Routledge \& Kegan Paul.

Bagaka, J. G. (2010). Many districts left behind: An individual change analysis of inequity in the Kenyan primary educational opportunities (2001 - 2007). International Journal of Educational development, 30, 586-591. 
Bauchmann, C. (1999). The state and schooling in Kenya: Historical developments and current challenges. Africa Today, 46(1), 94-116.

Bedi, A. S., Kimalu, P. K., Manda, D. K., \& Nafula, N. N. (2002). The decline in primary school enrollment in Kenya. KIPPRA Discussion Paper No. 14. Kenya Institute of Public Policy Research and Analysis, Nairobi

Birger, F., \& Craissati, D. (2009). Abolishing school fees in Africa: Lessons learned from Ethiopia, Ghana, Malawi, Kenya, Malawi and Mozambique. Washington DC: World Bank Publications.

Bogonko, S. N. (1992). A history of modern education in Kenya (1895-1991). Nairobi: Evan Brothers.

Bore, K. J., Mukuria, G., \& Adera, B. (2007). Educating children with emotional and behavioral disorders in Kenya: A right or a privilege? Journal of International Special Needs Education, 10, 49-57.

Brown v. Board of Education in Topeka Kansas, 347 U.S. 483 (1954)

Burnett, N. (2008). The Delors Report: A guide towards education for all. European Journal of Education, 43(2), 181-187.

Consortium for Research in Educational Access, Transitions, and Equity (CREATE) (n.d.). Retrieved from http://www.create-rpc.org/about/background/ on 03/22/2011.

Creswell, J.W. (2003). Research design: Qualitative, quantitative, and mixed methods approaches ( $2^{\text {nd }}$ Edition). Thousand Oaks, California: Sage Publications.

Creswell, J. W., \& Plano-Clark, V. L. (2011). Designing and conducting mixed methods research. $2^{\text {nd }}$ Edition. Thousand oaks, California: SAGE Publications. 
Darder, A., Baltodano, M.P., \& Torres, R.D. eds. (2009). The critical pedagogy leader. $2^{\text {nd }}$ Edition. New York: Routledge.

Eshiwani, G. S. (1993). Education in Kenya since independence. Nairobi: East African Educational Publishers.

Fields, A. P. (2005). Discovering statistics using SPSS: (and sex, drugs, and rock n' roll). Thousand Oaks, California: Sage Publications

Freire, P. (2007). Pedagogy of the oppressed. New York: Continuum.

Geuss, R. (1988). The idea of critical theory: Habermas and the Frankfurt School. New York: Cambridge University Press.

Giroux, H. (1985). Critical pedagogy, cultural politics and discourse of experience. Journal of Education, 167(2), 2 - 21.

Githitho-Muriithi, A. (2010). Education for all and child labor in Kenya: A conflict of capabilities? Procedia Social and Behavioral Sciences, 2, 4613-4621.

Githua, B.N. \& Mwangi J. R. (2003). Student's mathematics self-concept and motivation to learn mathematics: Relationship and gender differences among Kenya’s secondary-school students in Nairobi and Rift Valley provinces. International Journal of Educational Development, 23(5), 487-499.

Glick, P. (2008). What policies will reduce gender schooling gaps in developing countries: Evidence and interpretation. World Development, 36(9), 1623-1646.

Godia, G. (1987). Education and the unemployment problem in Kenya. The Journal of Negro Education, 56(3), 356-367.

Gramsci, A. (1971). Selections from the prison notebooks of Antonio Gramsci. New York: International Publishers. 
Grant, C. A., \& Ladson-Billings, G. (Eds.) (1997). Dictionary of Multicultural Education. Phoenix, Arizona: Oryx Press.

Grbich, C. (2007). Qualitative data analysis: an introduction. Thousand Oaks, California: SAGE Publications.

Greene, J. C., Caracelli, V. J., \& Graham, W. F. (1989). Toward a conceptual framework for mixed-methods evaluation designs. Educational Evaluation and Policy Analysis, 11(3), $255-274$

Gregory, G. H., \& Chapman, C. (2002). Differentiated instructional strategies: One size doesn't fit all. Thousand Oaks, California: Corwin Press.

Harper, F.D., Harper, J.A., \& Stills, A.B. (2003). Counseling children in crisis based on Maslow's hierarchy of basic needs. International Journal for the Advancement of Counseling, 25(1), $11-25$.

Himaz, R. (2009). The impact of parental death on schooling and subjective wellbeing: Evidence from Ethiopia using longitudinal data. Oxford, United Kingdom: United Kingdom Department of International Development, Young Lives. (Working paper).

Hsieh, H., \& Shannon, S. E. (2005). Three approaches to qualitative content analysis. Qualitative Health Research, 15(9), $1277-1288$.

Hungi, N., \& Thuku, F. (2010). Difference in pupil achievement in Kenya: Implications for policy and practice. International Journal of Educational Development, 30(1), 33-43.

Illinois State Board of Education. Retrieved on 5/20/10, from website: http://www.isbe.net/accountability/html/equity.htm

Johnson, R. B., \& Onwuegbuzie, A. J. (2004). Mixed methods research: A research paradigm whose time has come. Educational Researcher, 33(7), $14-26$. 
Jordan, W. J. (2010). Defining equity: Multiple perspectives to analyzing the performance of diverse learners. Review of Research in Education, 34, 142-178.

Kiare, M. W. (2004). Education of students with visual impairments in Kenya: Trends and issues. International Journal of Special Education, 19(2), 16-22.

Kincheloe, J. L. (2008). Critical pedagogy ( $2^{\text {nd }}$ Edition). New York: Peter Lang.

King, K. (2007). Balancing basic and post-basic education in Kenya: National versus international policy agendas. International Journal of Educational Development, 27(5), 358-370.

Kochung, E. (2003). Report on the task force on special needs education appraisal exercise. Nairobi, Kenya: Ministry of Education Science and Technology.

Krueger, R.A. (1994). Focus groups: A practical guide for applied research. Thousand Oaks, California: Sage Publications.

LeVine, R. A., Dixon, S., LeVine, S., Richman, A., Leiderman, P. H., Keefer, C. H., \& Brazelton, T. B. (1994). Childcare and culture: Lessons from Africa. New York: Cambridge University Press.

Lewin, K. (2009). Access to education in sub-Saharan Africa: Patterns, problems and possibilities. Comparative Education, 45(2), 151-174.

Lewin, K. (2008). Why some education for all and millennium development goals will not be met: Difficulties with goals and targets, in: Chisholm, L., Bloch, G., \& Fleisch, B. Education, growth, aid and development: Towards education for all (Hong Kong: Comparative Education Research Centre). Retrieved on 6/10/2010, from: http://www.dfid.gov.uk/R4D/PDF/Outputs/ImpAccess_RPC/SAREarticle.pdf

Lincoln, Y., \& Guba, E. (1985). Naturalistic inquiry. Beverly Hills, CA: Sage Publications, Inc. 
Lloyd, C. B., Mensch, B. S. \& Clark, W. H. (2000). The effects of primary school quality on school dropout among Kenyan boys and girls. Comparative Education Review, 44(2), $113-229$.

Lynch, P., McCall, S., Douglas, G., McLinden, M., Mogesa, B., Mwaura, M., Muga, J., \& Njoroge, M. (2011). Inclusive educational practices in Kenya: Evidencing practice of itenerant teachers who work with visual impairment in local mainstream school. International Journal of Educational Development, 31(5), 478 - 488.

Maxon, R. M. (1989). Conflict and accommodation in western Kenya: the Gusii and the British, 1907-1963. Cranbury, NJ: Associated University Presses.

McLaren, P. \& Kincheloe, J. L. (eds). (2007). Critical pedagogy: where are we now? New York: Peter Lang Inc.

McMahon, S. A., Winch, P. J., Caruso, B. A., Obure, A. A., Ogutu, E. A., Ochari, I. A., \& Rheingans, R. (2011). 'The girl child with her period is the one to hang her head': reflections on menstrual management among schoolgirls in rural Kenya. $B M C$ International Health \& Human Rights, 11(7), 1-10.

McTighe, J. \& Brown, J. (2005). Differentiated instruction and educational standards: Is détente possible? Theory Into Practice, 44(3), $234-244$.

Mills v. Board of Education, 348 F. Supp. 866 (1972).

Ministry of Education, Science and Technology (MOEST), (2005). Kenya Education Sector Support Program (KESSP), 2005-2010. Nairobi, Kenya: Government Printer.

Mukudi, E. (2004). Education for all: A framework for addressing the persisting illusion for the Kenyan context. International Journal of Educational Development, 24(3), 231-240. doi: DOI: 10.1016/j.ijedudev.2003.10.009 
Mukuria, G., \& Korir, J. (2006). Education for children with emotional and behavioral disorders in Kenya: Problems and prospects. Preventing School Failure, 50(2), 49-54.

Munene, I. I., \& Ruto, S. J. (2010). The right to education for children in child labor: Emperical evidence from Kenya. International Review of Education, 56(1), 127-147.

Mutua, K., \& Dimitrov, D. M. (2001). Prediction of school enrollment of children with intellectual disabilities in Kenya: The role of parents' expectations, beliefs, and education. International Journal of Disability, Development and Education, 48(2), 179191.

Nieto, S. (1996). Affirming diversity: The sociopolitical context of multicultural education $\left(2^{\text {nd }}\right.$ ed.). White Plains, NY: Longman.

Nkinyangi, J. A., \& Mbindyo, J. (1982). The condition of disabled persons in Kenya: Results of a national survey. Nairobi, Kenya: Institute for Development Studies, University of Nairobi.

Nyambedha, E. O., Wandibba, S., \& Aagaard-Hansen, J. (2001). Policy implications of the inadequate support systems for orphans in Western Kenya. Health Policy, 58(1), 89-96.

Oketch, M., \& Ngware, M. (2010). Free primary education still excludes the poorest of the poor in urban Kenya. Development in Practice, $20(4$ \& 5), 603-610.

Omwami, E. M., \& Omwami, R. K. (2010). Public investment and the goal of providing universal access to primary education by 2015. International Journal of Educational Development, 30(3), 243-253.

Oriedo, T. (2003). The state of persons with disabilities in Kenya. Council of Exceptional Children: Division of International Special Education and Services. Retrieved on 6/12/2010, from, 
http://www.cec.sped.org/Content/NavigationMenu/AboutCEC/International/DISES/Natio nalPerspectives/Kenya/default.htm

Ozmon, H. A., \& Craver, S. M. (2008). Philosophical foundations of education ( $8^{\text {th }}$ Ed.). Upper Saddle River, New Jersey: Pearson.

Patton, M. Q. (2002). Qualitative research and methods ( $3^{\text {rd }}$ Ed.). Thousand Oak, CA: Sage Publications.

Pennsylvania Association of Retarded Children (PARC) v. Commonwealth of Pennsylvania, 334 F. Supp. 1257 (E.D. PA 1971).

Plessy v. Fergussion, 163 U.S. 537 (1896).

Republic of Kenya. (1964). Kenya Education Commission Report (The Ominde Report). Nairobi: Government Printer

Republic of Kenya (1966). Development Plans (1966-1970). Nairobi, Kenya: Government Printer

Republic of Kenya (1970). Development Plans (1970 - 1974). Nairobi, Kenya: Government Printer

Republic of Kenya (1976). Report on National Committee on Educational Objectives and Policies (Gachathi Report). Nairobi, Kenya: Government Printer

Republic of Kenya (1981). The Presidential working party on the second university (McKay Report). Nairobi, Kenya: Government Printer.

Republic of Kenya (1991). The Kenya economic survey, 1964 - 1991. Nairobi, Kenya: Government Printer.

Republic of Kenya, (2004). Economic survey. Prepared by Central Bureau of Statistics, Ministry of Planning and National Development. Nairobi. 
Republic of Kenya. (2007). Strategic plan 2008 - 2012: Kenya vision 2030. Towards a globally competitive and prosperous Kenya. Nairobi: Government Printer.

Republic of Kenya. (2009). The national special needs education policy framework. Nairobi: Government Printer

Republic of Kenya. (2010). The 2009 census report. Nairobi: Government Printer.

Rharade, A. (1997). Education reform in Kenya. Prospects, 27(1), 163 - 179

Rock, M. L., Gregg, M., Ellis, E., \& Gable, R. A. (2008). REACH: A framework for differentiating classroom instruction. Preventing School Failure, 52(2), 31 - 47.

Rossman, G. B., \& Wilson, B. L. (1985). Numbers and words: Combining quantitative and qualitative methods in a single large-scale evaluation study. Evaluation Review, 9(5), 627 $-643$.

Rotich, D. C. (2004). The affordability of textbooks in Kenya: consumer experiences in the transformations to a liberalizing economy. Nordic Journal of African Studies, 13(2), 175 $-187$.

Shabaya, J. \& Konadu-Agyemang, K. (2004). Unequal access, unequal participation: Some spatial and socio-economic dimensions of the gender gap in education in Africa with special reference to Ghana, Zimbabwe, and Kenya. Compare, 34(4), 395-424.

Sheffield, J. R. (1973). Education in Kenya. New York, NY: Teachers College Press.

Sifuna, D. N. (1980). Short essays on education in Kenya. Nairobi: Kenya Literature Bureau.

Sifuna, D. N. (2005). Increasing access and participation of pastoralist communities in primary education in Kenya. International Review of Education, 51(5/6), 499-516. 
Sifuna, D. N. (2007). The challenge of increasing access and improving quality: An analysis of universal primary education interventions in Kenya and Tanzania since the 1970s. International Review of Education, 53(5), 687-699.

Sifuna, D. N., \& Otiende, J. E. (1994). An introductory history of education. Nairobi: University of Nairobi Press

Sifuna, D. N., \& Otiende, J. E. (2006). An introductory history of education (Revised Edition). Nairobi: University of Nairobi Press.

Smit, R., \& Humpert, W. (2012). Differentiated instruction in small schools. Teaching and Teacher Education, 28(8), 1152 - 1162

Somerset, A. (2011). Access, cost, and quality: tensions in the development of primary education in Kenya. Journal of Educational Policy, 26(4), 483 - 497.

Southern and Eastern Africa Consortium for Monitoring Educational Quality. (2011). Progress in gender equality in education. (Policy No. 6).

Strauss, A., \& Corbin, J. (1998). Basics of qualitative research: Techniques and procedures for developing Grounded Theory $\left(2^{\text {nd }}\right.$ Ed.). Thousand Oaks, CA: Sage.

Suda, C. (1997). Street children in Nairobi and the African based cultural ideology of kin-based support system: change and challenge. Child Abuse Review, 6(3), 199-217.

Swadener, B. B., Kabiru, M., \& Njenga, A. (2000). Does the village still raise the child? A collaborative study of changing child rearing and early childhood education in Kenya. Albany, New York: State University of New York Press.

Tashakkori, A., \& Teddlie, C. (2003). Handbook of mixed methods in social and behavioral research. Thousand Oaks, California: Sage.

The East African Standard Newspaper of 2/4/2013. 
Tomlinson, C. A. (2000). Reconcilable differences: Standards based teaching and differentiation. Educational Leadership, 58(1), 6-11

Tomlinson, C. A. (2001). How to differentiate instruction in mixed-ability classrooms $\left(2^{\text {nd }}\right.$ Edition). Alexandria, Virginia: Association for Supervision and Curriculum Development.

Tomlinson, C. A., \& McTighe, J. (2006). Integrating differentiated instruction and understanding by design: Connecting content to kids. Alexandria, Virginia: Association for Supervision and Curriculum Development.

Urban, W. J., \& Wagoner, Jr. J. L. (2004). American Education: A history ( $3^{\text {rd }}$ Ed.). New York, NY: McGraw Hill.

Urch, G. E. (1971). Education and colonialism in Kenya. History of Education Quarterly, 11(3), 249-264.

United Nations (1948). Continuation of the discussion on the draft universal declaration if human rights: report on the third committee (A/777). Paper presented at the Hundred and Eighty Third Plenary Meeting, Paris.

United Nations. (2000). United Nations General Assembly $55^{\text {th }}$ Session Resolution: Millennium Declaration. Retrieved on 5/30/10 from: http://www.un.org/millennium/declaration/ares552e.pdf United Nations (1989). Convention on the Rights of the Child (No. Resolution 44/25). New York: Office of the High Commissioner for Human Rights United Nations Educational, Scientific, and Cultural Organization. (1990). The World Conference on Education for All: Meeting basic learning needs. Jomtien, Thailand 1990. Retrieved on 6/22/2010 from: http://www.unesco.org/education/pdf/JOMTIE_E.PDF 
United Nations Educational, Scientific, and Cultural Organization. (2000). Dakar framework for action. Retrieved on 6/22/10 from: http://www.unesco.org/education/efa/ed_for_all/dakfram_eng.shtml United Nations Education Scientific \& Cultural Organization. (2010). Education for All Global Monitoring Report (p. 135-186). UNESCO: Paris. Retrieved on 10/17/10 from: http://www.unesco.org/fileadmin/MULTIMEDIA/HQ/ED/GMR/pdf/gmr2010/gmr2010$\underline{\operatorname{ch} 3 . p d f}$

Vaughn, S., Schumm, J.S., \& Sinagub, J.M. (1996). Focus groups interviews in education and psychology. Thousand Oaks, California: Sage Publications.

Vogt, F. (2002). Caring teacher: explorations into primary school teachers' professional identity and ethic of care. Gender and Education, 14(3), 251 - 264.

World Bank. (2001). A chance to learn: Knowledge and finance for education in sub - Saharan Africa. Africa Region Development Series. Washington D. C.: World Bank. 
Appendices

Appendix A: Map of Kenya Showing the County and Constituency Boundaries in Kenya

Figure A 1

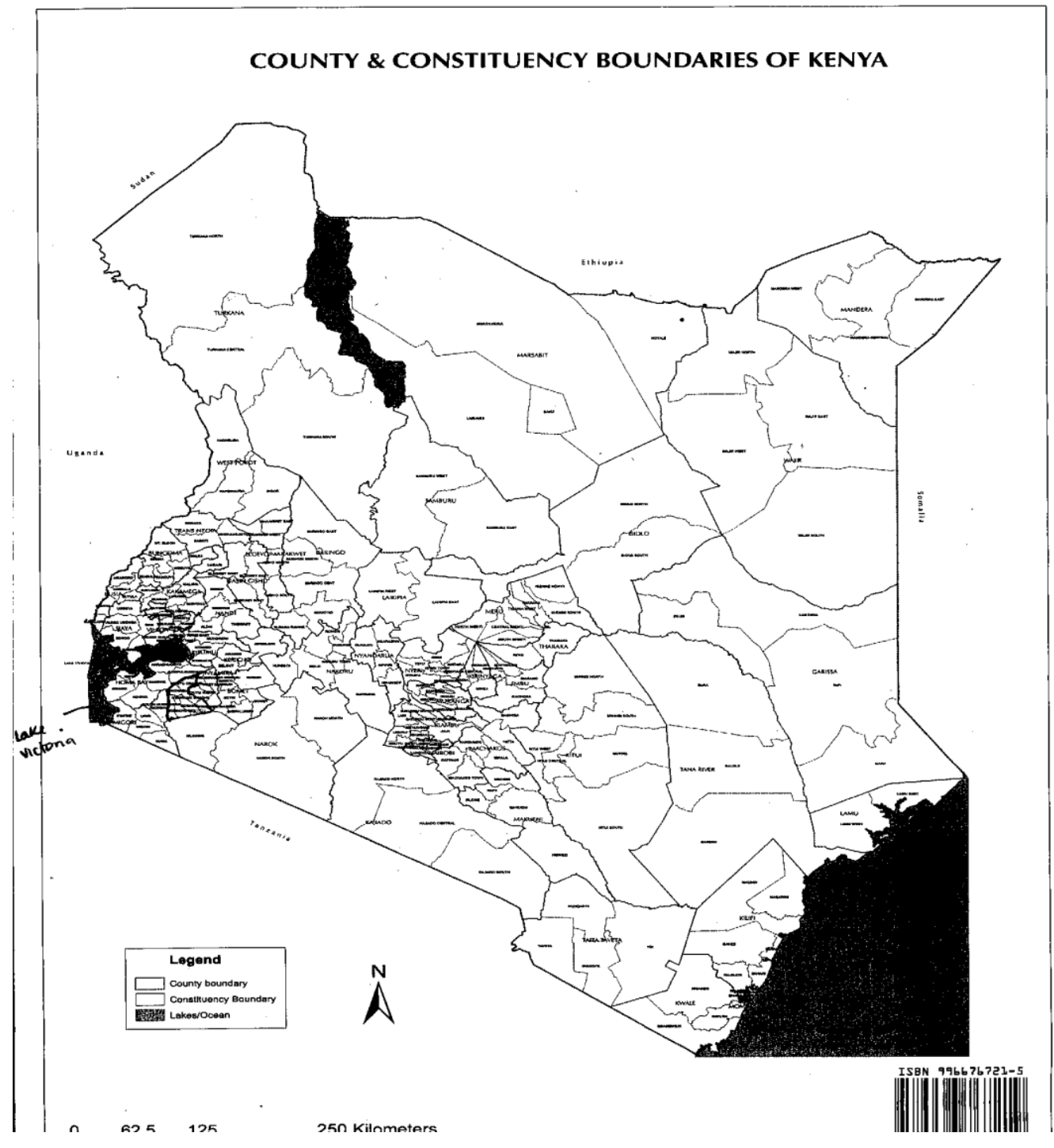


Appendix B: Kenya's Population Distribution for Ages 6 Years to 14 Years by Age and Sex

\section{Table B1}

Kenya's population distribution for ages 6 years to 14 years by age and sex

\begin{tabular}{llll}
\hline Age (years) & Male & Female & Total \\
\hline $\mathbf{6}$ & 590,310 & 577,107 & $1,167,417$ \\
$\mathbf{7}$ & 541,370 & 528,350 & $1,069,720$ \\
$\mathbf{8}$ & 561,120 & 553,788 & $1,114,908$ \\
$\mathbf{9}$ & 539,155 & 526,720 & $1,065,875$ \\
$\mathbf{1 0}$ & 612,711 & 585,911 & $1,198,622$ \\
$\mathbf{1 1}$ & 418,412 & 424,178 & 842,590 \\
$\mathbf{1 2}$ & 567,671 & 532,930 & $1,100,601$ \\
$\mathbf{1 3}$ & 487,708 & 475,577 & 963,285 \\
$\mathbf{1 4}$ & 478,811 & 450,946 & 929,757 \\
Total & & & $9,452,775$ \\
\hline
\end{tabular}

Source: Republic of Kenya, (2010). 2009 Kenya population and housing census: population distribution by age, sex and administrative units 
Appendix C: Kisii County Political Units (Constituencies as of 2011)

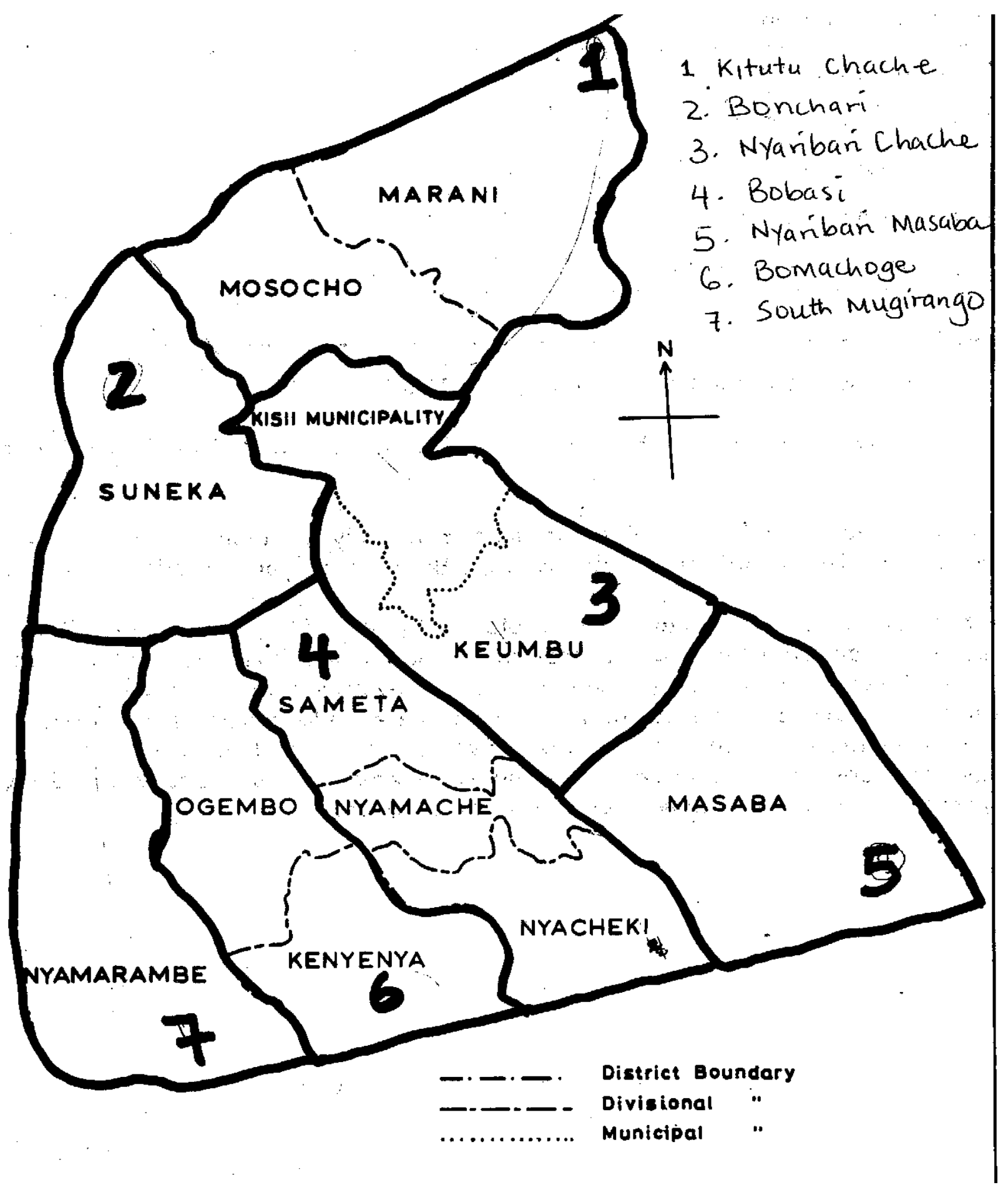




\section{Appendix D: Teacher Survey}

\section{Section One:}

\section{Part I: Demographics}

1. Gender

2. What is your age bracket?
20-24
25-29
$30-34$
$35-39$
$40-44$
$45-49$
${ }_{50-54} \Gamma 55+$

\section{Teaching experience}

3. State the number of years of your teaching experience

4. How many years have you taught in the current school?

5. What grade levels are you currently teaching? Check one that applies

$\ulcorner$ 1-4 (lower primary)

Г 5-8 (upper primary)

6. If in upper primary, list the content area(s) or subjects you are currently teaching

\section{Check one that represents your professional qualifications \\ $\Gamma$ Untrained teacher (with degree) \\ $\Gamma \quad$ Untrained teacher (with diploma) \\ $\Gamma \quad$ Untrained teacher (without degree nor \\ Г Diploma (3 years in college) \\ $\ulcorner$ Degree (4 years in college) \\ Г Masters} diploma)

$\Gamma$ Certificate

\section{Check all that describe the professional responsibilities you are engaged in school}

Г Curriculum master

$\Gamma \quad$ Special education teacher designee/itinerant teacher

$\Gamma$

Principal

$\Gamma$ Deputy Principal

$\Gamma$ Games teacher

\section{Part II. Classroom Demographics}

9. State the current number of students in your class Male

10. Marginalized students Female 
Marginalized students are students who come from marginal groups within society (which include: students from families that are extremely poor, teenage parents, children who are homeless, children who are orphans, children engaged in child labor, and children with disabilities), and who exhibit or are at risk of exhibiting one of the following characteristics: poor attendance, low achievement, repetition of grades, or dropping out of school.

\begin{tabular}{|c|c|c|c|c|c|}
\hline \multirow[t]{2}{*}{$\begin{array}{l}\text { Marginalized } \\
\text { groups } \\
\text { (Column 1) }\end{array}$} & \multirow[t]{2}{*}{$\begin{array}{l}\text { Number of } \\
\text { students } \\
\text { (Column 2) }\end{array}$} & \multicolumn{4}{|c|}{$\begin{array}{l}\text { How many of the students in each of the categories that } \\
\text { you have identified in column } 2 \text { are at risk for the } \\
\text { following categories }\end{array}$} \\
\hline & & $\begin{array}{l}\text { Dropping out } \\
\text { of school }\end{array}$ & $\begin{array}{l}\text { Repeating } \\
\text { grades }\end{array}$ & $\begin{array}{l}\text { Low } \\
\text { achievement }\end{array}$ & $\begin{array}{l}\text { Low } \\
\text { attendance } \\
\text { (missed } \\
\text { school for } \\
\text { more than } \\
10 \text { days in } \\
\text { a term) } \\
\end{array}$ \\
\hline Orphans & & & & & \\
\hline $\begin{array}{l}\text { Children engaged in } \\
\text { child labor }\end{array}$ & & & & & \\
\hline $\begin{array}{l}\text { Homeless or street } \\
\text { children }\end{array}$ & & & & & \\
\hline $\begin{array}{l}\text { Children with low } \\
\text { incidence } \\
\text { disabilities }\end{array}$ & & & & & \\
\hline
\end{tabular}

\section{Part III: Free Primary Education Policy}

11. Are you aware of the objectives of Free Primary Education Policy?<smiles>[3H][W]</smiles>

If yes, from your perception, please circle the number that indicates to what extent your school has met the following objectives of Free Primary Education?

\section{(1. Not at all; 2. To a little extent; 3 . To a moderate extent; 4 . To a great extent; 5 . To a} very great extent)

Free primary education has:

12. Reversed the declining enrollments of marginalized students at the primary level
$\left\ulcorner\Gamma_{1}\right.$
2
3
4
5

13. Enhanced access at the primary level
\ulcorner
2
3
4 
14. Increased retention of marginalized students at the primary level
Г 1
2
3
4
5

15. Increased quality of education given to marginalized students at the primary level
$\Gamma 1$
$\Gamma 2$
Г 3
$\Gamma 4$
5

16. Improved participation rates at the primary level

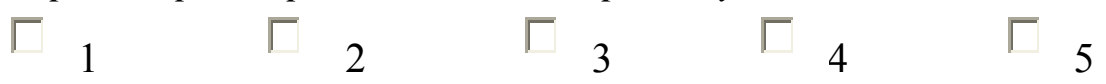

17. Improved progression rates of marginalized students at the primary school level
Г 1
Г 2
Г 3
4
5

18. Reduced the cost of education, previously borne by parents in the provision of primary school education
Г 1
2
$\Gamma 3$
$\Gamma 4$
$\Gamma 5$

19. Helped streamline and rationalize the use of educational resources
Г 1
Г 2
Г 3
Г 4
Г 5

20. Improved the learning achievements of the marginalized students (orphans, street children, teenage parents, students with disabilities)
Г 1
2
Г 3
Г 4 5

21. Did you teach in primary schools before the implementation of Free Primary Education (FPE) policy?

22. If you said yes to the above question, give an estimate of the increase in the number of students in the following categories?

\begin{tabular}{|l|l|l|l|l|l|}
\hline Category & $1-9$ & $10-19$ & $20-29$ & $30-39$ & Over 40 \\
\hline Orphans & & & & & \\
\hline Children engaged in child labor & & & & & \\
\hline Homeless or street children & & & & & \\
\hline $\begin{array}{l}\text { Children with low incidence } \\
\text { disabilities }\end{array}$ & & & & & \\
\hline
\end{tabular}




\section{Section Two:}

\section{Part I - Teaching Philosophy/Beliefs}

To what extent do the following statements reflect your teaching philosophy/beliefs? (1 Not at all; 2. To a little extent; 3 . To a moderate extent; 4. To a great extent; 5. To a very great extent)

I believe that:

23. All students/children are capable of learning within an equitable and just society
1
Г 1
2

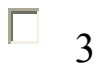
Г 4
5

24. Every child has a right to free and compulsory basic/primary education

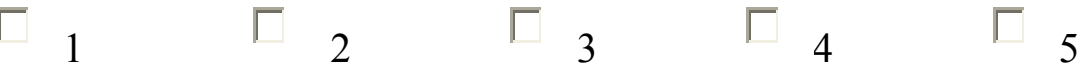

25. As a teacher, I can create an environment where all children can learn

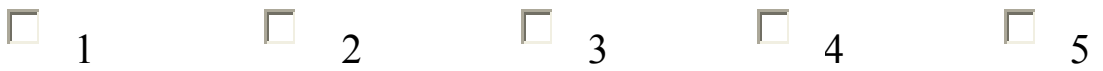

26. It is my role as a teacher to accommodate each student according to his or her learning needs

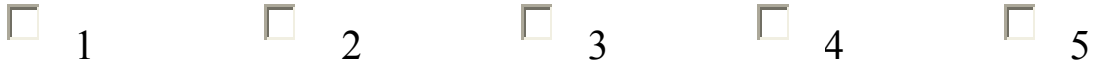

27. Integration of content as the best approach to teaching marginalized students
Г1
Г 2
Г 3
Г 4 Г 5

28. The use of multimedia as the best approach to teaching marginalized students
Г 1
Г 2
Г 3
Г 4
5

29. Since all children are different in ability, learning should be personalized with flexible schedules
Г 1
Г 2
Г 3
Г 4
5

30. Accommodations are necessary for marginalized students so as to ensure that they benefit from free primary education
Г 1
Г 2
Г 3
$\Gamma_{4}$
Г 5

31. My perceptions on the student background influences the way I teach
1
Г 2
Г 3
Г 4
5

32. Children should be treated with respect, empathy, and dignity at all times
Г 1
Г 2
$2+3$
Г 4
5

\section{Part II: Differentiated Instruction}

a. Differentiated instruction is an approach to teaching where a teacher proactively plans varied approaches to what students need to learn, how they will learn it, and/or how they can express what they have learned in order to increase the likelihood that each student will learn as much as he or she can and as efficiently as possible (Tomlinson, 2001). It is characterized by classes that utilize mixed groupings (where academically weaker 
students are paired with academically stronger students), multiple instructional strategies, wide range of assessment techniques, and lets learners take increasing responsibility of their own learning.

From your perceptions, please circle the number that indicates to what extent you differentiate instruction to meet the learning needs of marginalized students in your class (1 Not at all; 2. To a little extent; 3. To a moderate extent; 4. To a great extent; 5. To a very great extent)

To what extent do you:

33. Match content of what you teach to the student's capacity to read and understand?
- 1
Г 2

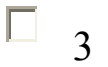
Г 4
5

34. Cater for the student's interest within the material you teach?

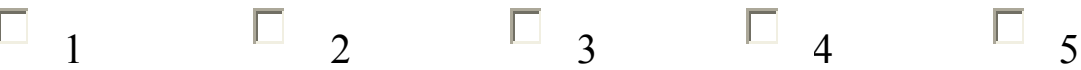

35. Use a variety of instructional strategies to deliver content?

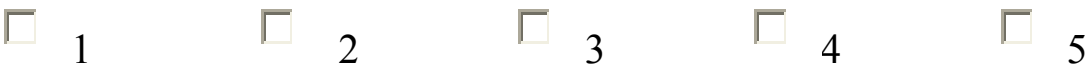

36. Use varied texts in your classroom?
- 1
Г 2
「 3
Г 4
Г 5

37. Use a variety of resource materials in your classroom?
ᄃ 1
Г 2
- 3
4
5

38. Use multimedia in your classroom?
Г 1
Г 2
Г 3
Г 4
5

39. Assign tasks/assignments to student's current level of understanding and skill?
$\Gamma$
1

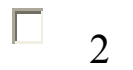
Г 3

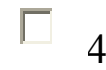
5

40. Give students choices in the type of tasks they can do?

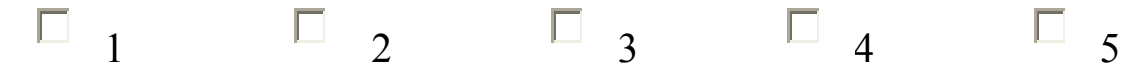

41. Allow students to use a variety of products to demonstrate learning?
Г1
Г 2
3
Г 4
5

\section{b. Teaching/Instructional Materials}

For the items below, please indicate the frequency in which you use the following instructional material in your classroom
(1. Never
2. Rarely
3. Sometimes
4. Almost always
5. Always)

42. Lesson plans

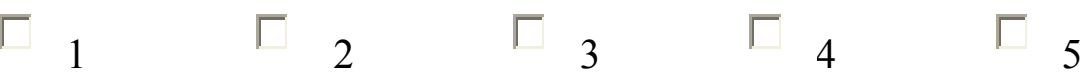

43. Modified lesson plans for marginal students
ᄃ 1
2

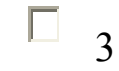
Г 4

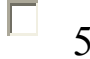

44. Lesson notes 
$\Gamma_{1} \quad{ }_{2}{ }_{2} \quad{ }_{3} \quad \Gamma_{4} \quad{ }_{5}$

45. Schemes of work (curriculum plans)
「 1
$\Gamma 2$
「 3
$\Gamma_{4}$
$\ulcorner 5$

46. Syllabus
广 1
$\ulcorner 2$
$\ulcorner 3$
$\Gamma 4$
5

47. Workbooks
$\Gamma$
$\ulcorner 2$
$\ulcorner 3$
$\ulcorner 4$
5

48. Other (

\section{c. Accommodations}

Check the frequency in which you provide the following accommodations in your classrooms for marginalized students (orphans, homeless children, children engaged in child labor, children with low incidence disabilities)
(1. Never
2. Rarely
3. Sometimes
4. Almost always
5. Always)

49. Extended test taking
\ulcorner

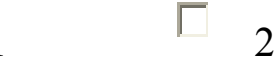
$\ulcorner 3$
$\Gamma_{4}$
$\ulcorner 5$

50. Use of guided notes

$\Gamma_{1} \Gamma_{2} \quad \Gamma_{3} \quad \Gamma_{4}{ }_{5}$

51. Provision of written notes
「 1
Г 2
$\ulcorner 3$
$\Gamma_{4}$
$\Gamma_{5}$

52. Modified tests
$\ulcorner 1$
$\ulcorner 2$
\ulcorner
$\Gamma 4$
$\Gamma 5$

53. Excused absences
Г 1
Г 2
Г 3
$\Gamma 4$
Г 5

54. Administering verbal tests in place of written tests
厂 1
Г 2
Г 3
Г 4
$\ulcorner 5$

55. Administering shortened tests
$\Gamma$
「 2
$\ulcorner 3$
$\Gamma_{4}$
$\ulcorner 5$

56. Providing a quiet room for testing
Г 1
$\Gamma 2$
$\Gamma 3$
$\Gamma 4$
$\Gamma_{5}$

57. Have you received specialized training to work with marginal students? Yes No

58. What professional development activities have you attended in regard to teaching marginalized students in the past 10 years? Check all that apply: 
$\Gamma$ Seminar

$\Gamma$ Workshop

$\Gamma$ College course

$\Gamma$ In-service training

59. For each of the professional development activity you attended above, state its title or purpose:

\section{Section Three:}

\section{Recruitment for interview or focus groups}

60. Would you be willing to participate in a focus group interview for this study?

Y Yes $\Gamma$ No

61. If you checked yes, please provide your phone number 


\section{Appendix E: Focus Group Screening Protocol}

Hello, my name is Harrison Oonge, a graduate student at West Virginia University. I am conducting research on access, retention, and progression of marginalized students. I am recruiting participants for a focus group interview to be held on July 9 \& 10 and also July 16 \& 17.

In each focus group there shall be 6 participants. The interview will be audio recorded. You have been pre selected to participate in this focus group.

Please respond to the following:

1. Are you still willing to participate in the focus group interview for this study?

2. Are you currently teaching in a public primary school?

3. Which of the following date do you prefer?

4. July 9 at 11 at a room in Tabaka.

5. July 10 at 11

6. July 16 at 11

7. And July 17

8. Are you aware of the Free Primary Education Objectives?

9. Do you have orphans in you classroom?

10. Do you have children with low incidence disabilities in your classroom?

11. Do you have homeless children in your classroom?

12. Are you still willing to participate in the focus group interview for this study? Thank you. 


\title{
Appendix F: Institutional Review Board of West Virginia University
}

\author{
West VirginiaUniversity. \\ Office of Research Compliance
}

\section{IRB Protocol-Exemption}

\author{
To: $\quad$ Dooley, Elizabeth \\ From: WU Office of Research Compliance \\ Date: Wednesday: May 18, 2011 \\ Subject: $\quad$ Exemption Acknowledgement \\ Tracking \#: $\quad \mathrm{H}-23217$ \\ Title: Access, retention, and progression, of marginalized students in Kisii, \\ Kenya
}

The above-referenced study was reviewed by the West Virginia University Institutional Review Board (IRB) and was granted exemption in accordance with 45 CFR 46.101(2).

This protocol was reviewed using the following

Exemption Checklist (210r)

This research study was granted an exemption because the Research involves educational tests, survey procedures, interview procedures or observation of public behavior and (i) information obtained is recorded in such a manner that human subjects cannot be identified, directly or through identifiers linked to the subjects; and (ii) any disclosure of the human subjects' responses outside the research could not reasonably place the subjects at risk of criminal or civil liability or be damaging to the subjects 'financial standing, employability, or reputation [45 CFR 46.101(2)].

All exemptions are only good for three years. If this research extends more than three years beyond the approved date, then the researcher will have to request another exemption.

NOTE: This study is granted contingent approval. Once the finalized research application permit from the Ministry of Education in Kenya is obtained, you must attach the document to your protocol and sumbit as an amendment to the Office of Research Integrity and Complaince. Do not begin your recruitment or conduct any research on this study until that time.

The following documents have been acknowledged for use in this study and are 
available in the BRAAN system:

Surveys, Questionnaires, Interviews

Attachments

hoonge_focus groups interview questions.doc hoonge_focus group interview questions

hoonge_survey instruments.doc hoonge_survey instrument

Miscellaneous Attachments

Attachments

hoonge_Letter to the Ministry of Education Science and

Technology.doc Request letter to the Ministry of Education Science and

Technology in Kenya for permission to conduct study

Kenya_Culture_Expert_RMaxon.pdf Letter by Dr. Robert Maxon, a professor and expert in Kenya. He has conducted research and written a book on the same region where I will conduct the research.

Oonge_Letter of Introduction.pdf Oonge_Letter of introduction

oonge_Masinde_Muliro_University affiliation.pdf As a requirement for the permit, they wanted local univeristy affiliation. Attached is my correspondence with Masinde Muliro University seeking affiliation under tutelage of Elizabeth Abenga (PhD).

Oonge_Research Permit Application_Kenya.pdf Research permit application forms were acquired from the Ministry of Education Website. No forms were available for Kenyan citizens. These forms have been signed by two of my committee members.

Thank you.
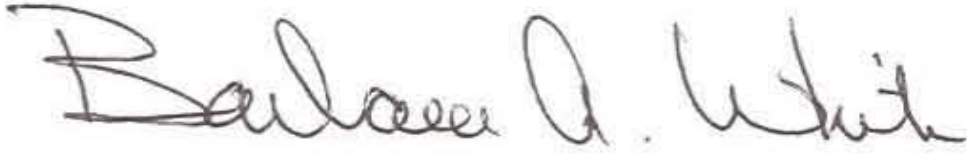

Board Designee: White, Barbara

Letter Sent By: White, Barbara, 5/18/2011 10:28 AM

Once you begin your human subject research, the following regulations apply:

1. Any modifications to the study protocol must be reviewed and acknowledged by the IRB prior to implementation.

2. You may not use a modified form until it has been acknowledged by the IRB. 
Appendix G: National Council of Science and Technology

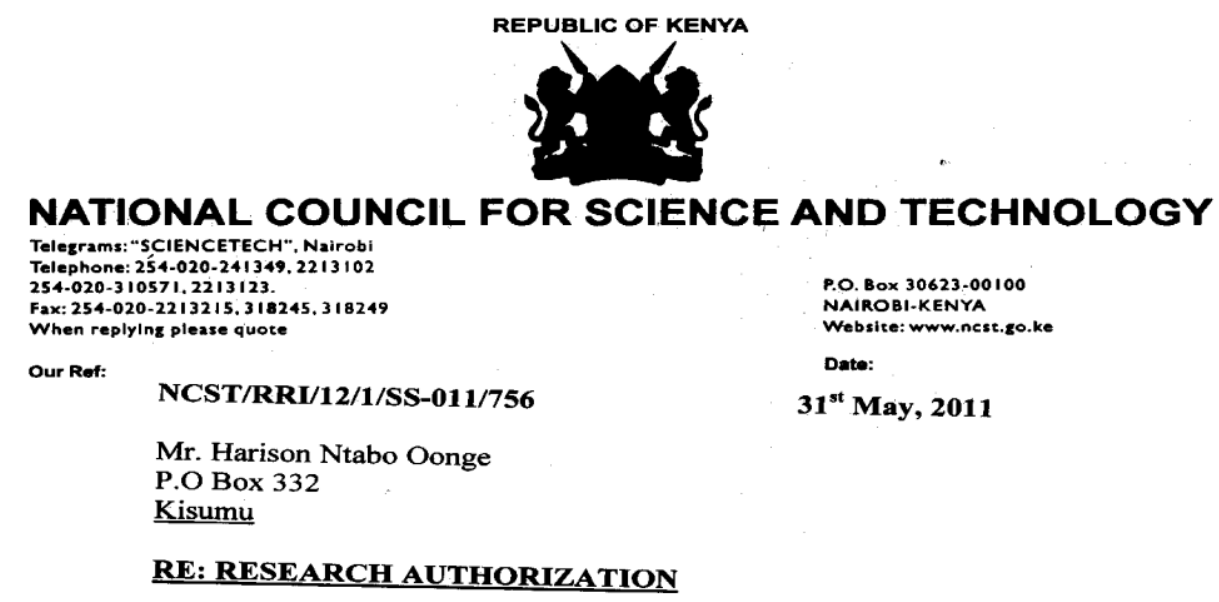

Following your application for authority to carry out research on Access, retention and progression of marginalized students in Primary School in Kisii County, Kenya I am pleased to inform you that you have been authorized to undertake research in Primary Schools in Kisii County for a period ending $30^{t h} \mathrm{July}, 2011$.

You are advised to report to the District Commissioner and the District Education Officer of Kisii District before embarking on the research project.

On completion of the research, you are expected to submit one hard copy and one soft copy of the research report/thesis to our office.

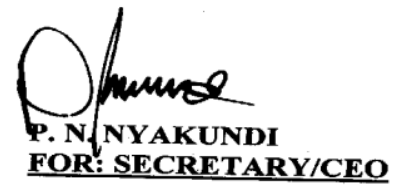

Copy to:

The District Commissioner Kisii District

The District Education Officer Kisii District 


\section{Appendix H: Permits from District Education Officers andAdminstration}

\section{MINISTRY OF EDUCATION}

REF: ED/GS/GEN/81/VOL.1/99

DISTRICT EDUCATION OFFICE SOUTH GUCHA DISTRICT

P.O BOX 2

NYAMARAMBE.

DATE: $3 / 06 / 2011$

TOWHOM IT MAY CONCERN

RE:RESEARCH AUTHORIZATION MR. HARRISON NTABO

The above named person has the authority of this office to carry out research based on

access. Retention and progression of marginalized pupils.

Please accord him the support that he may require accordingly.

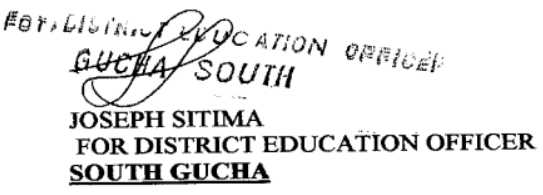

CC THE DISTRICT COMMISSIONER THE DISTRICT OFFICER/AEO

ETAGO DIVISION MOTICHO DIVISION NYAMARAMBE DIVISION 
MINISTRY OF EDUCATION

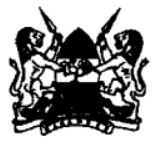

REPUBLIC OF KENYA

DISTRICT EDUCATION OFFICE

Telegram: ............................

Telephone:

FAX ......................

MASABA SOUTH DISTRICT

P.O. BOX 757

KEROKA

When replying please quote

$9^{\text {TH }}$ JUNE, 2011

REF: ED/MS/16

THE HEADTEACHERS

PUBLIC PRIMARY SCHOOLS

MASABA SOUTH

\section{RE: RESEARCH AUTHORIZATION}

MR. HARISON NTABO OONGE

The above mentioned person has been authorized by this office to carry out his research in our district.

Kindly accord him the necessary assistance.

hom

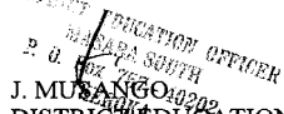

DISTRICT $\$ D U C A T I O N$ OFFICER

MASABA SOUTH

CC: THE DISTRICT COMMISSIONER MASABA SOUTH 
OFFICE OF THE PRESIDENT

\section{PROVINCIAL ADMINISTRATION AND INTERNAL SECURITY}

Telegrams;DISTRICTER". Musab Email: de masabasouthog mail com

Telephone /FAX:020-3508247

REF ; MS/ED/12/1/VOL.1/11

TO WHOM IT MAY CONCERN

RE; RESEARCH AUTHORIZATION

Following your request to carry out research on access, retention and progression of marginalized students to primary Schools in Masaba South District. I'm pleased to inform you that you have been authorized to undertake research to Primary Schools in this District for a period ending $30^{\text {th }}$ July, 2011.

You are advised to report to the District Education Officer Masaba South District before embarking on the research project to forward this authority.

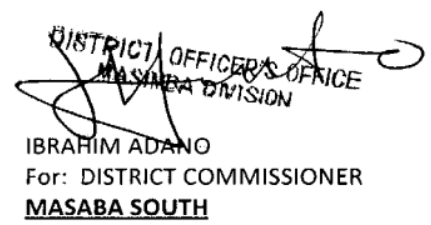

DISTRICT COMMISSIONER

MASABA SOUTH

P O BOX 78

KEROKA

$8^{\text {TH }}$ JUNE , 2011
MASABA SOUTH 


\section{REPUBLIC OF KENYA}

MINISTRY OF EDUCATION

$\begin{array}{ll}\text { Telephone: } 058 \text {-4l31020 } & \begin{array}{l}\text { DISTRICT EDUCATION OFFICE } \\ \text { GUCHA DISTRICT }\end{array} \\ \text { When replying please quote } & \text { OGEMBO - 40204 }\end{array}$

\section{RE: AUTHORITY LETTER}

The bearer of the letter MR.HARISON NTABO OONGE has been authorized by the Gucha District Education Office to carry out an academic research on Education in your school.

Please accord him any necessary assistance.

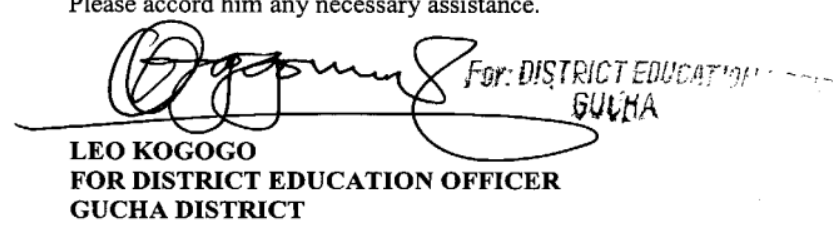




\section{OFFICE OF THE PRESIDENT}

Telegrams "DISTRICTER" Nyamarambe Telephone N0.0208003575fax0208028870 When replying please quote

REF: GCA/S/ED.12/25 VOL.1/43

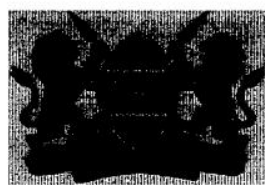

DISTRICT COMMISSIONER

GUCHA SOUTH DISTRICT

P.O BOX 10

NYAMARAMBE

$3 / 06 / 2011$

\section{TO WHOM IT MAY CONCERN}

\section{RE: RESEARCH AUTHORIZATION-:HARRISON NTABO OONGE}

The above mentioned student has been duly authorized to carry out research on "ACCESS Retention And Progression Of Marginalized Students In Primary Schools" for the period ending $30^{\text {th }}$ July, 2011.

This office has no objection whatsoever to the intended research. We therefore request you to accord Harrison Ntabo Oonge the necessary support during his research.

Upon completion, he has been asked to submit a hand copy of his research report to this office.

(1)20

D.K.TEGUTWA

FOR: DISTRICT COMMISSIONER

GUCHA SOUTH DISTRICT

CC

DISTRICT EDUCATION OFFICER

GUCHA SOUTH DISTRICT 


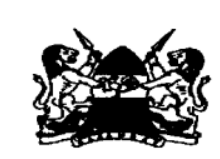

OFFICE OF THE PRESIDENT

Provincial Administration \& internal Security

Telegrams "DC'S OFFICE"; GUCHA Telephone (058) 4131024/4131028

When replying please quote

Ref: GCA/ED/12/9/118
The District commissioners office Gucha District

P.O.BOX 2

OGEMBO

3RD JUNE 2011

TO WHOM IT MAY CONCERN

RE: RESEARCH AUTHORIZATION

MR HARISON NTABO OONGE

The above named person is undertaking research on Access, retention and progression of marginalized students in primary school in Kisii County, Kenya for a period ending 30th July 2011.

$\mathrm{He}$ is therefore been given the authority by this office to carry out research hence accord him the assistance he may require.

lal

E. A. AFEMI

FOR: DISTRICT COMMISSIONER

GUCHA DISTRICT

Copy to: THE DISTRICT EDUCATION OFFICER GUCHA DISTRICT 
OFFICE OF THE PRESIDENT

MINISTRY OF STATE FOR PROVINCIAL

ADMINISTRATIONAND INTERNAL SECURITY

Telegrams" DISTRICTER' KISI]

Telephone: KISII (058-30237 Fax.30231

When replying please quote

OFFICE OF THE

Ref. No. ......... $/ 8$ VI. II $/ 32$

DISTRICT COMMISSIONER

P.O BOX 590

$$
\text { and date }
$$

2. June $20.11 .$.

TO WHUM IT MAY CUNCERT

MR. HARISUI NTABU UMTGT

ADIT. NU. NCST/RRI/12/1/SS-011/756

This is to authorize the above named student to take research on Access, Retention and marginalized students in primary schools in this District.

Nattoo

M. OMCRO

FUR: DISTRICT CUMISSIUNGR

KIA'II CDTTRAI

IIsix

IISTRICI COMAHSSIONEZ:

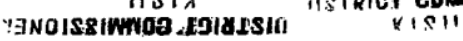




\section{MINISTRY OF EDUCATION \\ DISTRICT EDUCATION OFFICE KISII CENTRAL DISTRICT \\ REPUBLIC OF KENYA P.0. Box 79, TEL.058-30695, KISII}

REF:EI)/100/VOL.XIIL/50

DATE: $2^{\text {nd }}$ June 2011

To All

llead teachers

KISII CENTRAL DISTRICT

RE: MR. HARIRISON OONGE - OUT ON RESEARCH WORK

The bearer of this letter is hereby permitted to carry our research on access, retention and progression of marginalized pupils in primary schools, in the following schools in Kisii Central District.

- Kari Primary

- Kegati Primary

- Amasago Primary

- Gianchere FAM Primary

- Daraja Mbili Primary

- St. Joseph's Nyabururu Primary

- St. Patricks Mosocho Primary

- Ong'icha Primary

Kindly do assist him.

Thanks.

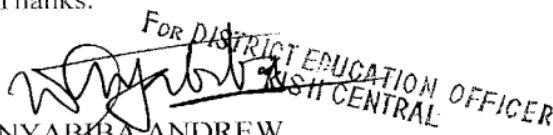

NYABHBA $\triangle$ NDTREW

FOR: DISTRICT EDUCATION OFIICER

KISII CENTRAL 


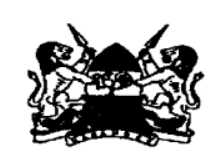

OFFICE OF THE PRESIDENT

Provincial Administration \& internal Security

Telegrams "DC'S OFFICE"; SAMETA

Telephone

When replying please quote

Ref:

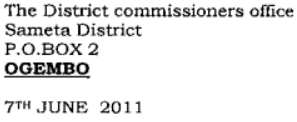

The District commissioners office Sameta District

P.O.BOX 2

OGEMBO

$7^{\text {TH }}$ JUNE 2011

TO WHOM IT MAY CONCERN

RE: RESEARCH AUTHORIZATION

MR HARISON NTABO OONGE

The above named person is undertaking research on Access, retention and progression of marginalized students in primary school in Kisii County, Kenya for a period ending 30 th July 2011.

$\mathrm{He}$ is therefore been given the authority by this office to carry out research hence accord him the assistance he may require.

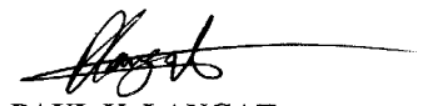

PAUL K. LANGAT

FOR: DISTRICT COMMISSIONER

SAMETA DISTRICT

Copy to: THE DISTRICT EDUCATION OFFICER SAMETA DISTRICT 


\section{Appendix I: Letter of Introduction}

Dear Participant

The purpose of this letter is to request you to take part in a research project which aims to gather data on "Access, retention, and progression of marginalized students in primary education in Kisii Kenya". My name is Harrison Oonge, a doctoral student at West Virginia University in the program of Curriculum and Instruction. I am conducting this research for partial fulfillment of the requirements for my dissertation research in Curriculum \& Instruction at West Virginia University, with supervision of Dr. Elizabeth Dooley, a professor in the College of Human Resources and Education.

To participate in this survey and focus group research, you must be 18 years or older, and must be currently teaching in a public primary sehool in Kenya. Your participation in this research is voluntary and anonymous. The survey will take approximately 40 minutes to complete. You do have the option of continuing or opting out of the survey at any point. You may skip a question or may discontinue from filling out the survey at any time. In no way will your job status be affected by this study. Acknowledgements to conduct this project from both the West Virginia's University's Institutional Review Boand (IRB) and the Ministry of Education in Kenya are on file,

I hope that you will participate in this research project as it could be beneficial in understanding instructional issues related to marginalized students. Thank you for your time. For any questions please feel free to contact me through boonge@mix.wvu.edu or +13042166396 or 0721293490.

Sincerely

Harrison Oonge 


\section{Appendix J: Interview Protocol}

1. Describe to me students you know who have dropped out or stopped coming to school?

a. From your own perspective, why do you think students leave school?

b. What factors affect the dropout rate in your school?

2. Who do you perceive as a marginalized student in your school?

3. How has free primary education influenced access to primary education for marginalized students?
a. Instructional materials
b. Fees and/or school levies
c. Nutritional programs

4. Describe your school's policy in regard to marginalized students?

a. How do you treat marginalized students in your school?

b. What inequalities do you notice in your school and or/classrooms?

c. Do all children have a fair chance of succeeding in your classroom? If yes please give examples.

5. Describe your own approach to teaching marginalized students?
a. Accommodations
b. Instructional strategies
c. Instructional materials

6. How has Free Primary Education affected your school?
a. Benefits
b. Problems
c. What is the future of Free primary education

7. In the past 10 years, have you attended and/or participated in a professional development activity? If yes, what was its title and purpose? 


\section{Appendix K: Letter of Invitation to Participate in Focus Group Interview}

\section{Dear Participant,}

Thank you for accepting my invitation to attend a discussion on "Access, Retention, and Progression of Marginalized Students in Primary Schools in Kisii County" which will be held on Tuesday, July $\mathbf{1 2}^{\text {th }}$ at Hotel Dados in Kisii Town. The discussion/interview will begin at 2 p.m. sharp and end at 3:30 p.m. Give yourself enough time by coming 30 minutes early.

The focus group discussion/interview you will be attending will be constituted of primary school teachers in Kisii County. We will be discussing and/or fielding questions on educational access, retention and progression of marginalized students in your school who are at risk of repeating grades, dropping out, low achievement, and low attendance within a term. You opinion and insight into this topic is key to the success of this research. This is strictly a research project and in no way will your job and status be affected. At the conclusion of the focus group session, we will be giving you a token of Ksh.1000 to cover your expenses for attending.

If for some reason you find you are not able to attend, please call us to let us know as soon as possible. My telephone number(s) are 0721-293490 or 0704-333810.

Sincerely,

Harrison Oonge

Focus Group Moderator 


\section{Appendix L: Informed Consent}

\section{Statement of Informed Consent}

I , a gree to participate in this research project on "Access, Retention, and Progression of Marginalized Students in Kisii County Kenya," that is being conducted by Harrison Oonge from West Virginia University.

I understand that the study involves a focus group interview that lasts two hours or less and will be audiotaped.

I understand that my participation in this study is entirely voluntary, and that if I wish to withdraw from the study or leave, I may do so at any time, and that I do not need to give reasons of doing so.

I understand that all the information I will give during the discussion will be kept confidential to the extent permitted by the law, and that the names of all focus group participants will be kept confidential.

I also understand that I have an obligation to respect the privacy of other members of the group by not disclosing any personal information that they share during our discussion.

I have read and understood this information and agree to take part in this study.

Date

Signature

If you have any questions or concerns about this study, please contact Harrison Oonge at +304216-6396 or 0721-293490 


\section{Appendix M: Emergent Codes and Themes from Focus Groups and Administrator}

\section{Interviews on who the Consider as Marginalized in their Classrooms}

\section{Table M1}

\begin{tabular}{|c|c|}
\hline Codes & Broad themes or categories \\
\hline $\begin{array}{l}\text { 1. Orphans } \\
\text { 2. Orphans under care of grandmothers or } \\
\text { guardians } \\
\text { 3. Children who engage in sibling care }\end{array}$ & Orphans \\
\hline $\begin{array}{l}\text { 4. Teenage pregnancies } \\
\text { 5. Lack of access to sanitary towels }\end{array}$ & The girl child \\
\hline $\begin{array}{l}\text { 6. Children with special needs } \\
\text { 7. Slow learners } \\
\text { 8. Academic dwarfs } \\
\text { 9. Repeaters } \\
\text { 10. Gifted children } \\
\text { 11. Children with mental impairments } \\
\text { 12. Children with physical impairments } \\
\end{array}$ & Children with special needs \\
\hline $\begin{array}{l}\text { 13. Children from negligent parents } \\
\text { 14. Children whose parents are brewers (make } \\
\text { locally processed alcohol) } \\
\text { 15. Children whose parents were school dropouts } \\
\text { 16. Children from dysfunctional families }\end{array}$ & Poor parenting \\
\hline $\begin{array}{l}\text { 17. Bastards } \\
\text { 18. Children from single parents }\end{array}$ & Children from single parents \\
\hline $\begin{array}{l}\text { 19. Children from extremely poor families } \\
\text { 20. Child labor } \\
\text { 21. Malnourished children } \\
\text { 22. Children living in poor housing }\end{array}$ & Children from poor families \\
\hline $\begin{array}{l}\text { 23. Children affected and/or infected with } \\
\text { HIV/AIDS } \\
\text { 24. Children with chronic illnesses }\end{array}$ & Children with poor health \\
\hline
\end{tabular}

